\title{
GNREL
}

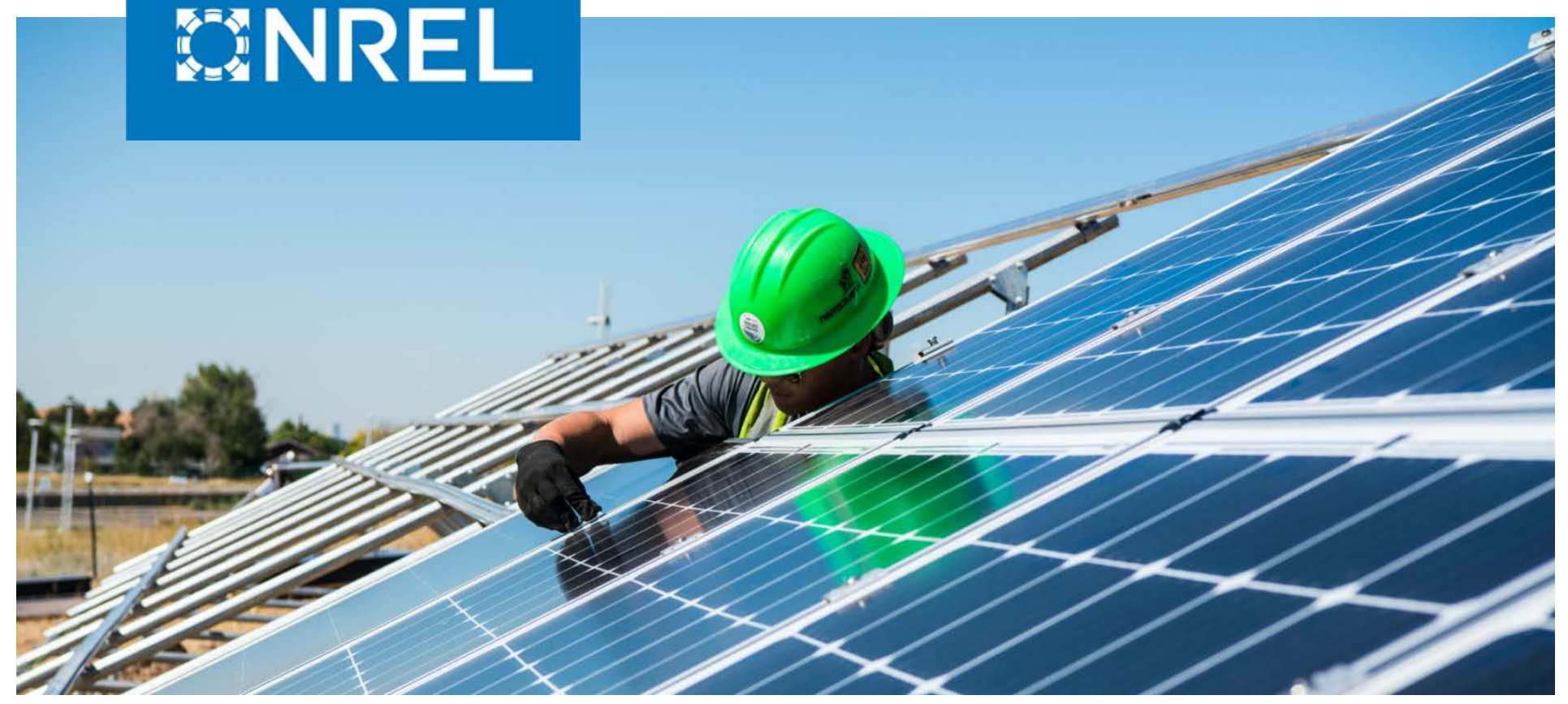

\section{The Role of Concentrating Solar-Thermal Technologies in a Decarbonized U.S. Grid}

Chad Augustine, Craig Turchi, and Mark Mehos

National Renewable Energy Laboratory

NREL is a national laboratory of the U.S. Department of Energy Office of Energy Efficiency \& Renewable Energy

Operated by the Alliance for Sustainable Energy, LLC

This report is available at no cost from the National Renewable Energy Laboratory (NREL) at www.nrel.gov/publications.

\section{Technical Report}

NREL/TP-5700-80574

Revised February 2022 


\title{
BNREL
}

\section{The Role of Concentrating Solar- Thermal Technologies in a Decarbonized U.S. Grid}

\author{
Chad Augustine, Craig Turchi, and Mark Mehos
}

National Renewable Energy Laboratory

\section{Suggested Citation}

Augustine, Chad, Craig Turchi, and Mark Mehos. 2021. The Role of Concentrating SolarThermal Technologies in a Decarbonized U.S. Grid. Golden, CO: National Renewable Energy Laboratory. NREL/TP-5700-80574. https://www.nrel.gov/docs/fy21osti/80574.pdf.

NREL is a national laboratory of the U.S. Department of Energy Office of Energy Efficiency \& Renewable Energy Operated by the Alliance for Sustainable Energy, LLC

This report is available at no cost from the National Renewable Energy Laboratory (NREL) at www.nrel.gov/publications.

Contract No. DE-AC36-08GO28308
Technical Report

NREL/TP-5700-80574

Revised February 2022

National Renewable Energy Laboratory 15013 Denver West Parkway Golden, CO 80401

303-275-3000 • www.nrel.gov 


\section{NOTICE}

This work was authored by the National Renewable Energy Laboratory, operated by Alliance for Sustainable Energy, LLC, for the U.S. Department of Energy (DOE) under Contract No. DE-AC36-08GO28308. Funding provided by U.S. Department of Energy Office of Energy Efficiency and Renewable Energy Solar Energy Technologies Office. The views expressed herein do not necessarily represent the views of the DOE or the U.S. Government.

This report is available at no cost from the National Renewable Energy Laboratory (NREL) at www.nrel.gov/publications.

U.S. Department of Energy (DOE) reports produced after 1991 and a growing number of pre-1991 documents are available free via www.OSTI.gov.

Cover Photo by Dennis Schroeder: NREL 40820.

NREL prints on paper that contains recycled content. 


\section{Errata}

This report, "The Role of Concentrating Solar-Thermal Technologies in a Decarbonized U.S. Grid" (NREL/TP-5700-80574) originally published in September 2021, has been revised in February 2022 to update Table 2 and the preceding text in the report. Table 2 shows the "State of the Art Baseline CSP Power Tower Design, Costs, and Performance used by DOE". After consulting with SETO, we found that we had used financial assumptions inconsistent with the assumptions that DOE SETO uses. Also, SETO usually reports the levelized cost of electricity (LCOE) assuming "no incentives", or a $0 \%$ investment tax credit (ITC), while Table 2 implicitly assumes one.

The text in the paragraph preceding Table 2 was updated to include a description of the financial assumptions used by SETO and how the current TC varies by year - it is $26 \%$ for 2020 and declines to $10 \%$ in 2024 . It also updates resulting LCOE's.

The table was updated to include some additional model input details that are important to the analysis. It also updates the values in the "Performance and Results" section to match the updated model results. The LCOE values for an ITC of $26 \%, 10 \%$ and $0 \%$ are reported. 


\section{The Solar Futures Study and Supporting Reports}

The Solar Futures Study, initiated by the U.S. Department of Energy (DOE) Solar Energy Technologies Office and led by the National Renewable Energy Laboratory (NREL), envisions how, over the next few decades, solar could come to power $40 \%$ or more of U.S. electricity demand, dramatically accelerating the decarbonization of buildings, transportation, and industry.

Through state-of-the-art modeling, the Solar Futures Study is the most comprehensive review to date of the potential role of solar in decarbonizing the U.S. electric grid and broader energy system. However, not all the detailed analysis that informed the Solar Futures Study could be included within its pages. This further analysis is collected in additional National Renewable Energy Laboratory reports, each dedicated to a different technology or socioeconomic concern.

This report, The Role of Concentrating Solar-Thermal Technologies in a Decarbonized U.S. Grid, focuses on a particular technology area that could contribute to decarbonization.

\section{The Solar Futures Study Reports}

- Solar Futures Study (main report published by DOE)

- $\quad$ Research Priorities for Solar Photovoltaics in a Decarbonized U.S. Grid

- $\quad$ The Role of Concentrating Solar-Thermal Power Technologies in a Decarbonized U.S. Grid

- The Demand-Side Opportunity: The Roles of Distributed Solar and Building Energy Systems in a Decarbonized Grid

- Maximizing Solar and Transportation Synergies

- $\quad$ The Potential for Electrons to Molecules Using Solar Energy

- Affordable and Accessible Solar for All: Barriers, Solutions, and On-Site Adoption Potential

- Forthcoming Environment and Circular Economy Report

You can learn more about the project and reports on the NREL website at https://www.nrel.gov/analysis/solar-futures.html. 


\section{List of Acronyms}

\begin{tabular}{|c|c|}
\hline $\mathrm{AEO}$ & Annual Energy Outlook \\
\hline ATB & Annual Technology Baseline \\
\hline $\mathrm{CO}_{2}$ & carbon dioxide \\
\hline CSP & concentrating solar-thermal power \\
\hline CST & concentrating solar-thermal \\
\hline DNI & direct normal irradiance \\
\hline DOE & Department of Energy \\
\hline EFS & Electrification Futures Study \\
\hline EPA & Environmental Protection Agency \\
\hline ETES & electric thermal energy storage \\
\hline E2M & electrons to molecules \\
\hline FIT & feed-in tariff \\
\hline FOM & fixed operations and maintenance \\
\hline FPC & flat plate collector \\
\hline GHG & greenhouse gas emissions \\
\hline GTI & Gas Technology Institute \\
\hline HTF & heat transfer fluid \\
\hline $\mathrm{IPH}$ & industrial process heat \\
\hline IRENA & International Renewable Energy Agency \\
\hline LCOE & levelized cost of electricity \\
\hline NGCC & natural gas combined cycle \\
\hline OCC & overnight capital costs \\
\hline O\&M & operations and maintenance \\
\hline PPA & power purchase agreement \\
\hline PTC & parabolic trough collectors \\
\hline PTES & pumped thermal electricity storage \\
\hline PV & photovoltaic \\
\hline RE-CT & renewable energy combustion turbine \\
\hline ReEDS & Regional Energy Deployment System \\
\hline $\mathrm{R} \& \mathrm{D}$ & research and development \\
\hline SAM & System Advisor Model \\
\hline SEGS & solar electricity generating systems \\
\hline $\mathrm{SIPH}$ & solar industrial process heat \\
\hline SolarPACES & Solar Power and Chemical Energy Systems \\
\hline SM & solar multiple \\
\hline STEP & Supercritical Transformational Electric Power \\
\hline SwRI & Southwest Research Institute \\
\hline TES & thermal energy storage \\
\hline VOM & variable O\&M \\
\hline
\end{tabular}




\section{Table of Contents}

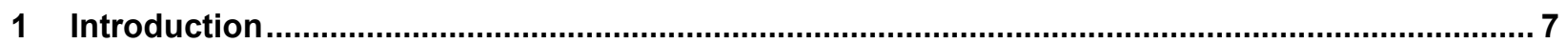

2 Concentrating Solar-Thermal Power Market Status …......................................................... 11

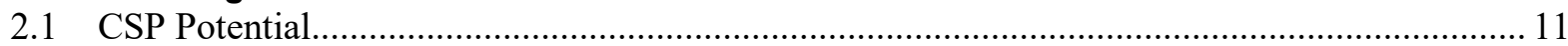

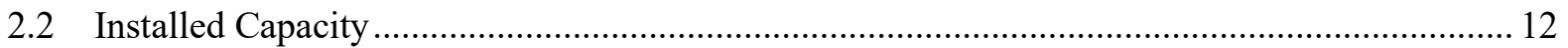

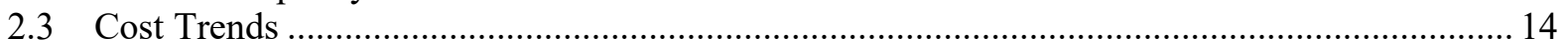

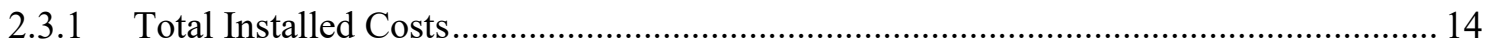

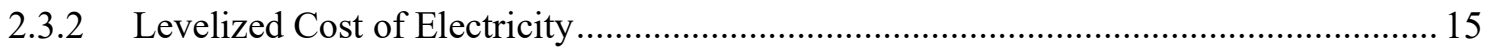

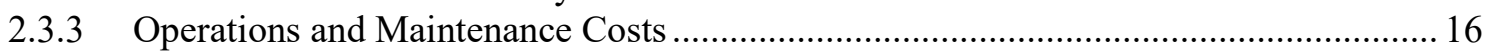

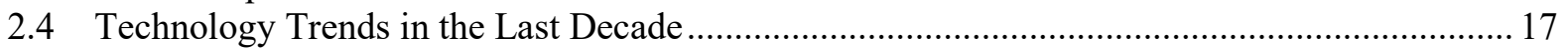

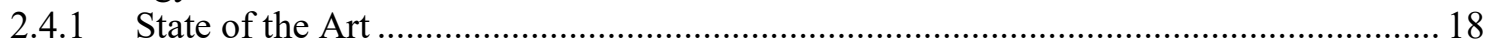

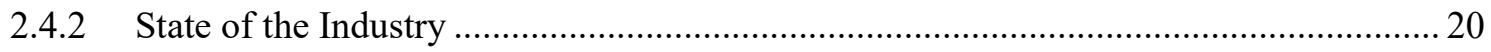

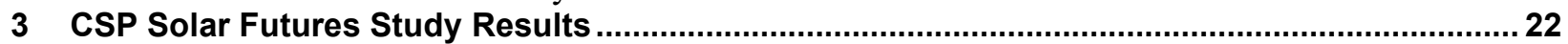

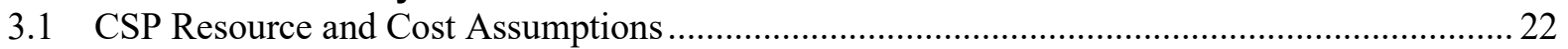

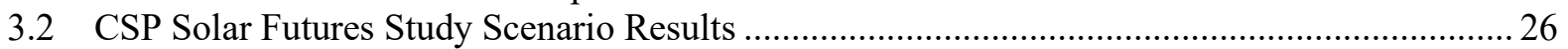

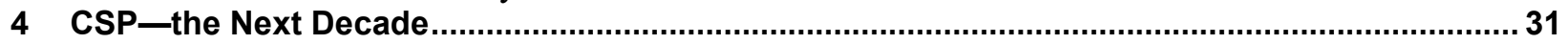

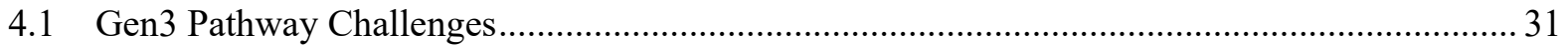

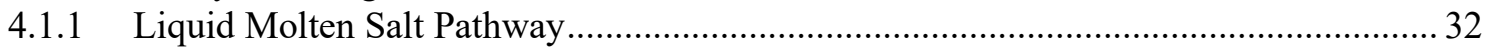

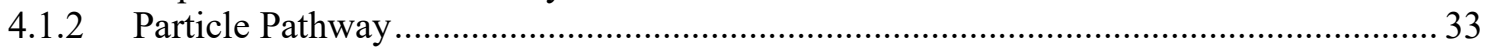

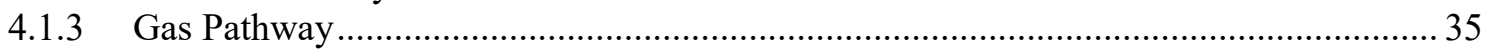

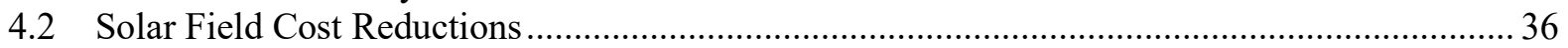

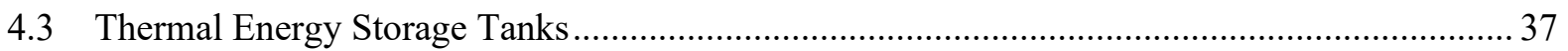

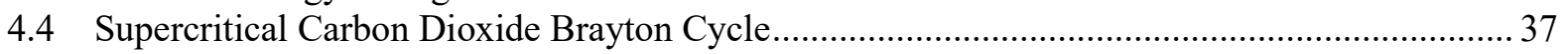

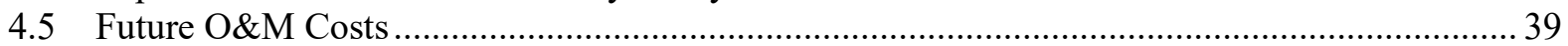

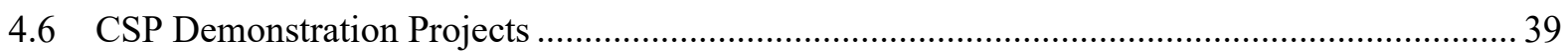

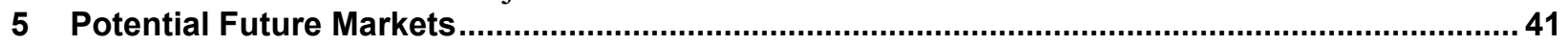

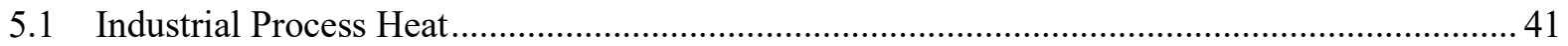

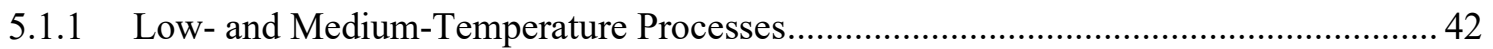

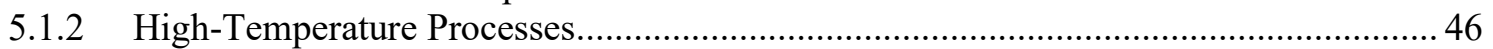

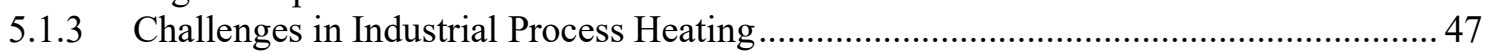

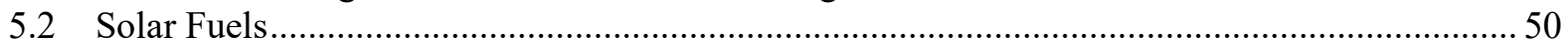

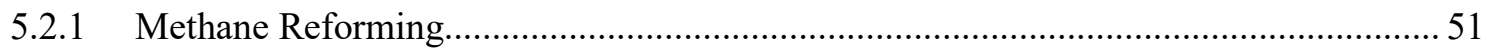

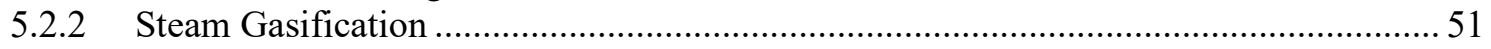

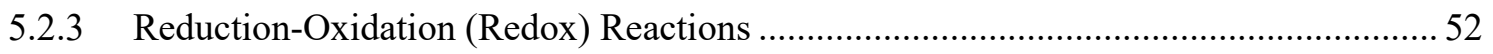

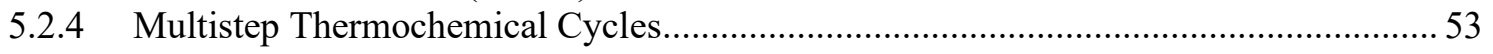

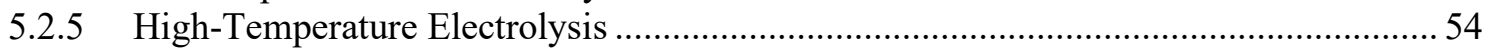

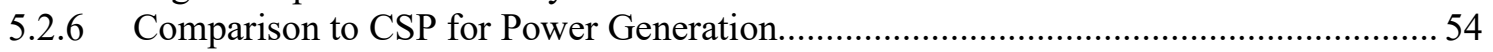

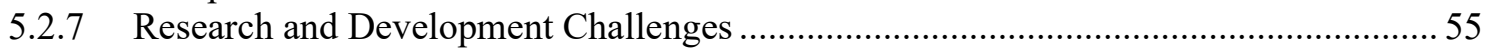

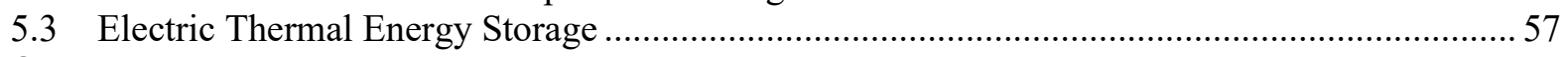

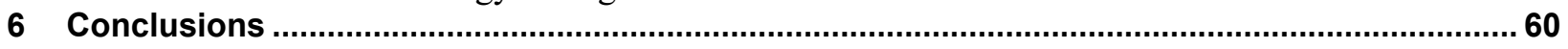

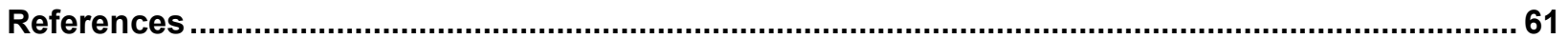




\section{List of Figures}

Figure 1. The black tube illuminated in center of this concentrating solar-thermal power parabolic trough

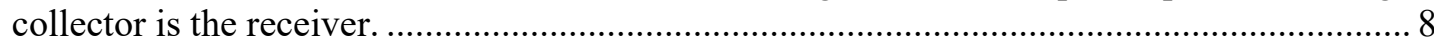

Figure 2. Power tower concentrating solar-thermal power systems such as this one use focused mirrors, called heliostats, to reflect sunlight onto a receiver on top of a tower. Each heliostat uses a two-axis tracking system to focus the sun on the power tower receiver.

Figure 3. Fresnel concentrating solar power collectors comprise many thin, flat mirror strips that run parallel to the receiver. Each collector rotates on a single axis to keep the sun focused on the

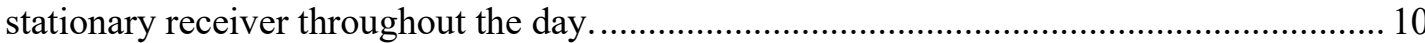

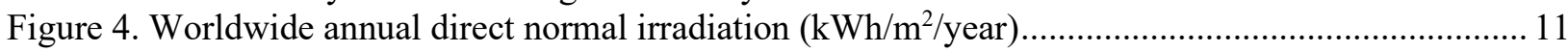

Figure 5. The CSP direct normal solar irradiance resource in the United States is greatest in the Southwest.

Figure 6. The CSP projects that are operational, under construction, or in development worldwide represent more than 9,000 MW in current and future generation capacity....

Figure 7. Global weighted average total installed costs, capacity factors, and LCOE for CSP, 2010-2019

Figure 8. CSP total installed costs $\left(\$ / \mathrm{kW}_{\mathrm{e}}\right)$ by project size, collector type, and thermal energy storage

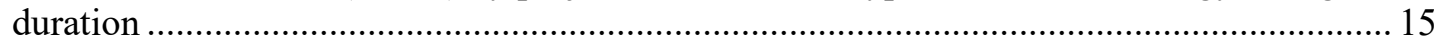

Figure 9. CSP project historical levelized cost of electricity and future plant auction prices $\left(\$ / \mathrm{kWh}_{\mathrm{e}}\right)$ by

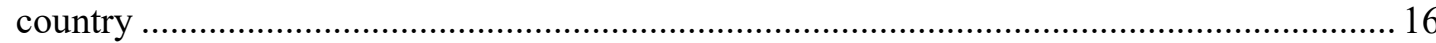

Figure 10. Estimated O\&M costs, including insurance, for parabolic trough and power tower CSP plants

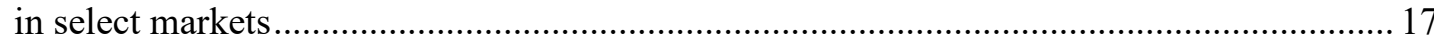

Figure 11. Concentrating solar-thermal power capacity under construction per year compared to

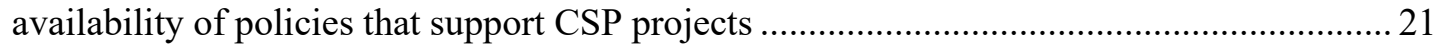

Figure 12. Geographic distribution of available CSP capacity by CSP resource class (solar resource

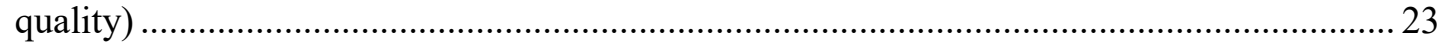

Figure 13. Breakdown of overnight capital costs by system component for representative molten salt power tower CSP plant with 10 hours thermal energy storage ........................................... 25

Figure 14. Cost projections (2018 USD $\$ / \mathrm{kW}_{\mathrm{e}}$ ) for representative molten salt power tower CSP plant with 10 hours thermal energy storage used in Solar Futures Study modeling ..............................26

Figure 15. Solar Futures Study core scenario generation results in 2020, 2035, and 2050 .................... 27

Figure 16. Solar Futures Study core scenario installed capacity results in 2020, 2035, and 2050 ........... 28

Figure 17. CSP deployment in Solar Futures Study core scenarios, 2020-2050 .................................. 28

Figure 18. CSP deployment in Solar Futures Study core scenarios compared to sensitivity scenarios varying the cost and availability of RE-CT technology ....................................................... 29

Figure 19. Concentrating solar-thermal power installed capacity in 2050 as a function of thermal energy storage duration for Decarb scenario and the Decarb+More TES Options scenario including

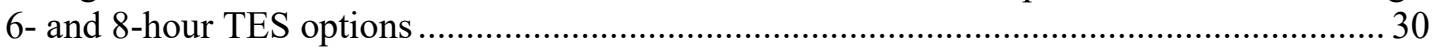

Figure 20. Pathways, component cost and performance targets, and risks for CSP Gen3 technology identified in the Gen 3 road mapping study .................................................................... 32

Figure 21. The Gen3 CSP design promoted by the liquid pathway team uses a liquid-sodium HTF for receiver flexibility and efficiency combined with molten-chloride salt storage.................... 33

Figure 22. Artist's rendering of the Gen3 particle pathway concept that directly irradiates falling solid

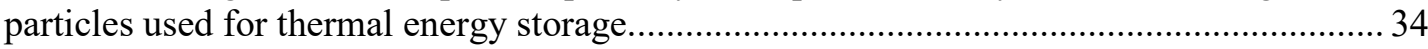

Figure 23. The gas pathway uses the supercritical fluid for the receiver HTF and in the power cycle. Integrating the power cycle compressor for HTF circulation and the TES heat exchangers as recuperators reduces operating and capital costs.

Figure 24. Heliostat costs have dropped by $50 \%$ since the inception of SunShot in 2013, but further cost reductions are necessary to achieve DOE's $\$ 50 / \mathrm{m}^{2}$ cost target. 
Figure 25. Schematic of simple supercritical carbon dioxide Brayton power cycle (different configurations are possible)

Figure 26. Total fuel use in the U.S. manufacturing sector by fuel type and end use

Figure 27. Industrial process heating unit processes and their temperature ranges compared to solar collector and electricity-powered heating technologies and their temperature ranges.

Figure 28. Industrial process heat estimated energy use (TJ) in 2015 for facilities with largest emissions $\left(>25,000\right.$ metric tons of $\mathrm{CO}_{2}$ equivalent emissions) in the United States by temperature range for (a) $<100 \mathrm{C}$, (b) $100^{\circ}-400^{\circ} \mathrm{C}$ and (c) $>400^{\circ} \mathrm{C}$

Figure 29. Industrial heat demand (TBtu) by county in 2014 in the continental United States......

Figure 30. U.S. cumulative industrial process heat demand in 2014 by end-use category comparted to

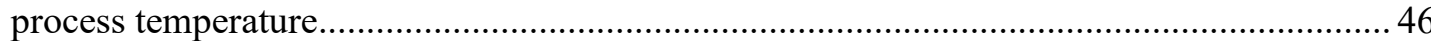

Figure 31. Comparison of solar industrial process technologies' ability to meet U.S. IPH demand .......... 49

Figure 32. Summary of solar fuel chemical pathways ........................................................................51

Figure 33. Solar-to-chemical efficiency and research and development time plotted against demonstration scale for solar reactor technology research projects at the Paul Scherrer Institute ................56

Figure 34. Schematic of a pumped thermal energy storage system using solid media ............................. 58 


\section{List of Tables}

Table 1. Operational CSP Plants in the United States 13

Table 2. State of the Art Baseline CSP Power Tower Design, Costs, and Performance used by DOE...... 19

Table 3. Resource Classes, Based on DNI and the Available Technical Potential Resource in the

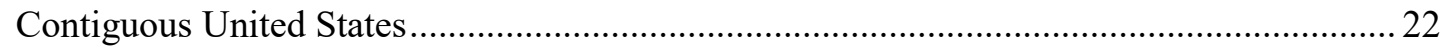

Table 4. Summary of Solar Futures Study Core Scenarios................................................................... 27

Table 5. Typical Range of Operating Temperatures and Relevant Heat Transfer Fluid for Solar- Thermal

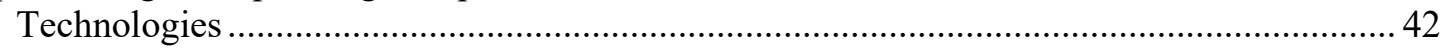

Table 6. Key Parameters for Modeling SIPH Systems ................................................................. 48

Table 7. Summary of Upper Operating Temperature, Annual-Average Solar Concentration Ratio, and Annual-Average Optical Efficiency for Solar-Thermal Collection Systems ......................... 54 


\section{Introduction}

The National Renewable Energy Laboratory's Solar Futures Study (DOE 2021) explores the roles solar energy technologies could play in the future U.S. energy markets under different scenarios. This report discusses the role of concentrating solar-thermal (CST) technologies in those future scenarios.

CST use reflective surfaces to focus and concentrate the sun's rays onto a surface and capture the solar radiation as heat. Concentrating solar-thermal power (CSP) refers to converting thermal energy to electricity, which is the primary end application discussed in this report. However, CST can be used in any application that requires thermal energy, such as industrial process heating, thermal desalination, and fuel production. The thermal energy can also be stored for later use, giving CST technologies greater generation flexibility than solar photovoltaic (PV) or wind technologies.

Concentrating the solar energy from reflective surfaces to a small area increases the maximum temperature that can be achieved by CST. CSP plants are broadly categorized by the type of collector they use to concentrate the sun's rays. The most widely deployed CSP plant type uses the parabolic trough collector and consists of a parabolic-shaped reflector that concentrates the sun onto a linear receiver positioned along the reflecting trough's focal line (Figure 1).

The receiver for parabolic trough collectors is a pipe, typically with a specialized solar-absorbing coating, placed inside an evacuated glass tube to reduce heat losses. A heat transfer fluid (HTF) flows through the pipe in the receiver to collect the thermal energy generated by the concentrated solar beams and transfer it to its end use. Parabolic trough systems that use synthetic oil as the $\mathrm{HTF}$ can reach temperatures of $390^{\circ} \mathrm{C}$, whereas those that use steam or molten salt can reach $500^{\circ} \mathrm{C}$ or higher (Boretti, Castelletto, and Al-Zubaidy 2019). Parabolic troughs rotate on a single axis throughout the day to track the sun's position in the sky and focus its rays on the receiver. 


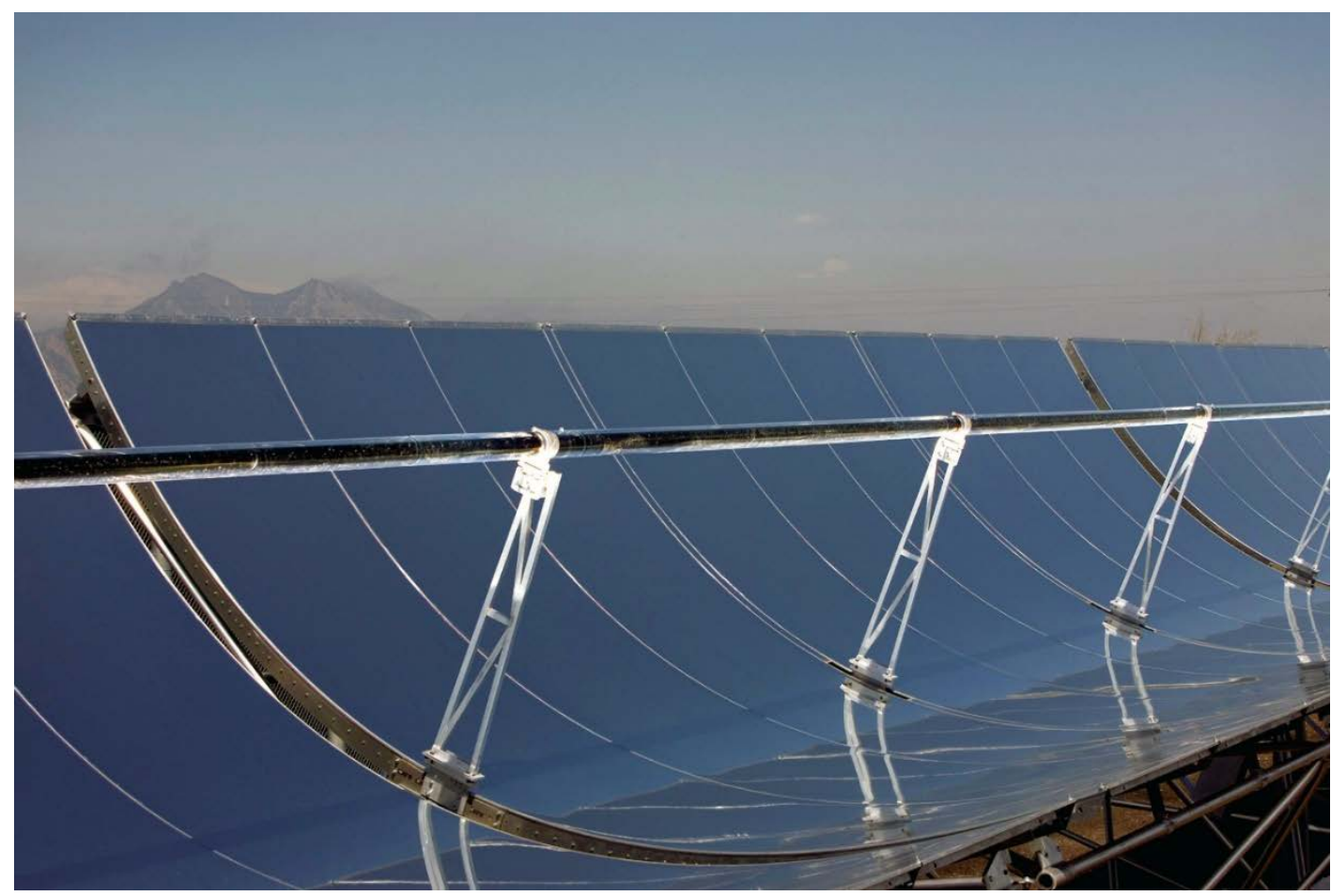

Figure 1. The black tube illuminated in center of this concentrating solar-thermal power parabolic trough collector is the receiver.

Photo from SkyFuel Inc., NREL 16604

Power tower systems are the second most widely deployed CSP collector technology and are the subject of a great deal of current research and development in the CSP industry (Ho 2017). Power tower CSP systems use thousands of focused mirrors, called heliostats, to reflect sunlight onto a receiver on top of a tower. Each heliostat uses a two-axis tracking system to focus the sun on the power tower receiver. Because the heliostats can focus light from such a large area, power towers can achieve higher concentration ratios and hence higher temperatures than parabolic troughs. The higher temperatures translate to higher thermal power plant efficiencies and greater power output potential.

The HTF in operational power tower receivers is usually either water (steam) or molten salt and reaches temperatures of up to $565^{\circ} \mathrm{C}$ (Boretti, Castelletto, and Al-Zubaidy 2019). Nextgeneration power tower CSP plants are being designed to operate at $720^{\circ} \mathrm{C}$ (Mehos et al. 2017) and power tower designs for providing heat to industrial processes are targeting temperatures of $1,000^{\circ} \mathrm{C}$ (Ho 2016). 


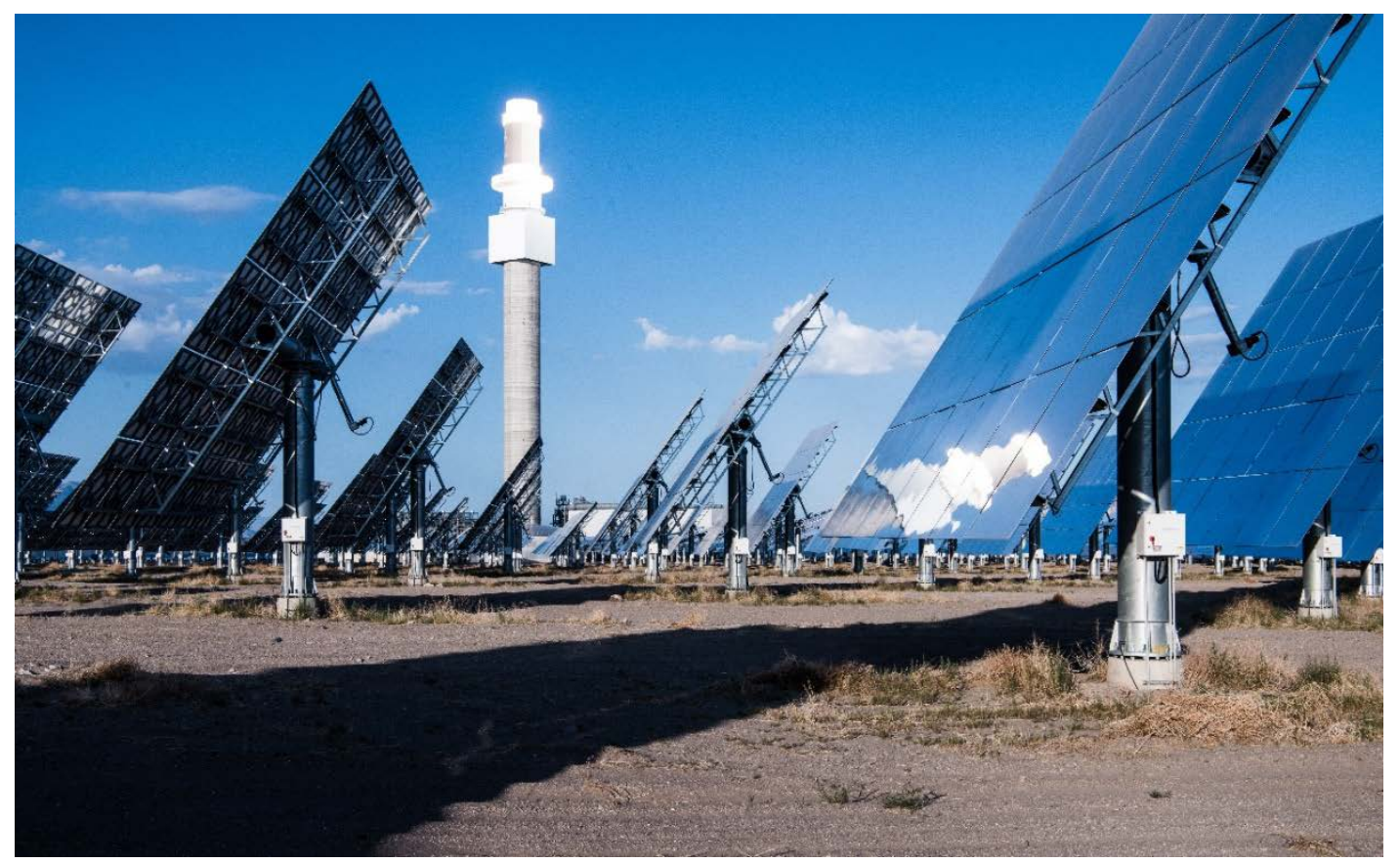

Figure 2. Power tower concentrating solar-thermal power systems such as this one use focused mirrors, called heliostats, to reflect sunlight onto a receiver on top of a tower. Each heliostat uses a two-axis tracking system to focus the sun on the power tower receiver.

Photo by Dennis Schroeder, NREL 46150

Other CST collector technologies exist but lag in development and deployment. Linear Fresnel collectors are similar to parabolic trough collectors in that they are both line focus systems that use a linear receiver tube. Linear Fresnel reflectors are made of many thin, flat mirror strips that run parallel to the receiver with each oriented to reflect the sun onto the fixed receiver (Figure 3). The mirrors rotate on a single axis to keep the sun focused on the stationary receiver throughout the day. Due to their geometry, linear Fresnel collectors have a lower optical efficiency than parabolic trough collectors (IRENA 2012). However, their simple design and ability to use lowcost, flat glass mirrors hold significant cost-reduction potential (Morin et al. 2012).

Dish Engine CSP uses a parabolic dish collector to concentrate sunlight. Like a heliostat, it uses two-axis tracking to follow the sun, but each dish has its own receiver mounted at the focal point of the dish. The receiver is often directly coupled to a Stirling engine to generate electricity, hence the name. Despite their modular design, and despite having the highest demonstrated solar-to-electricity efficiency (Reuters Events 2012) of any CSP technology, dish Stirling systems suffer from a lack of available thermal energy storage (TES) options, making their generation profile nearly identical to much less costly solar PV systems. 


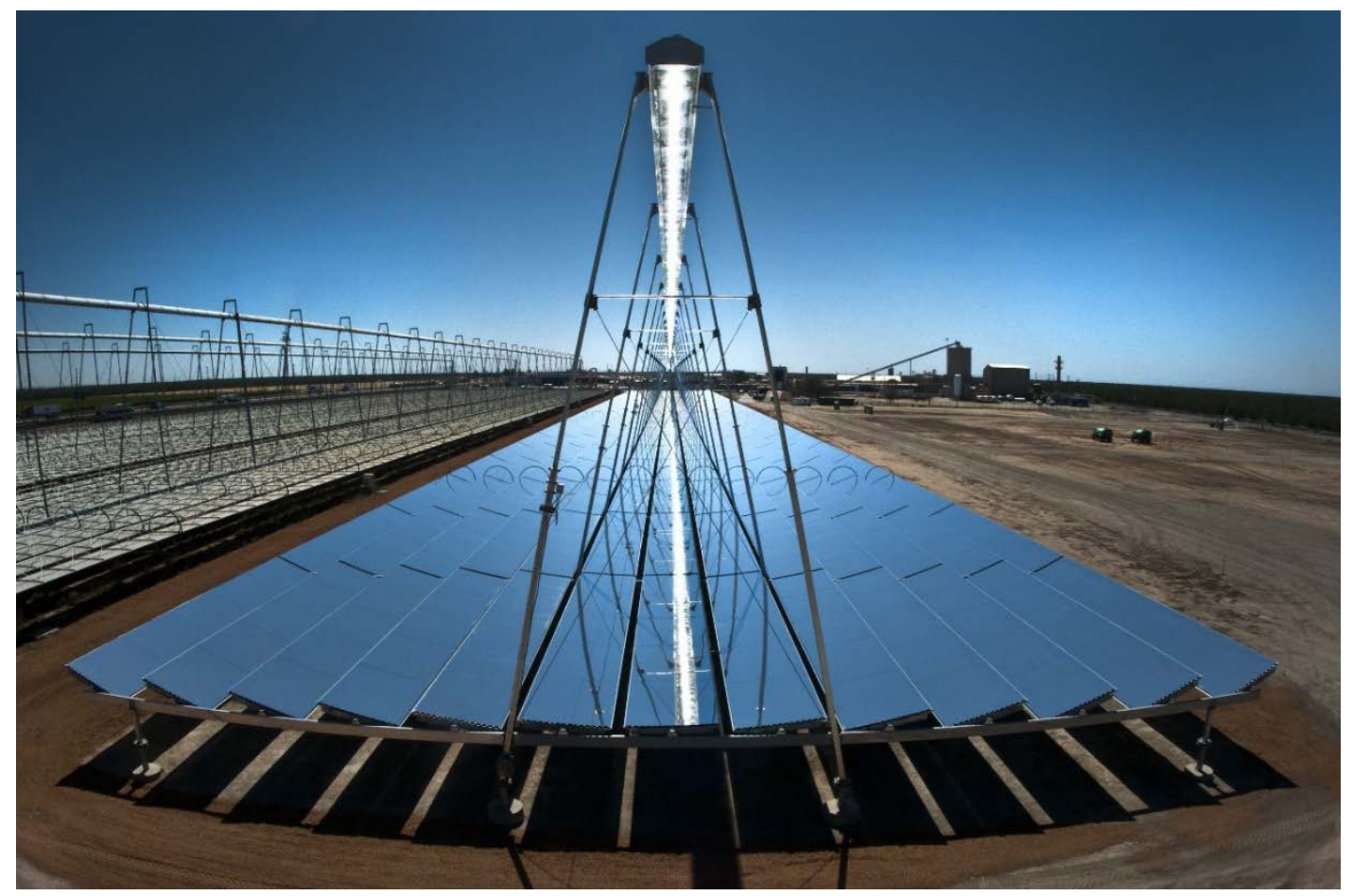

Figure 3. Fresnel concentrating solar power collectors comprise many thin, flat mirror strips that run parallel to the receiver. Each collector rotates on a single axis to keep the sun focused on the stationary receiver throughout the day.

Photo from AREVA Solar, NREL 19882

Besides collector type, the other major defining feature of CSP plants is whether they use TES. TES stores the thermal energy collected from the solar field for later use. The most common method of TES is a two-tank system using molten nitrate-based salt. Thermal energy is stored as sensible heat in a "hot" tank of molten salt. During discharge, the molten salt transfers its heat to another fluid through a heat exchanger and moves to a "cold" tank. During the charge phase, the molten salt moves from the cold tank, is heated by thermal energy from the solar field, and is sent back to the hot tank for storage.

TES decouples solar collection from electric power generation and allows CSP plants to generate electricity when the sun is not shining. With proper solar field and TES sizing, CSP is one of the few renewable energy technologies that can operate as either fully dispatchable or baseload at grid scale (Pfenninger et al. 2014).

We begin this report by reviewing the CSP resource potential, the current state of CSP deployments, and recent trends in the industry in Section 2. Then we explore the results of the Solar Futures Study grid capacity expansion modeling, focusing the projected deployment of CSP under different scenarios, in Section 3. The Solar Futures Study electricity grid capacity expansion modeling only included power tower CSP with TES because cost models indicate such plants have the greatest cost reduction potential and will have a significantly lower cost that parabolic trough CSP plants in the future U.S. market. Next, in Section 4, we discuss likely developments in CSP over the next decade. Finally, we discuss other potential markets where CST technologies can be employed in Section 5 and present the main conclusions from the report in Section 6. 


\section{Concentrating Solar-Thermal Power Market Status}

The first CSP plant in the U.S. was the $10 \mathrm{MW}_{\mathrm{e}}$ Solar One power tower, a U.S. Department of Energy (DOE) demonstration plant constructed in 1981. Since then, the globally installed generating capacity of CSP plants has grown to $6.3 \mathrm{GW}_{\mathrm{e}}$ in 2019 . In that time, CSP costs have decreased substantially. This section reviews the market status of CSP, starting with resource potential and current installed capacity, then presenting cost and technology trends and ending with a summary of the current industry and state of the art in CSP technology.

\subsection{CSP Potential}

CST power potential depends on direct normal irradiance (DNI), or solar radiation directly from the sun. Unlike PV, which can generate electricity from solar radiation that has been scattered, absorbed, or reflected within the atmosphere (diffuse radiation), as well as DNI, CST can only focus direct solar radiation. In other words, while PV can operate on cloudy days (albeit less effectively), CST requires direct sunlight to operate.

DNI is typically reported as an annual average, in either $\mathrm{kWh} / \mathrm{m}^{2} /$ year or $\mathrm{kWh} / \mathrm{m}^{2} /$ day. Figure 4 shows the average annual DNI globally. Trieb et al. (2009) generated this map and used it to estimate the global CSP resource potential. They assumed a cutoff of $2,000 \mathrm{kWh} / \mathrm{m}^{2} /$ year DNI $\left(5.5 \mathrm{kWh} / \mathrm{m}^{2} /\right.$ day) as being sufficient for CSP (electricity) generation and further excluded land with slope, water, forests, shifting sands, protected and restricted areas, population centers, and other criteria that made an area unsuitable for CSP deployment. They found more than 3 million $\mathrm{TWh}_{\mathrm{e}} / \mathrm{y}$ of total CSP resource potential worldwide, with Africa, Australia, and the Middle East having the greatest share. This resource potential represents more than 100 times the world demand for electricity, demonstrating that CSP technologies are not resource limited.

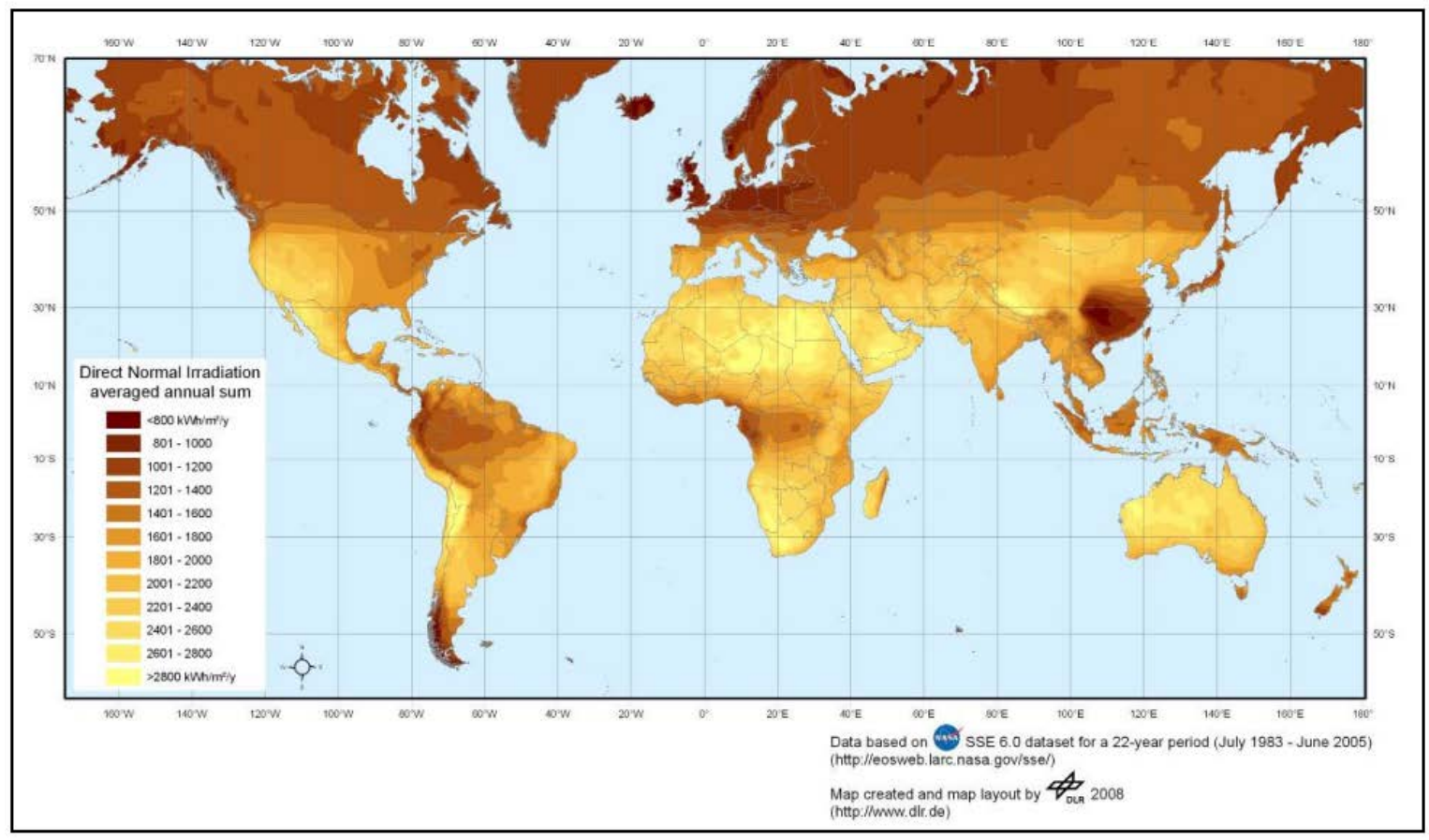

Figure 4. Worldwide annual direct normal irradiation $\left(\mathrm{kWh} / \mathrm{m}^{2} / \mathrm{year}\right)$

Source: Trieb et al. 2009 
A similar story can be told for the CSP resource potential of the United States (Figure 5). Limiting the CSP resource to areas with an average DNI $>5 \mathrm{kWh} / \mathrm{m}^{2} /$ day $\left(1,825 \mathrm{kWh} / \mathrm{m}^{2} /\right.$ year $)$ and excluding areas for slope, land ownership, and land types not suitable for CSP development, NREL found that the CSP technical potential of the United States exceeds $16 \mathrm{TW}_{\mathrm{e}}-$ greater than tenfold the roughly $1 \mathrm{TW}_{\mathrm{e}}$ of current total U.S. electricity generation capacity (Murphy et al. 2019; Sengupta et al. 2018). The best CSP resource is concentrated in the Southwest United States. As with the global resource, the U.S. CSP resource potential is tremendous, but the quality of the resource varies greatly, with the best resources geographically constrained to a few regions.

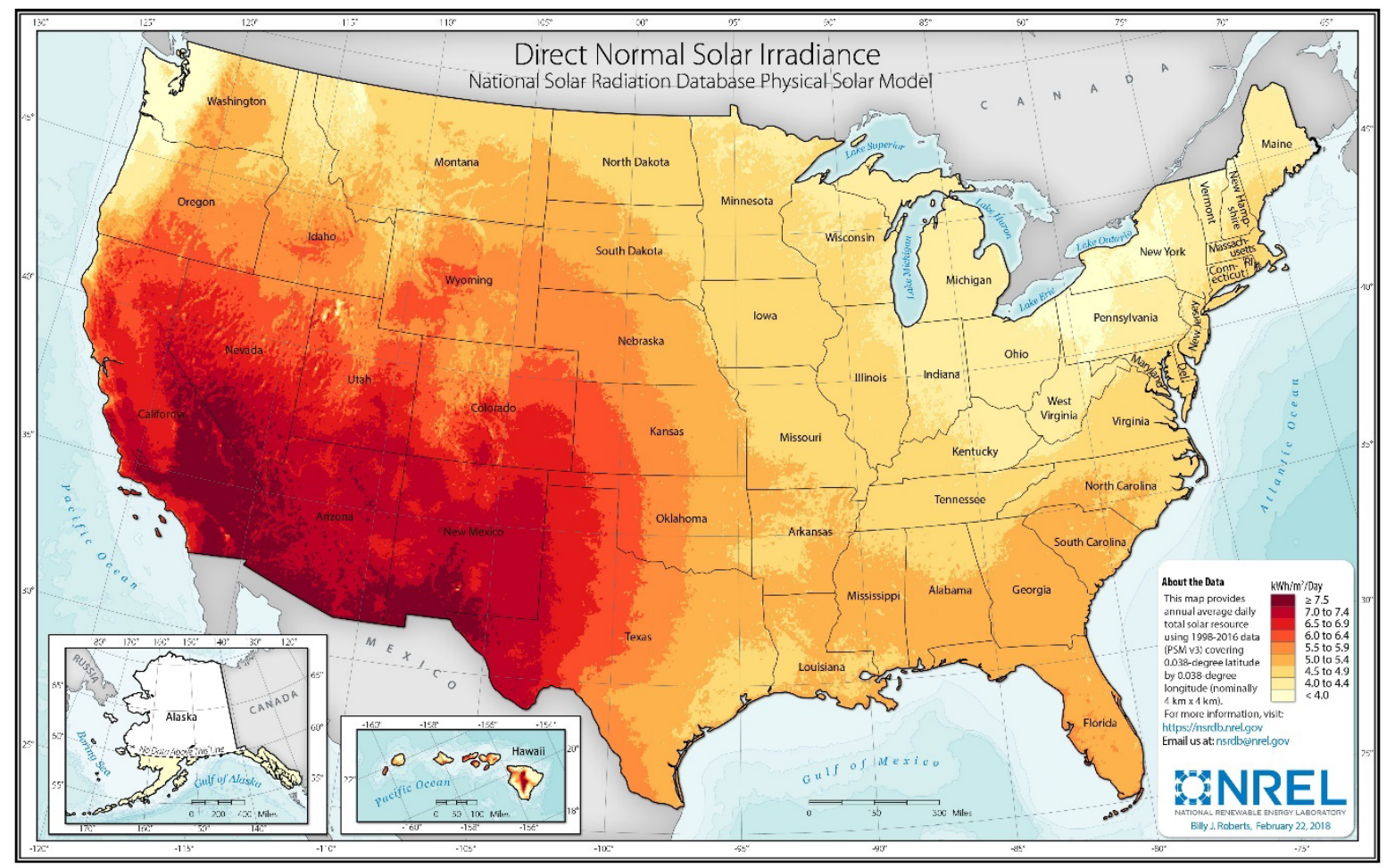

Figure 5. The CSP direct normal solar irradiance resource in the United States is greatest in the Southwest.

Source: Sengupta et al. 2018

\subsection{Installed Capacity}

Cumulative installed CSP electricity generation capacity reached $6.3 \mathrm{GW}_{\mathrm{e}}$ in 2019 , a fivefold increase since 2010 (IRENA 2020). Working with member countries, Solar Power and Chemical Energy Systems (SolarPACES) has compiled a database of CSP projects operating, under construction, or under development around the world (see Figure 6). According to the database, which NREL's CSP Program helps maintain, there are 108 operational CSP projects worldwide. The majority, 82, are parabolic trough CSP systems with a total installed net capacity of 4,933 $\mathrm{MW}_{\mathrm{e}}$. There are 20 power tower systems accounting for $1,170 \mathrm{MW}_{\mathrm{e}}$ of installed capacity. 


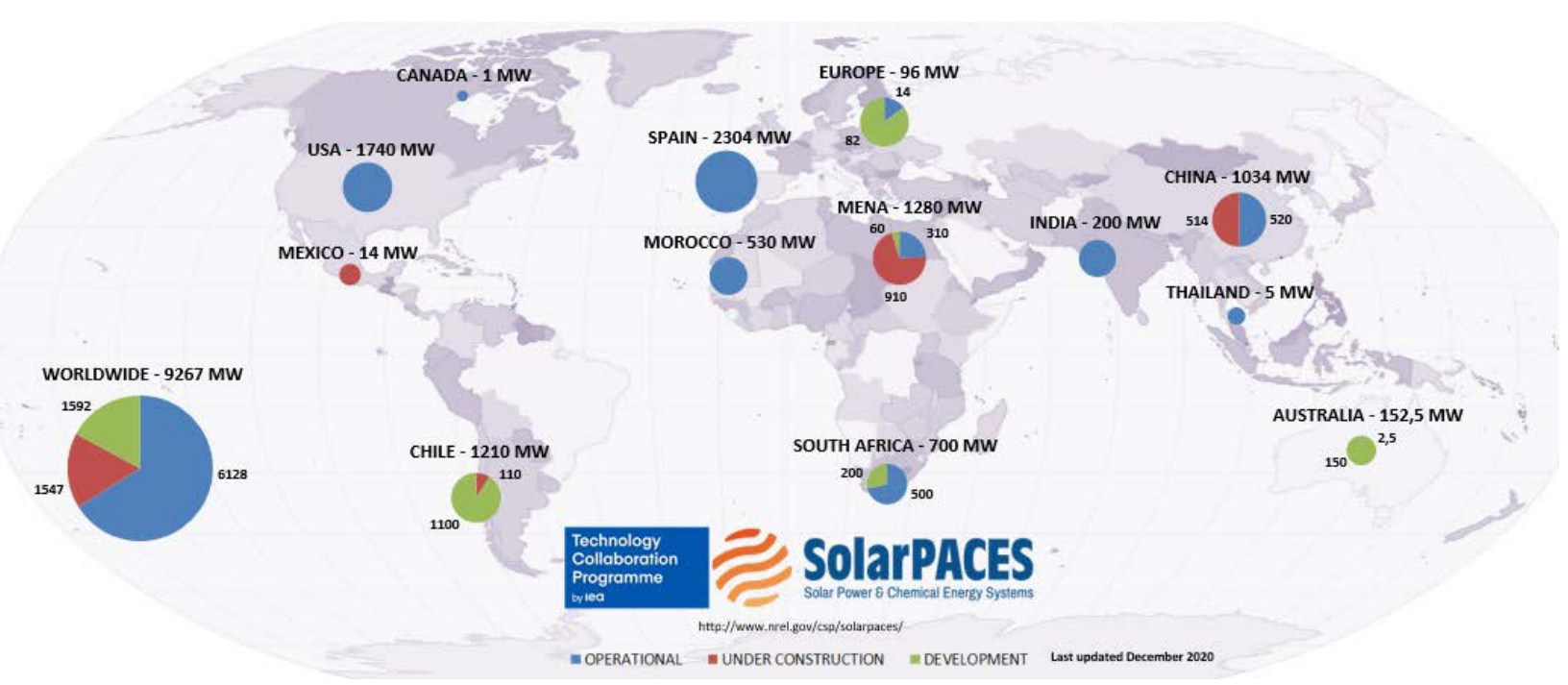

Figure 6. The CSP projects that are operational, under construction, or in development worldwide represent more than $9,000 \mathrm{MW}$ in current and future generation capacity.

Source: SolarPACES

The operational CSP plants in the United States, listed in Table 1, consist of 14 parabolic trough and two power tower CSP projects. (The Ivanpah Solar Electric Generating System project consists of three power towers, bringing the total number of CSP towers in the United States to four.) The four largest CSP plants in the world are in the United States, including the largest parabolic trough project and the largest power tower project. Conversely, the United States currently has no CSP plants under construction.

Table 1. Operational CSP Plants in the United States

\begin{tabular}{|l|l|l|l|l|l|}
\hline Plant Name & $\begin{array}{l}\text { Short } \\
\text { Name }\end{array}$ & CSP Type & $\begin{array}{l}\text { Start } \\
\text { Year }\end{array}$ & $\begin{array}{l}\text { Net } \\
\text { Capacity } \\
\text { (MW) }\end{array}$ & State \\
\hline Solar Electric Generating Station VIII & SEGS VIII & Parabolic Trough & 1989 & 80 & CA \\
\hline Solar Electric Generating Station IX & SEGS IX & Parabolic Trough & 1990 & 80 & CA \\
\hline Nevada Solar One & NSO & Parabolic Trough & 2007 & 72 & NV \\
\hline $\begin{array}{l}\text { Martin Next Generation Solar Energy } \\
\text { Center }\end{array}$ & MNGSEC & Parabolic Trough & 2010 & 75 & FL \\
\hline Solana Generating Station & Solana & Parabolic Trough & 2013 & 250 & AZ \\
\hline $\begin{array}{l}\text { Ivanpah Solar Electric Generating } \\
\text { System }\end{array}$ & ISEGS & Power Tower & 2014 & 377 & CA \\
\hline Genesis Solar Energy Project & & Parabolic Trough & 2014 & 250 & CA \\
\hline Mojave Solar Project & & Parabolic Trough & 2014 & 250 & CA \\
\hline Crescent Dunes Solar Energy Project & Tonopah & Power Tower & 2015 & 110 & NV \\
\hline Stillwater GeoSolar Hybrid Plant & & Parabolic Trough & 2015 & 2 & NV \\
\hline
\end{tabular}

Source: NREL 2021 


\subsection{Cost Trends}

The cost of a CSP project is affected by its technology type, location (resource quality, local costs), and whether it employs TES. TES increases the total installed costs of the project without changing its nameplate capacity, which depends solely on its power cycle capacity. Total installed costs increase due to the cost of the TES system and the increase in the size of the plant's solar field and receiver required to increase the solar energy collected during the day and fill the TES system. However, TES increases the capacity factor of a project, i.e., increases annual operating hours of the power cycle, because it can operate using the stored thermal energy after sunset. The higher total generation increases plant revenue and utilization of the plant's power cycle, which can lower the overall levelized cost of electricity (LCOE). LCOE calculations are also affected by financial assumptions and project lifetime (see Section 2.3.2 for more details). When considering CSP plant costs, it's important to factor in the use and duration of TES, recognizing this makes it difficult to draw direct cost comparisons between plants.

Despite the increased use of TES, both the total installed cost and LCOE of CSP projects have decreased in the last decade. Installed total costs, capacity factor, and LCOE for CSP projects globally, which are tracked by the International Renewable Energy Agency (IRENA), are shown in Figure 7.

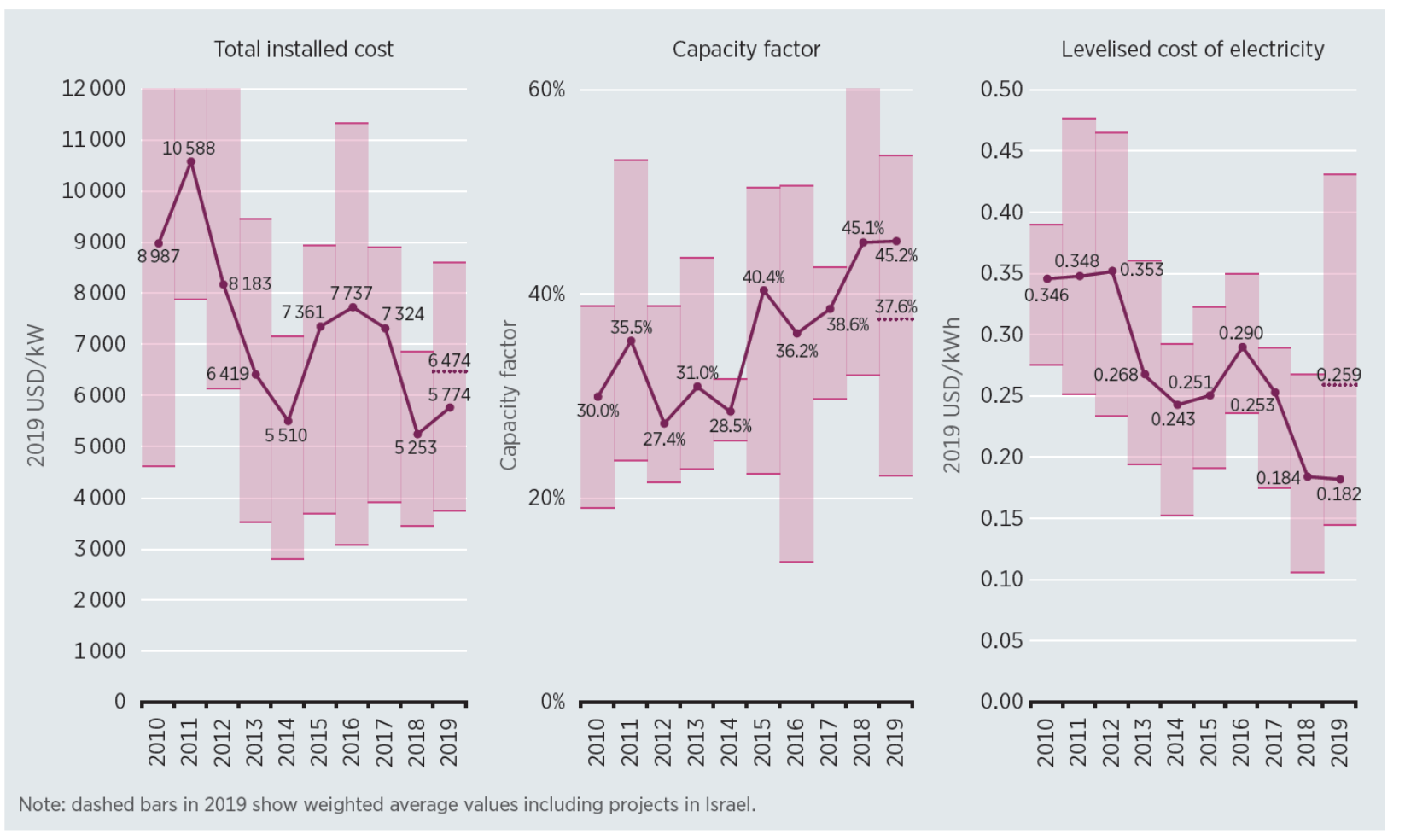

Figure 7. Global weighted average total installed costs, capacity factors, and LCOE for CSP, 2010-2019

Source: IRENA 2020

\subsubsection{Total Installed Costs}

The capacity weighted-average installed cost of CSP projects globally has fallen from USD $\$ 8,987 / \mathrm{kW}_{\mathrm{e}}$ in 2010 to $\$ 5,774$ in 2019 (IRENA 2020), a 36\% decrease. Installed total costs for 
CSP projects globally_ grouped by project size, collector type, and TES duration — are shown in Figure 8. Comparing across these groups is challenging, and there is a lot of variability in costs from year to year, but the trend over the decade clearly shows costs decreasing. The data also shows an increase in power tower (solar tower) deployments and an increase in the use of TES.

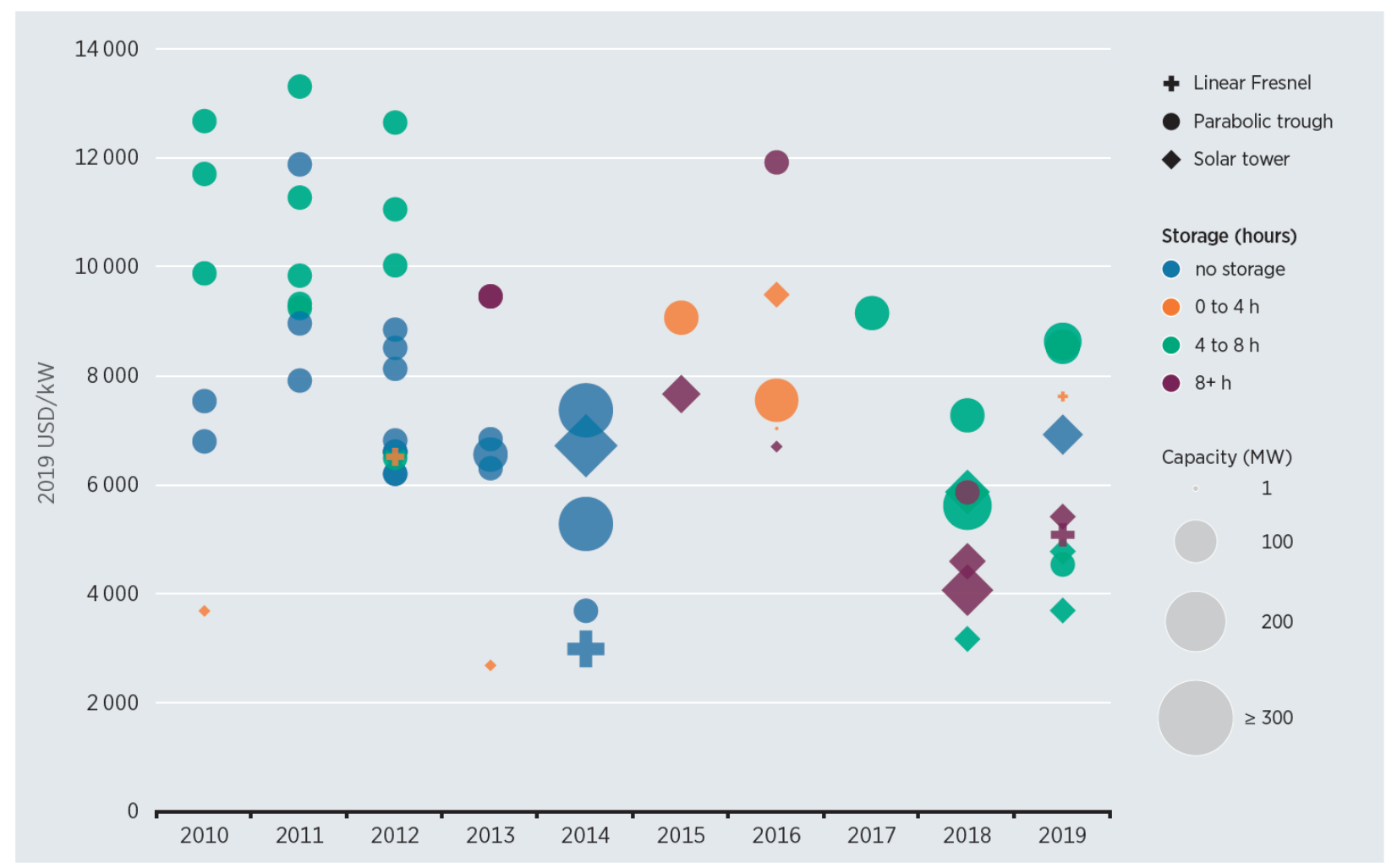

Figure 8. CSP total installed costs $\left(\$ / \mathrm{kW}_{\mathrm{e}}\right)$ by project size, collector type, and thermal energy storage duration

Source: IRENA 2020

\subsubsection{Levelized Cost of Electricity}

The weighted average LCOE of installed CSP plants globally fell by $47 \%$ between 2010 and 2019 , from USD $\$ 0.35 / \mathrm{kWh}$ to USD $\$ 0.18 / \mathrm{kWh}$, according to IRENA (2020). Figure 9 shows the LCOE of plants by location and year.

Although total capital costs have decreased over the same period, technology cost decreases alone do not explain LCOE cost reductions. The move of CSP markets from Spain to areas with higher DNIs after 2012 also contributed to higher capacity factors and lower LCOE (Lilliestam et al. 2017). The incorporation of TES in recent years further contributed to the increase in capacity factor and lower LCOE (IRENA 2020).

As mentioned previously, LCOE calculations are affected by the financial parameters used, particularly the discount rate (time value of money) and project lifetime assumed. IRENA assumes a real (as opposed to nominal) weighted average cost of capital (WACC) of $7.5 \%$ in OECD countries and China and a real WACC of 10\% in the rest of the world, and assumes an economic lifetime of 25 years for CSP plants (IRENA 2020). 
When comparing the LCOE of plants, especially from different sources, one must ensure that the assumptions in the LCOE calculations are consistent to give a fair or "apples-to-apples" comparison. The auction database values in Figure 9 illustrate this. In recent years, some projects have signed power purchase agreements (PPAs) to deliver electrical power for less than $\$ 0.10 / \mathrm{kWh}_{\mathrm{e}}$, much lower than the LCOE values in years prior. One would assume that these companies signed PPAs at prices higher than their LCOE. Evidence suggests that the companies were able to secure low-cost financing over an extended period of time, which would lower their LCOE (see Section 2.4.2 for more discussion).

If the LCOE were calculated using the IRENA assumptions instead, they would likely be higher (see IRENA 2020, Box 8.1). The important thing to note from Figure 9 is that when assumptions are kept reasonably consistent, LCOE projects worldwide have decreased significantly in the last decade.

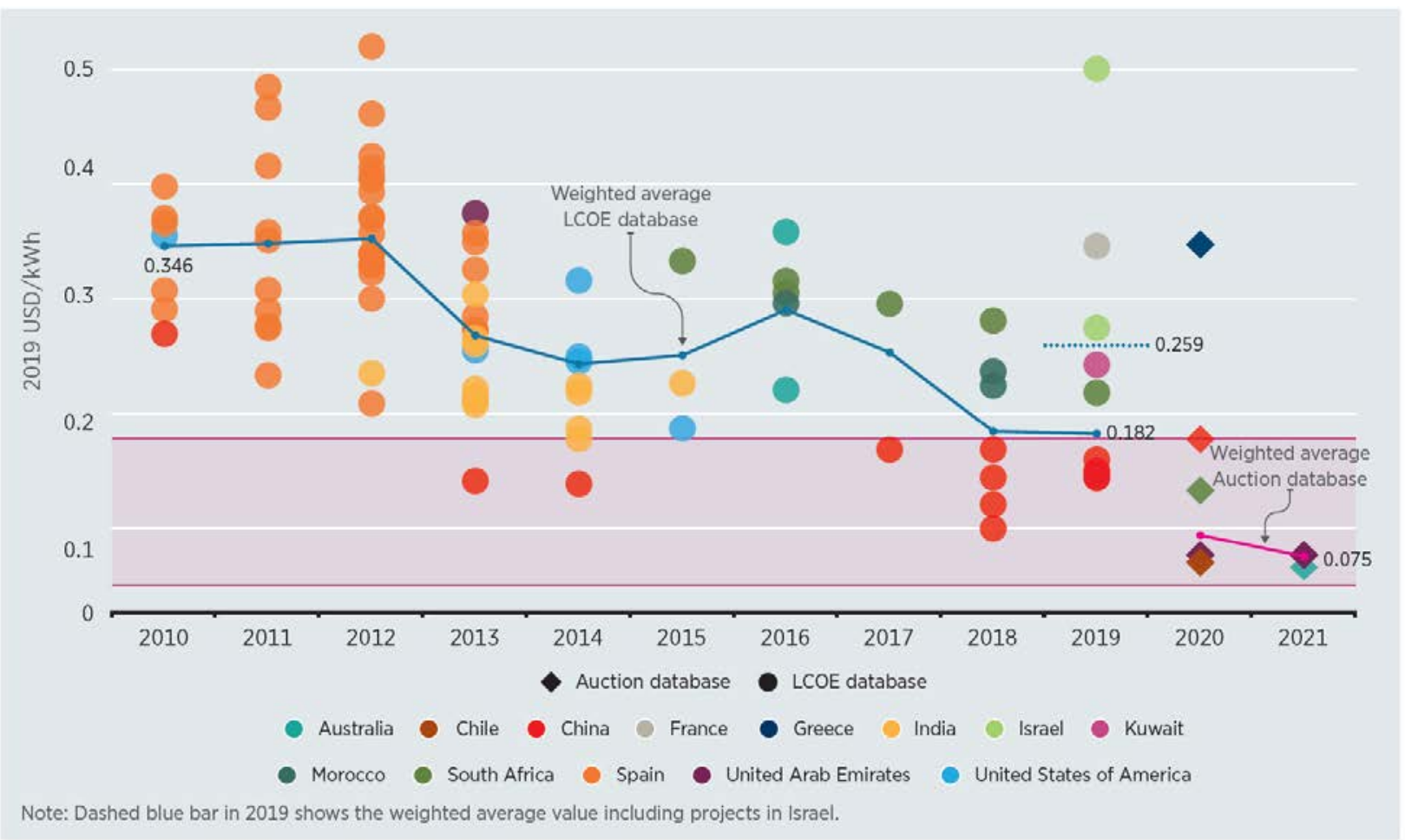

Figure 9. CSP project historical levelized cost of electricity and future plant auction prices $(\$ / k W h$ e) by country

Source: IRENA 2020

\subsubsection{Operations and Maintenance Costs}

Operations and maintenance (O\&M) costs for CSP plants are typically $0.02-0.04 \$ / \mathrm{kWh}$ (IRENA 2020). O\&M costs for CSP power tower and parabolic trough plants include the plant operations and power plant maintenance, similar to conventional thermal power generators. O\&M also includes cleaning, maintaining, and replacing parts in the solar field. O\&M costs vary with plant size, location, and local labor rates but typically account for $20 \%-25 \%$ of the plant LCOE (Sargent \& Lundy 2003; Kutscher et al. 2010). 
On-site staff account for about half of the annual O\&M costs ((Sargent \& Lundy 2003; C. Turchi 2010). Insurance can also be a significant contribution to O\&M costs (IRENA 2020). IRENA estimates O\&M costs, including insurance, for power tower and parabolic trough plants in selected G20 countries range from 0.011-0.032 \$/kWh (Figure 10). The data suggest that power tower and parabolic trough plants have comparable O\&M costs, although power tower costs are slightly lower (IRENA 2020).

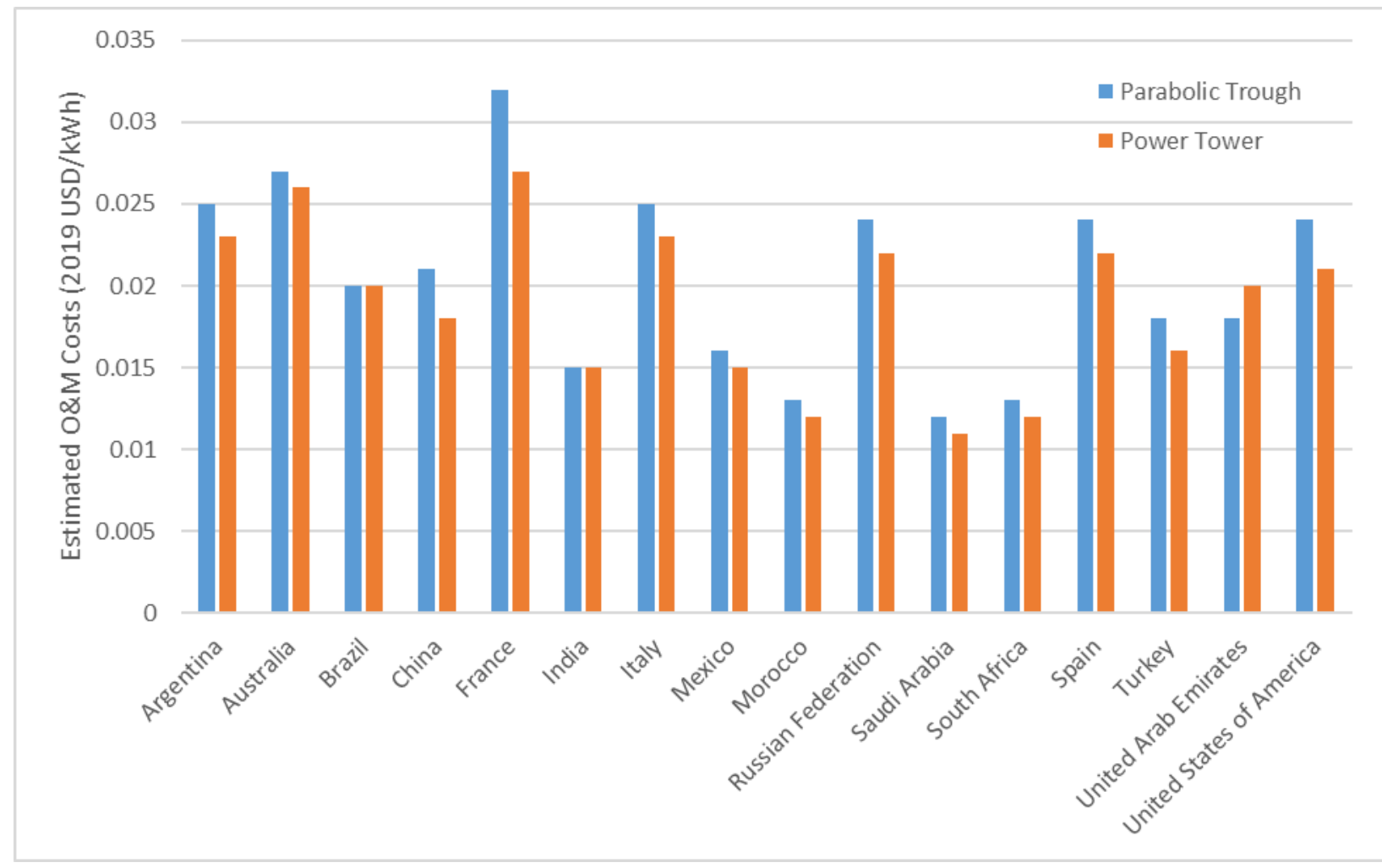

Figure 10. Estimated O\&M costs, including insurance, for parabolic trough and power tower CSP plants in select markets

Source: IRENA 2020

\subsection{Technology Trends in the Last Decade}

The CSP industry has experienced a series of boom-bust cycles over its history. The first boom cycle started in 1984 in California and resulted in the construction of nine solar electricity generating system (SEGS) plants totaling $350 \mathrm{MW}_{\mathrm{e}}$ of generating capacity. This initial CSP deployment period ended in 1991 after falling natural gas rates priced CSP out of the market (Lilliestam et al. 2017).

Following a 15-year cycle that saw no new CSP plant construction, the second boom cycle began in 2007 with a feed-in tariff (FIT) in Spain that supported the construction of 49 CSP plants totaling $2.3 \mathrm{GW}_{\mathrm{e}}$ of generating capacity (Lilliestam et al. 2017). The boom cycle also included a surge in CSP support and development in the United States (Lilliestam et al. 2020) aided by USD \$5.1 billion in loan guarantees for four large CSP projects (DOE 2019). The end of the Spanish FIT and U.S. loan guarantee program prompted another bust phase from 2014 through 2016, and the generating capacity of CSP plants under construction in 2016 fell to a 
third of its 2012 value (Lilliestam et al. 2020). A third boom phase started in late 2016 when China announced a FIT to support the construction of 20 CSP plants by end of 2018 (Lilliestam et al. 2020).

\subsubsection{State of the Art}

Based on recent projects, the state of the art for CSP plants is in flux and includes two dominant designs: the established parabolic trough plant and the new power tower plant. This mix is best exemplified by 950-MW $\mathrm{M}_{\mathrm{e}}$ Noor Energy 1 project in Dubai, which, when completed, will consist of three 200-MW $\mathrm{MW}_{\mathrm{e}} \mathrm{CSP}$ parabolic trough systems, one 100-MW $\mathrm{MWS}_{\mathrm{e}}$ power tower plant, 15 hours of molten salt CSP TES (for both parabolic and power tower plants), and $250 \mathrm{MW}_{\mathrm{e}}$ of PV capacity (Reuters Events 2020a).

The vast majority of the latest CSP parabolic trough plant capacity is from plants that use thermal oil as the HTF, a steam Rankine power cycle, and two-tank indirect molten salt TES (NREL 2021). The most common CSP power tower design operating or under construction uses a central external receiver, molten salt as the HTF, a steam Rankine power cycle, and two-tank direct molten salt TES (NREL 2021). The molten salt is a sodium nitrate-potassium nitrate mixture referred to as "solar salt". Solar salt is thermally stable up to $600^{\circ} \mathrm{C}$ in ambient air, which limits current CSP power towers to operating temperatures to approximately $565^{\circ} \mathrm{C}$ (Mehos et al. 2017).

NREL tracks the cost and performance of state-of-the-art CSP technologies for the DOE Solar Energy Technologies Office. These values are reviewed and updated annually at NREL. The current state of the art CSP design used by DOE as a technology baseline is a $100-\mathrm{MW}_{\mathrm{e}}$ netcapacity power tower (heliostat field with central external receiver) using solar salt, two-tank direct TES, and a steam Rankine cycle with dry cooling. The plant has 14 hours of TES, a solar multiple of 2.7, and is assumed to be located in Daggett, CA. The current costs and financial assumptions for the current DOE Solar Energy Technologies Office baseline molten-salt power tower are summarized in Table 2 and are calculated using the System Advisor Model (SAM). ${ }^{1}$ The financial parameters come from the "On the Path to SunShot" study and were chosen to align with how CSP projects are expected to be funded in the future and assume a mature technology capable of obtaining equity and debt priced similarly to that for other mature technologies developed by investor-owned utilities and independent power producers (Mehos et al. 2016). Two financial parameters, the federal tax rate and investment tax credit, deviate from the "On the Path to SunShot" assumptions. The federal tax rate was set to $21 \%$ to reflect current law. The investment tax credit was $26 \%$ in 2020 and drops to $10 \%$ after 2024. The Solar Futures Study applies the investment tax credit, along with all other current laws and mandates, in its models. The DOE Solar Energy Technologies Office usually reports LCOE assuming no incentives ( $0 \%$ investment tax credit). LCOE results for all three investment tax credit assumptions are shown in Table 2 for comparison. SAM estimates a real LCOE of 9.5 cents $/ \mathrm{kWh}_{\mathrm{e}}(0.095 \$ / \mathrm{kWh})$ for a commercially mature state of the art CSP power tower plant in the United States with no incentives. The LCOE drops to 8.8 cents $/ \mathrm{kWh}_{\mathrm{e}}$ and 7.7 cents $/ \mathrm{kWh}_{\mathrm{e}}$ assuming investment tax credits of $10 \%$ and $26 \%$, respectively.

${ }^{1}$ https://sam.nrel.gov/ 
Table 2. State of the Art Baseline CSP Power Tower Design, Costs, and Performance used by DOE

\begin{tabular}{|c|c|c|c|}
\hline CSP Design Overview & \multicolumn{3}{|c|}{ State of the Art Baseline } \\
\hline Model & \multicolumn{3}{|c|}{ SAM 2020.2 .29} \\
\hline Source of Financial Assumptions & \multicolumn{3}{|c|}{ "On the Path to SunShot" (Mehos et al. 2016) } \\
\hline Location & \multicolumn{3}{|l|}{ Daggett, CA } \\
\hline Technology & \multicolumn{3}{|c|}{ Molten-Salt Power Tower } \\
\hline HTF & \multicolumn{3}{|c|}{$\begin{array}{l}\text { Solar Salt } \\
(60 \mathrm{wt} \% \text { sodium nitrate } 40 \mathrm{wt} \% \text { potassium nitrate }\end{array}$} \\
\hline Solar Multiple & \multicolumn{3}{|l|}{2.7} \\
\hline TES (hours) & \multicolumn{3}{|l|}{14} \\
\hline TES Tank Temperatures: Hot/Cold $\left({ }^{\circ} \mathrm{C}\right)$ & \multicolumn{3}{|l|}{$575 / 290$} \\
\hline Plant Capacity (MWe, net) & \multicolumn{3}{|l|}{100} \\
\hline Power Cycle & \multicolumn{3}{|c|}{ Steam Rankine cycle } \\
\hline Power-Cycle Gross Efficiency & \multicolumn{3}{|l|}{$41.2 \%$} \\
\hline Cooling Method & \multicolumn{3}{|l|}{ Dry Cooling } \\
\hline \multicolumn{4}{|l|}{ Cost Assumptions } \\
\hline Site Preparation (\$/m2) & \multicolumn{3}{|l|}{16} \\
\hline Solar Field (\$/m2) & \multicolumn{3}{|l|}{140} \\
\hline Thermal Energy Storage ( $\$ / k W h t h)$ & \multicolumn{3}{|l|}{22} \\
\hline Power Cycle $(\$ / k W e)$ & \multicolumn{3}{|l|}{1,040} \\
\hline Balance of Plant $(\$ / k W e)$ & \multicolumn{3}{|l|}{290} \\
\hline Contingency & \multicolumn{3}{|l|}{$10 \%$} \\
\hline EPC \& Owner Costs & \multicolumn{3}{|l|}{$17.6 \%$} \\
\hline Sales Tax & \multicolumn{3}{|l|}{$0 \%$} \\
\hline Federal and State Income Tax Rate & \multicolumn{3}{|c|}{ Federal: $21 \%$ State: $5 \%$} \\
\hline Analysis Period & \multicolumn{3}{|l|}{30 years } \\
\hline Weighted Average Cost of Capital & \multicolumn{3}{|l|}{$7 \%$} \\
\hline Fixed O\&M cost ( $\$ / \mathrm{kWe} /$ year) & \multicolumn{3}{|l|}{66} \\
\hline Variable O\&M cost (\$/MWh) & \multicolumn{3}{|l|}{3.5} \\
\hline \multicolumn{4}{|l|}{ Performance and Results } \\
\hline Capacity Factor (\%) & \multicolumn{3}{|l|}{$69.0 \%$} \\
\hline Overnight Installed Cost (\$/kWe) & \multicolumn{3}{|l|}{$\$ 7,067$} \\
\hline Total Installed Cost (\$/kWe) & \multicolumn{3}{|l|}{$\$ 7,561$} \\
\hline Investment Tax Credit & $26 \%(2020)$ & $10 \%(\geq 2024)$ & $0 \%$ \\
\hline LCOE (real) (cents/kWhe) & 7.6 & 8.8 & 9.5 \\
\hline
\end{tabular}

Sources: Murphy et al. 2019; Craig S Turchi and Boyd 2019; Mehos et al. 2016 
Despite its growth in the last decade, CSP, and especially power tower CSP, is still an immature technology (del Río, Peñasco, and Mir-Artigues 2018), as evidenced by the existence of two competing commercial CSP designs. The industry is shifting toward using power towers because of their ability to achieve higher solar concentrations and thus higher temperatures and higher power cycle efficiencies. Higher temperatures also increase the potential for lower marginal $\left(\$ / \mathrm{MWh}_{\text {th }}\right)$ TES costs due a larger temperature difference between the hot and cold stores. However, the reliability of power tower systems is less demonstrated, and many projects still opt to use the more commercially proven parabolic trough design.

The industry is making efforts to consolidate around designs and best practices (Mehos et al. 2020). Cost modeling points to power tower designs as having greater cost reduction potential, but it is not clear which technology will become the dominant standard design — or whether both will continue to be commercially deployed far into the future.

Regardless of the solar collector technology, CSP projects have made a significant shift toward including TES. By enabling CSP plants to generate electricity even when the sun is not shining, TES increases their generation flexibility and value to the grid and avoids direct competition with lower-cost generation from PV during the daytime hours. The average TES capacity for CSP plants has increased from 3.3 hours in the first half of the last decade to 5.7 hours in the second half (IRENA 2020). Of the 21 projects in the SolarPACES CSP database to become operational since 2015, only one did not incorporate TES (NREL 2021). TES has become essential for CSP plants to complement daylight-hour PV generation and will likely continue to be used at most CSP plants in the future.

Another recent industry trend is to develop projects that combine CSP and PV. In addition to the Noor Energy 1 project described above, the Redstone ${ }^{2}$ CSP power tower plant has $100 \mathrm{MW}_{\mathrm{e}}$ of generation capacity with 12 hours of TES and is situated in the Humansrus Solar Park in South Africa next to the 96- $\mathrm{MW}_{\mathrm{e}}$ Jasper and the $75-\mathrm{MW}_{\mathrm{e}}$ Lesedi PV projects. The Cerro Dominador ${ }^{3}$ plant in Chile will combine $100 \mathrm{MW}_{\mathrm{e}}$ of PV capacity and a 110-MWe $\mathrm{MSP}_{\mathrm{e}}$ power tower with 17.5 hours of TES. The 800-MWe Noor Midelt I project in Morocco is set to become the first project in the world to include thermal storage of CSP and PV (using electric heating) (Kraemer 2020). Combining CSP and PV helps the plant supply load throughout the day, and low-cost PV lowers the overall LCOE of the project.

\subsubsection{State of the Industry}

The CSP industry finds itself at a crossroads. On one hand, the boom cycle that began in 2016 with the Chinese FIT has helped strengthen the value chain, diversity, and competition in the industry (Lilliestam et al. 2020). CSP LCOE costs have declined by almost half since 2010, and costs for projects under construction and under development are even lower. The Noor Energy 1 project will deliver electricity at an overall tariff of USD $\$ 0.073 / \mathrm{kWh}$, with the tariff for the PV component set at $\$ 0.024 / \mathrm{kWh}$ and the CSP component at $\$ 0.083 / \mathrm{kWh}$ (Reuters Events 2018). The Noor Midelt I CSP-PV hybrid plant won its contract with a record-low bid for CSP projects of USD $\$ 0.071 / \mathrm{kWh}$ (Reuters Events 2019). In Dubai, the DEWA IV project signed a PPA to

\footnotetext{
${ }^{2}$ https://www.nomac.com/en/our-operations/nomac-globally/redstone-csp-ipp/

3 https://cerrodominador.com/en/
} 
deliver power at USD $\$ 0.073 / \mathrm{kWh}$. The $700-\mathrm{MW}_{\mathrm{e}}$ combined power tower and parabolic trough project currently under construction was able to achieve these low costs because of the long term of the PPA -35 years instead of a more standard 20-year agreement - and low financing costs (Lilliestam and Pitz-Paal 2018).

On the other hand, CSP is still a relatively immature technology (del Río, Peñasco, and MirArtigues 2018). Immature technologies typically rely on policy incentives to reduce private sector risk and encourage developers to deploy the new technology. CSP deployment in the past has been driven by policy, and CSP policy support and the CSP project pipeline is disappearing. Figure 11 shows CSP policy support and the capacity of CSP plants under construction. Spain's FIT drove significant deployment in Spain before it ended. U.S. deployments were driven by the Section 1705 loan guarantee program, which required plant construction to begin by September 30, 2011 to qualify. ${ }^{4}$ The Chinese FIT encouraged deployments in China but is ending in 2021, and Morocco saw CSP deployments as a result of two successful auctions but does not have any additional auctions for CSP projects scheduled (Lilliestam et al. 2020). No new CSP plants broke ground in 2019, and Noor Energy 1 accounts for the majority of CSP capacity under construction. As mentioned earlier, the United States has no CSP projects under construction. If CSP policy support and new construction starts remain weak, the CSP industry may enter another bust phase, and the industry could lose companies and CSP talent as workers move on to other industries (Lilliestam et al. 2020).
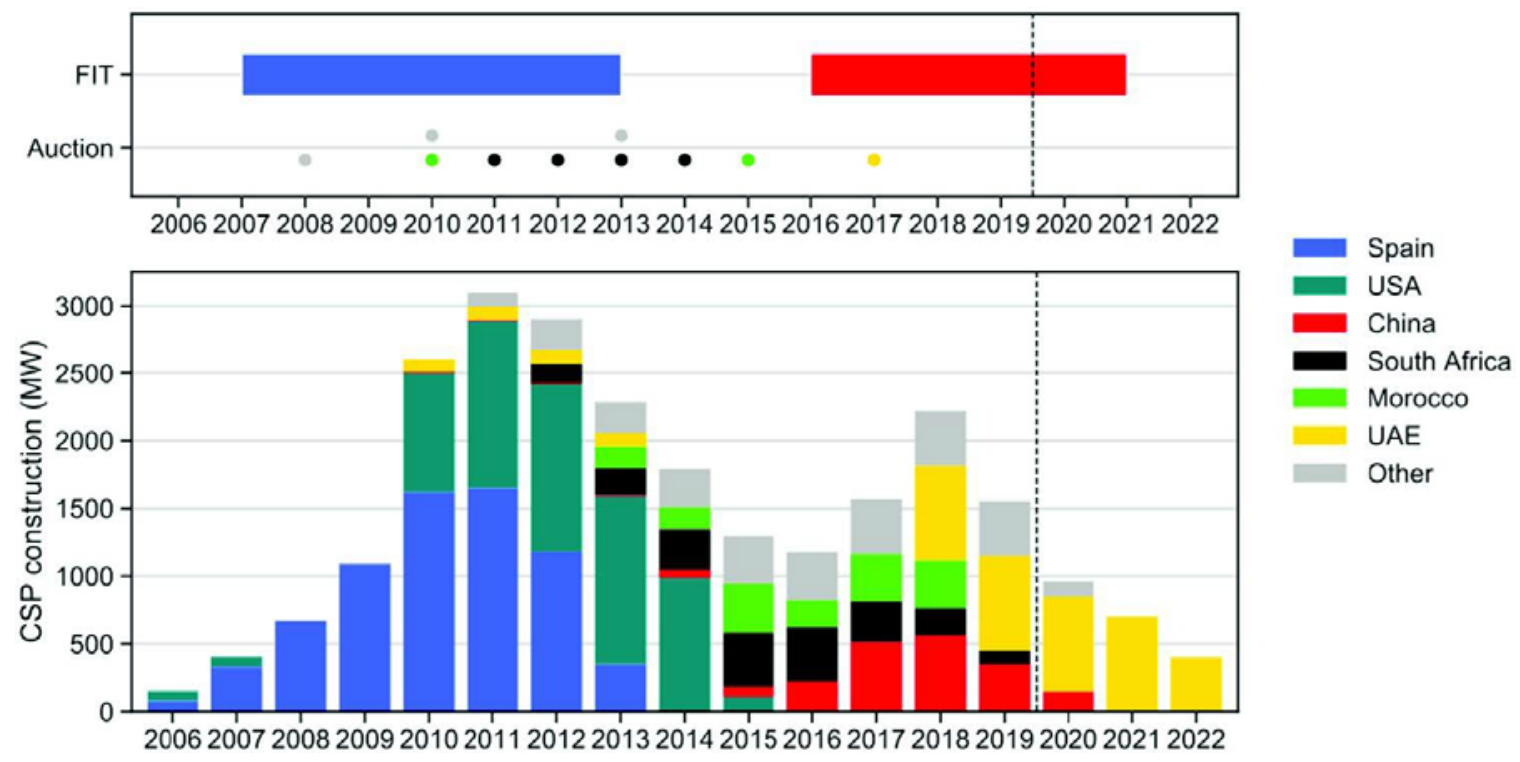

Figure 11. Concentrating solar-thermal power capacity under construction per year compared to availability of policies that support CSP projects

Source: Lilliestam et al. 2020

\footnotetext{
${ }^{4}$ Section 1705 is not included in the policy incentives shown in Figure 11.
} 


\section{CSP Solar Futures Study Results}

The Solar Futures Study explores the role of solar technologies, including CSP, under several future scenarios with aggressive grid-based emissions reductions. To do this, the study requires estimates of present and future costs of solar technologies, as well as estimates for all competing technologies, to model how these scenarios could unfold. This section describes CSP resource and cost assumptions used as inputs in the Solar Futures Study model runs. It then discusses CSP projected deployments in the Solar Futures Study results and the role of CSP in future decarbonized grids for both the core study scenarios and sensitivity scenarios specific to CSP.

\subsection{CSP Resource and Cost Assumptions}

The Solar Futures Study used the Regional Energy Deployment System (ReEDS) model, a capacity planning model for the electric power sector developed by NREL, ${ }^{5}$ to make future projections of installed electricity capacity and generation in the contiguous United States. For the Solar Futures Study, we assumed the resource and cost assumptions for CSP from the NREL 2020 Annual Technology Baseline (ATB) (NREL 2020). Here, we briefly discuss the data sources and assumptions used for CSP inputs to the ReEDS model.

The CSP technical resource potential is broken into 12 classes based on DNI, starting at 5 $\mathrm{kWh} / \mathrm{m}^{2} /$ day and increasing in $0.25 \mathrm{kWh} / \mathrm{m}^{2} /$ day increments up to $>7.75 \mathrm{kWh} / \mathrm{m}^{2} /$ day, the highest-quality CSP resource class. Table 3 shows the CSP resource classes and the available resource in each class. Figure 12 shows the geographic distribution and quantity of CSP resources in the United States for each class. The best CSP resources are found in the Southwest, and resource quality degrades as one moves north and east. Most of the Midwest and Northeast have a CSP resource of $<5 \mathrm{kWh} / \mathrm{m}^{2} /$ day and/or land exclusions and are not included in the CSP technical resource potential. (Murphy et al. 2019) includes a more in-depth discussion of the CSP resource potential development.

Table 3. Resource Classes, Based on DNI and the Available Technical Potential Resource in the Contiguous United States

\begin{tabular}{|l|l|l|}
\hline CSP Resource Class & DNI (kWh/m2/day) & Available Resource (GWe) \\
\hline Class 1 & $>7.75$ & 114 \\
\hline Class 2 & $7.50-7.75$ & 677 \\
\hline Class 3 & $7.25-7.50$ & 1,251 \\
\hline Class 4 & $7.00-7.25$ & 1,381 \\
\hline Class 5 & $6.75-7.00$ & 1,098 \\
\hline Class 6 & $6.50-6.75$ & 1,252 \\
\hline Class 7 & $6.25-6.50$ & 1,282 \\
\hline Class 8 & $6.00-6.25$ & 1,850 \\
\hline Class 9 & $5.75-6.00$ & 1,725 \\
\hline Class 10 & $5.50-5.75$ & 1,495 \\
\hline
\end{tabular}

${ }^{5}$ https://www.nrel.gov/analysis/reeds/ 


\begin{tabular}{|l|l|l|}
\hline CSP Resource Class & DNI (kWh/m2/day) & Available Resource (GWe) \\
\hline Class 11 & $5.25-5.50$ & 1,925 \\
\hline Class 12 & $5.00-5.25$ & 2,641 \\
\hline
\end{tabular}

Available resource excludes areas not suitable for concentrating solar-thermal power deployment due to topographic, environment, and land-use considerations.

Source: Murphy et al. 2019
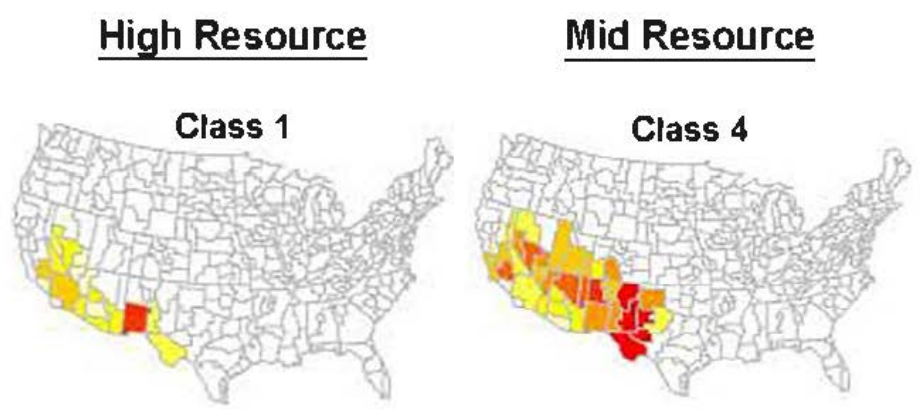

\section{Low Resource}
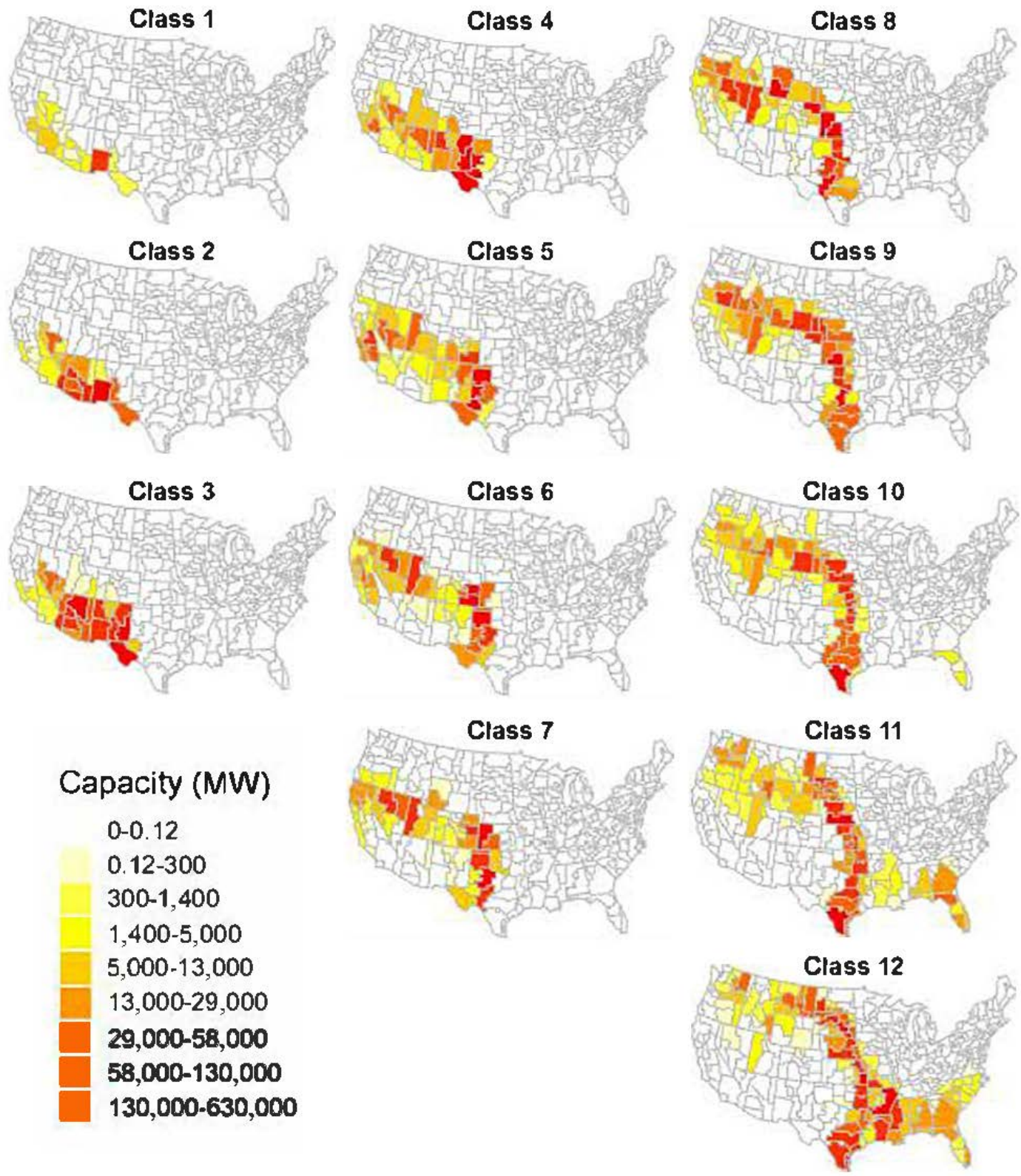

Figure 12. Geographic distribution of available CSP capacity by CSP resource class (solar resource quality)

Source: Murphy et al. 2019 
The representative technology for CSP in the ATB, used in the ReEDS model, is a sodium nitrate/potassium nitrate (solar salt) molten-salt power tower with direct two-tank TES using a steam-Rankine power cycle using dry cooling operating at $575^{\circ} \mathrm{C}$ and a gross cycle efficiency of $41.2 \%$. The plant has 10 hours of TES, a solar multiple (SM) ${ }^{6}$ of 2.4 , and a net capacity of 100 $\mathrm{MW}_{\mathrm{e}}$. The representative CSP plant is based on the Crescent Dunes plant located near Tonopah, Nevada, and commissioned in early 2016, and reflects the technologies and configuration used in commercial CSP power tower plants worldwide. Power towers were selected as the representative technology over parabolic troughs because they have a greater potential for cost reductions (NREL 2020).

CSP current installed capital costs are based on the representative plant in NREL's System Advisor Model (SAM), where the costs are estimated from industry surveys and literature reviews (Craig S Turchi and Boyd 2019), and are described in detail, along with financial assumptions, in the 2020 NREL Annual Technology Baseline (ATB) (NREL 2020). Overnight capital costs for the $100-\mathrm{MW}_{\mathrm{e}}$ net-capacity CSP power tower with 10 hours of storage and an $\mathrm{SM}$ of 2.4 are estimated at $\$ 6,475 / \mathrm{kW}_{\mathrm{e}}$ (2018 USD). The current LCOE for the representative plant is estimated at $\$ 0.088 / \mathrm{kWh}$ (2018 USD) assuming a 30 year project lifetime and 5.3\% real $\mathrm{WACC}^{7}$ (NREL 2020).

A breakdown of the cost components for the representative CSP plant is shown in Figure 13. CSP overnight capital cost is divided among the primary subsystems of the heliostat field (29\%), power cycle (23\%), tower/receiver (17\%), and, to a lesser degree, the TES system (9\%). The solar collection subsystems (heliostat field, tower, and receiver) account for $59 \%$ of direct capital costs. Since contingency, indirect costs, and tax are $22 \%$ of overnight capital costs and are largely estimated as a percentage of direct capital cost, it is safe to say that the solar collection subsystems account for roughly half of overnight capital costs. SAM is also used to calculate energy generation and capacity factor for CSP plants as a function of location for use in ReEDS.

\footnotetext{
${ }^{6}$ Solar multiple (SM) is the ratio of solar receiver design point thermal output to the power cycle thermal rating. Larger solar multiples are required to provide longer-duration thermal energy storage.

${ }^{7}$ Coincidentally, the installed capital costs for the representative CSP plant for this study is nearly identical to the global weighted average value (including Israeli projects) in Figure Error! Main Document Only.. Despite this, the corresponding global weighted LCOE in the IRENA data is $\$ 0.259 / \mathrm{kWh}$ due to the differences in assumptions when calculating LCOE.
} 


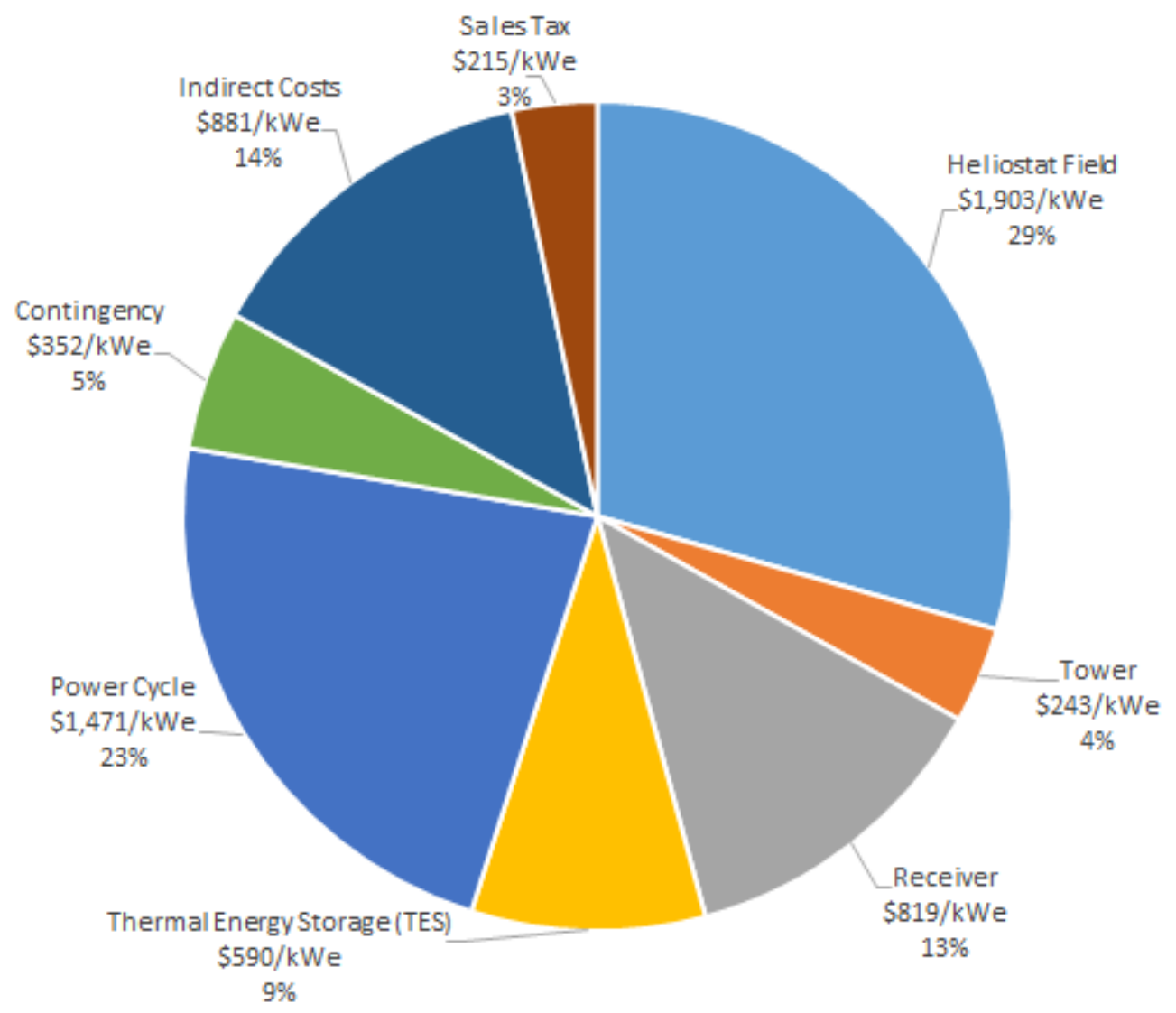

Figure 13. Breakdown of overnight capital costs by system component for representative molten salt power tower CSP plant with 10 hours thermal energy storage

ReEDS is configured to model CSP plants with 6-, 8-, 10-, and 14-hour TES. The overnight capital costs for these plants as a function of TES duration are calculated based on the costs of the representative system and account for the change in storage capacity and field capacity. The correlation for overnight capital costs (OCC) is shown in Equation 1. ReEDS only includes the 10- and 14-hour TES CSP as deployment options in the core Solar Futures Study scenarios. Sensitivity scenarios for CSP that explore the impact of including 6- and 8-hour TES CSP plants are presented and discussed in Section 3.2. O\&M costs are split into fixed O\&M (FOM) and variable O\&M (VOM) costs. VOM is assumed to be $\$ 4.20 / \mathrm{MWh}$, and FOM is assumed to be $\$ 68 / \mathrm{kW} /$ year (Kurup and Turchi 2015b).

OCC $=\$ 1,894 / \mathrm{kW}_{\mathrm{e}}+\mathrm{SM} * \$ 1,592 / \mathrm{kW}_{\mathrm{e}}+\mathrm{TES}$ duration $(\mathrm{h}) * \$ 76 / \mathrm{kWh}_{\mathrm{e}}$ Eq. 1

Where: $\mathrm{OCC}=$ overnight capital costs $(\$ / \mathrm{kW}), \mathrm{SM}=$ solar multiple, TES duration $=$ hours of storage

ReEDS uses future cost projections for technologies in its capacity expansion modeling. For the Solar Futures Study, we considered two scenarios: Moderate and Advanced. Both scenarios are described in the ATB (NREL 2020). The moderate scenario cost projection is based on published literature projects for CSP costs through 2050 and represents the expected level of technology innovation given current levels of industry research and development. The Advanced scenario cost projection is based on the lower bound of the literature sample (IRENA 2016), plants with 
cost and performance based on the DOE SunShot goals for CSP (Murphy et al. 2019), and NREL analyst judgment. The CSP OCC projections for the representative 10-hour TES plant for both the Moderate and Advanced scenarios are shown in Figure 14. Future VOM costs decrease to $\$ 3.60 / \mathrm{MWh}$ in 2022 and stay constant through 2050 (Kurup and Turchi 2015a). Future FOM costs are assumed to decline to $\$ 52 / \mathrm{kW} /$ year by 2030 in the Moderate scenario and then stay constant through 2050 (DOE 2012).

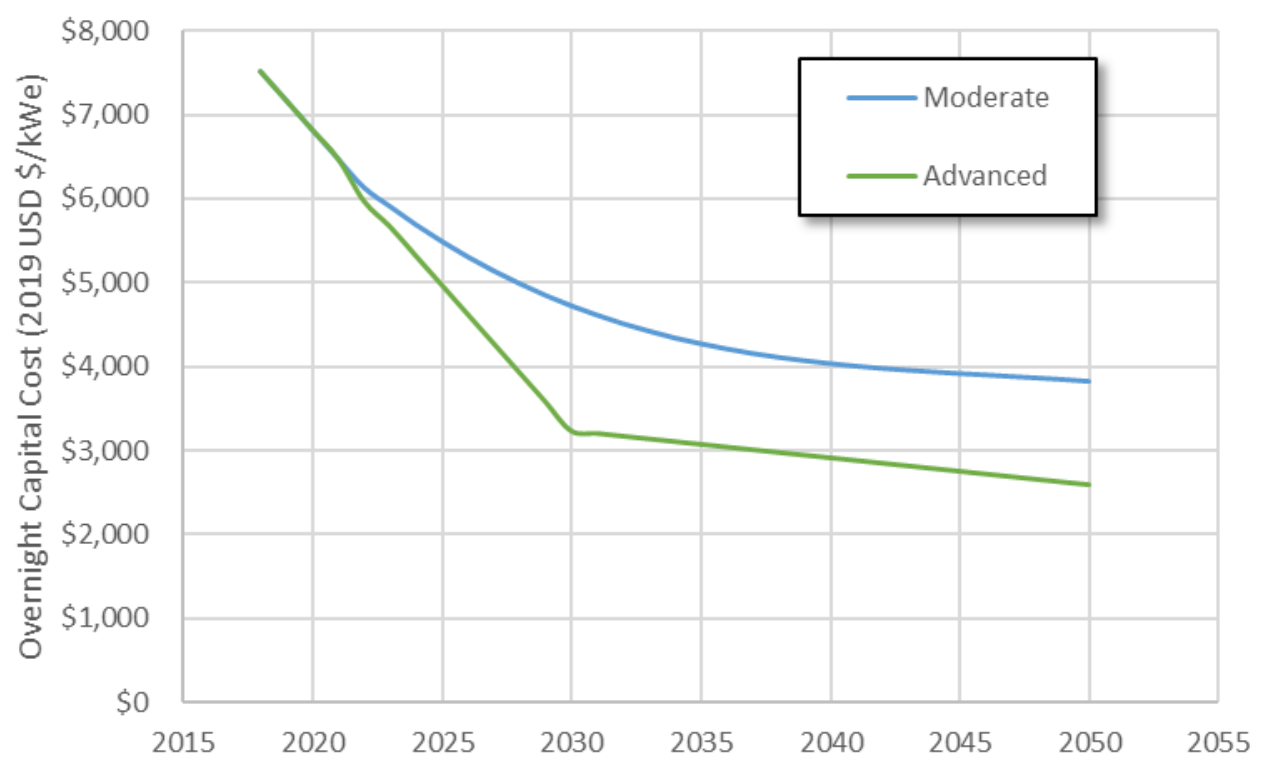

Figure 14. Cost projections (2018 USD \$ $/ \mathrm{kW}_{\mathrm{e}}$ ) for representative molten salt power tower CSP plant with 10 hours thermal energy storage used in Solar Futures Study modeling

\subsection{CSP Solar Futures Study Scenario Results}

The Solar Futures Study core scenarios explored future energy scenarios to determine how technology costs, electricity demand, carbon dioxide $\left(\mathrm{CO}_{2}\right)$ emissions reduction policies, and demand flexibility impact future electricity generation and storage. The three core scenarios are summarized in Table 4 below and discussed in detail in Section 2.1.2 of the Solar Futures Study. The Reference scenario assumes the Moderate ATB cost projections for all technologies, no future demand flexibility, the Reference scenario for future electricity demand from the 2020 EIA Annual Energy Outlook (AEO), and existing energy policies. The Decarbonization (Decarb) scenario assumes the Advanced ATB cost projections for technologies and assumes an aggressive $95 \%$ reduction in grid $\mathrm{CO}_{2}$ emissions from 2005 levels by 2035 and a $100 \%$ reduction by 2050. The Decarbonization with Electrification (Decarb+E) scenario further assumes increased end-use electrification, such as charging electric vehicles, as described in the High Electrification scenario of the Electrification Futures Study (EFS). It also assumes demand-side flexibility to shift loads as described in the EFS Enhanced demand flexibility case. 
Table 4. Summary of Solar Futures Study Core Scenarios

\begin{tabular}{|c|c|c|c|c|}
\hline Scenario Name & $\begin{array}{l}\text { RE \& Storage } \\
\text { Technologies } \\
\text { (ATB 2020) }\end{array}$ & $\begin{array}{l}\text { Demand } \\
\text { Flexibility } \\
\text { (EFS) }\end{array}$ & $\begin{array}{l}\text { Electricity } \\
\text { Demand }\end{array}$ & Policies \\
\hline Reference & Moderate & \multirow{2}{*}{ None } & \multirow{2}{*}{$\begin{array}{l}\text { AEO2020 } \\
\text { Reference }\end{array}$} & $\begin{array}{l}\text { Existing policies as of } \\
\text { June } 2020\end{array}$ \\
\hline Decarbonization (Decarb) & \multirow[b]{2}{*}{ Advanced } & & & \multirow{2}{*}{$\begin{array}{c}95 \% \text { reduction in grid } \\
\mathrm{CO}_{2} \text { emissions from } \\
2005 \text { levels by } 2035 \\
100 \% \text { by } 2050\end{array}$} \\
\hline $\begin{array}{l}\text { Decarbonization with } \\
\text { Electrification (Decarb+E) }\end{array}$ & & Enhanced & EFS High & \\
\hline
\end{tabular}

Source: NREL Solar Futures Study (DOE 2021)

Figure 15 shows the electricity generation projected in 2020 (current), 2025, and 2050 by technology for the core scenarios. Figure 16 shows the projected installed capacity results. Figure 17 shows CSP deployments from 2020 through 2050 for each of the nine scenarios. In the scenarios that assume existing policies (labeled as Reference or Ref. scenarios), no additional CSP is deployed in the United States, and existing CSP capacity retires so that by 2050 there is no CSP deployed in the United States. CSP deployed capacity is greatest under the Decarb scenario, with new deployments starting after 2035 and CSP deployments reaching $39 \mathrm{GW}_{\mathrm{e}}$ by 2050 .

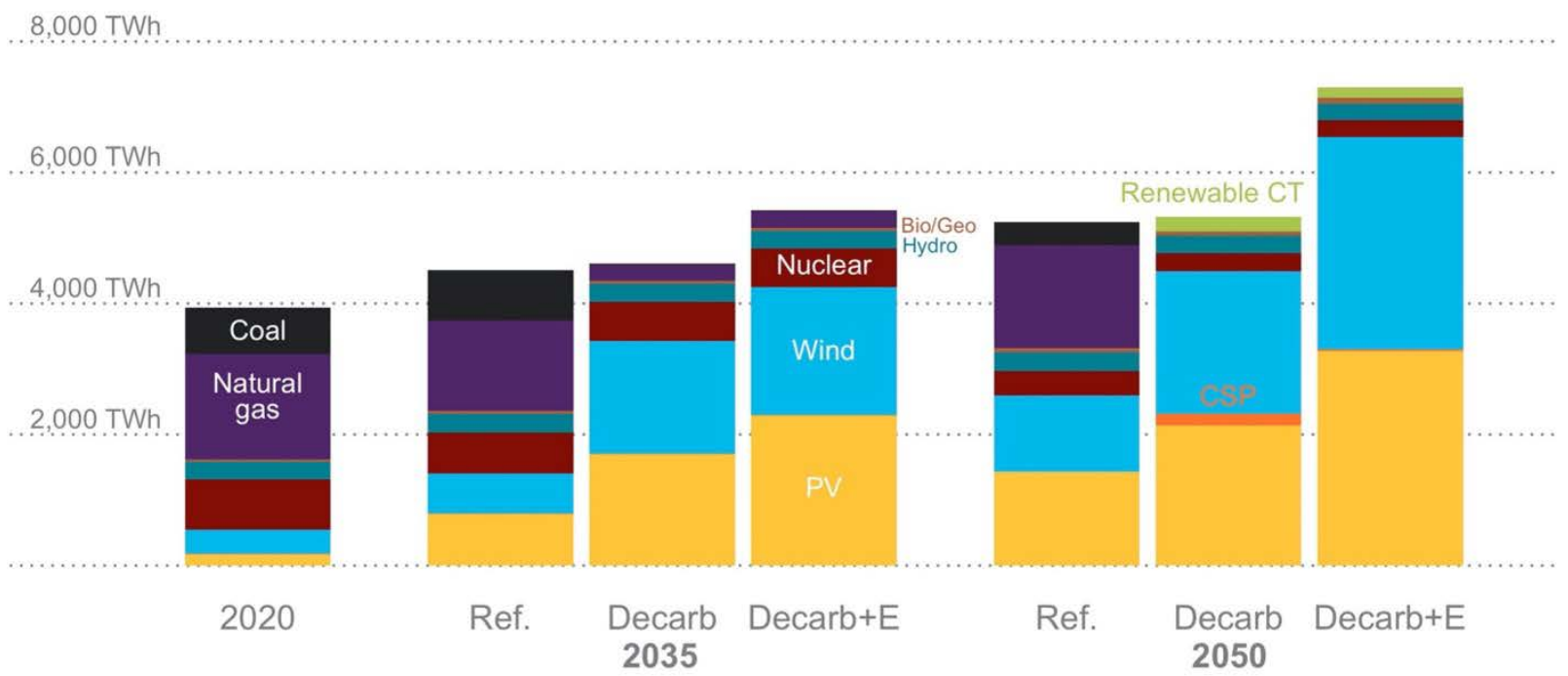

Figure 15. Solar Futures Study core scenario generation results in 2020, 2035, and 2050 


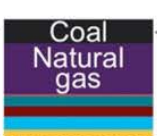

2020
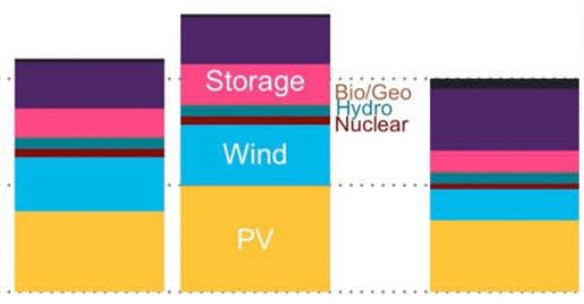

Ref. Decarb Decarb+E 2035

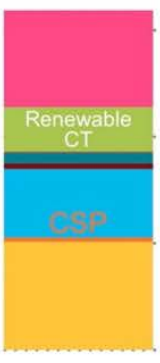

Ref. Decarb Decarb+E

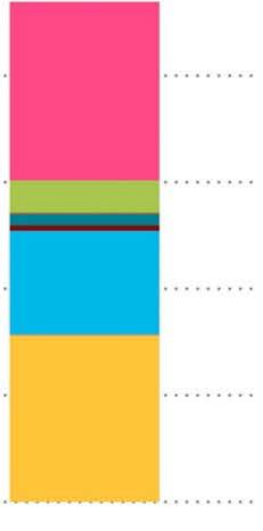

2050

Figure 16. Solar Futures Study core scenario installed capacity results in 2020, 2035, and 2050

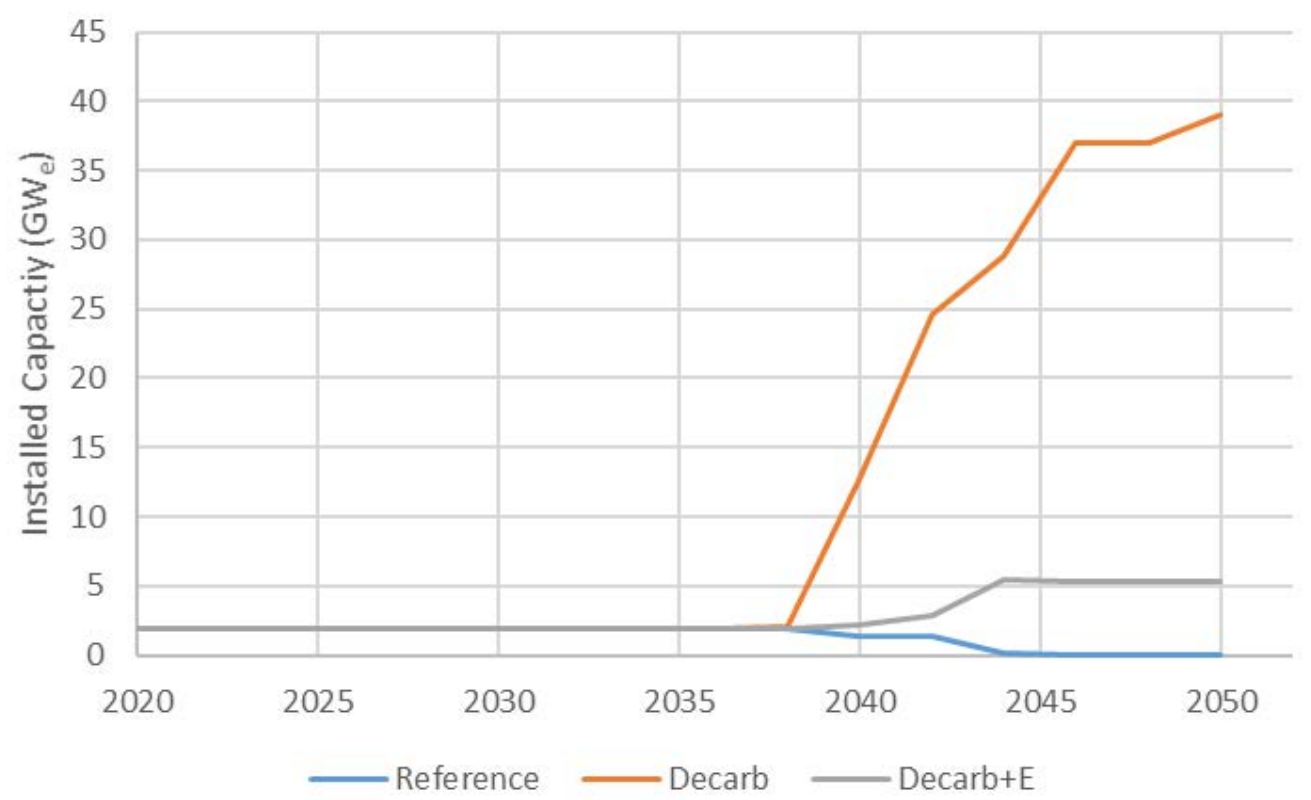

Figure 17. CSP deployment in Solar Futures Study core scenarios, 2020-2050

CSP deployments under Decarb+E scenario are lower than under the Reference electricity demand. New CSP deployments start after 2035 as before, but new deployments stop by 2045 or sooner. The reason for this decline with increased electricity demand is not clear and requires further study.

In the Decarb scenario, CSP is deployed during the last 5\% of decarbonization of the grid. At this level of variable generation technology penetration, the ability to provide firm capacity is the main driver for deployment. In the core scenarios, renewable energy combustion turbines (RECTs) provide the majority of this firm capacity, with 300-600 $\mathrm{GW}_{\mathrm{e}}$ of RE-CTs deployed in the core scenarios. Like CSP, all of this deployment occurs after 2035. 
Accordingly, the Solar Futures Study explored the sensitivity of CSP deployment to competition from RE-CT technology. Solar Futures Study researchers reran core scenarios using low (\$16/MMBtu) (Decarb+Low RE-CT Cost) and high (\$30/MMBtu) (Decarb+High RE-CT Cost) cost assumptions for renewable energy fuel (vs. \$22/MMBtu base cost) and removing RE-CT as an option altogether (Decarb+RE-CT Excluded). The resulting deployment projections (Figure 18) confirm that CSP and RE-CT technologies compete directly in the core scenarios, with CSP deployments increasing as RE-CT costs increase and falling when RE-CT costs decrease. If RECT technologies are assumed to be unavailable, then CSP installed capacity by 2050 exceeds 120 $\mathrm{GW}_{\mathrm{e}}$.

There are two major take-aways from these results: first, CSP provides a key service to the grid as firm capacity when decarbonization of the grid approaches $100 \%$; second, if other technologies like RE-CT that provide firm capacity do not meet the cost and performance levels assumed in the core scenarios, there is the potential for CSP to play a much larger role filling that need.

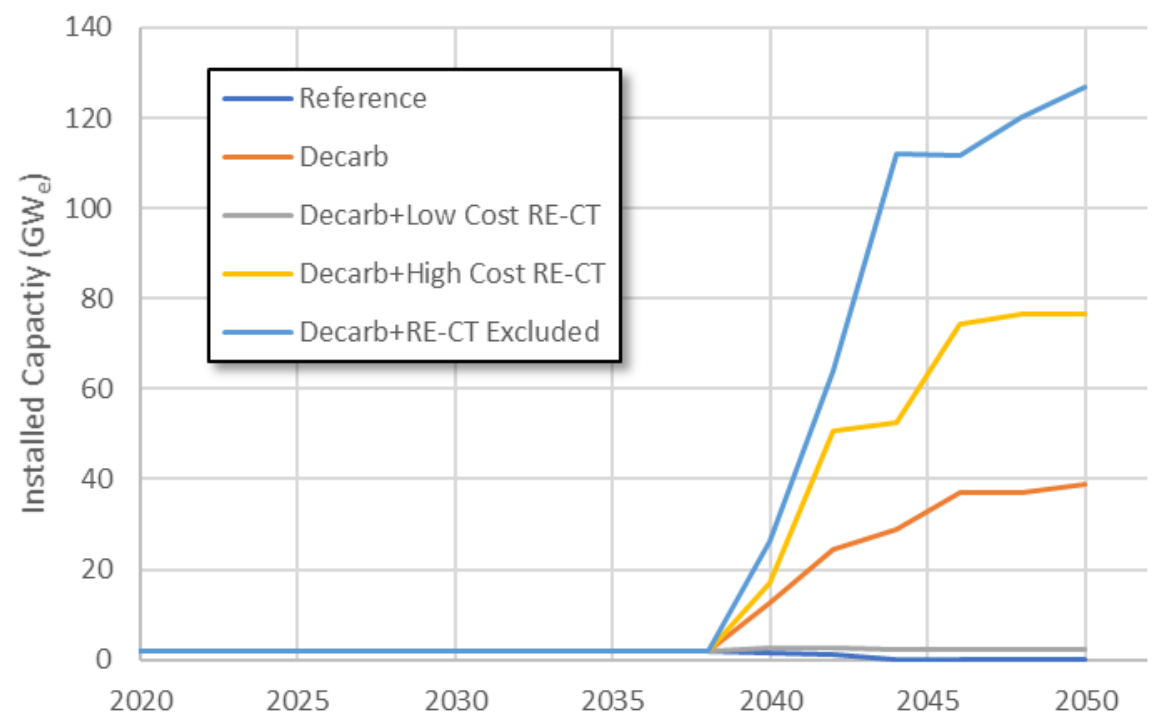

Figure 18. CSP deployment in Solar Futures Study core scenarios compared to sensitivity scenarios varying the cost and availability of RE-CT technology

Another sensitivity scenario (Decarb+More TES Options) included CSP with 6- and 8-hour TES in addition to the 10- and 14-hour TES used in the core scenarios to test the impact of TES duration on CSP deployment. Figure 19 shows the sensitivity scenario 2050 CSP installed capacity by TES duration. The Decarb scenario with additional CSP TES storage duration options results in a total installed CSP capacity of $45 \mathrm{GW}_{\mathrm{e}}$, about $6 \mathrm{GW}_{\mathrm{e}}$ of additional capacity by 2050 compared to the Decarb scenario alone, with about $16.5 \mathrm{GW}_{\mathrm{e}}$ of that capacity provided by the shorter 6-hour and 8-hour TES CSP plants. These results indicate that CSP plants that act more like "peaker" plants may be cost competitive in grids that reward firm capacity. 


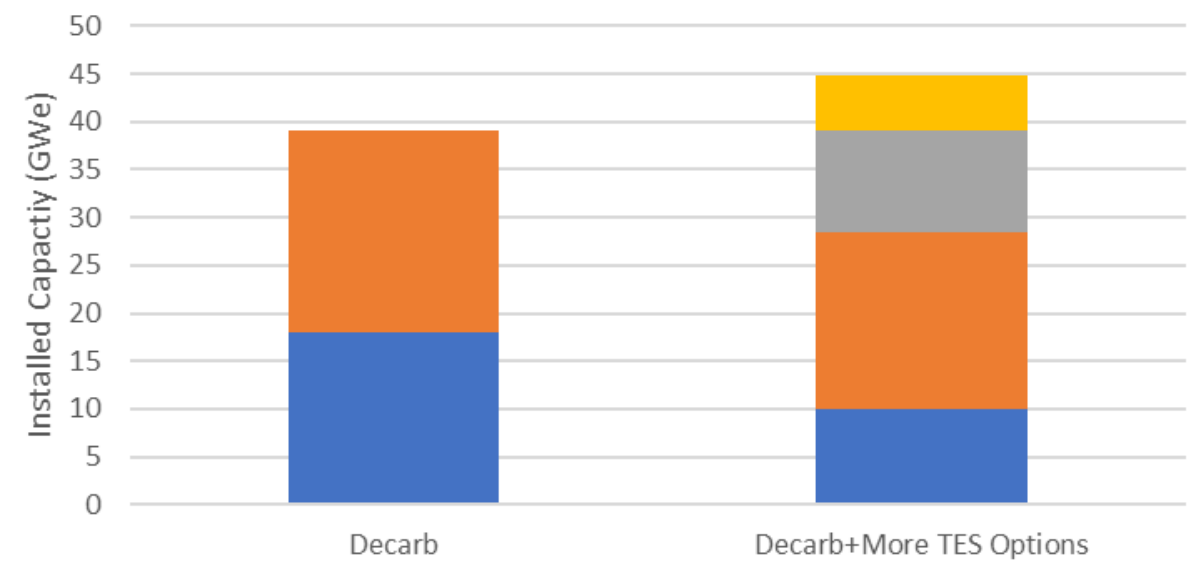

Thermal Energy Storage Duration

-14hour 10 hour $\mathbf{8}$ hour $\quad 6$ hour

Figure 19. Concentrating solar-thermal power installed capacity in 2050 as a function of thermal energy storage duration for Decarb scenario and the Decarb+More TES Options scenario including 6- and 8-hour TES options 


\section{CSP_the Next Decade}

As Figure 13 showed, CSP costs are not dominated by one single component. There is not a single technology breakthrough or cost reduction that will be a game changer for CSP. The CSP industry will need advances across a range of components to achieve significant cost reductions. This section discusses research and development (R\&D) and industry directions expected for CSP technologies over the next decade.

\subsection{Gen3 Pathway Challenges}

DOE started the SunShot initiative in 2011 with the goal of making solar electricity generation technologies competitive with conventional generation technologies. The original SunShot targets were reviewed and updated in 2015 with publication of the "On the Path to SunShot" report (Mehos et al. 2016), when DOE began development of the next-generation CSP plants (CSP Gen3), culminating in the publication of the "Concentrating Solar Power Gen3 Demonstration Roadmap" in 2017 (Mehos et al. 2017). One of the underlying goals of the Gen3 roadmap was to increase the operating temperature of the CSP plant to increase the power cycle and overall system efficiency. The Gen3 roadmap identified three potential pathways, each using a different phase of matter to collect and transport thermal energy from the receiver: molten salt (liquid), particles (solid), and supercritical $\mathrm{CO}_{2}\left(\mathrm{sCO}_{2}\right.$, gaseous). A sCO $\mathrm{s}_{2}$ Brayton cycle was chosen as the best power cycle option for meeting the target goals for cycle efficiency and cost. DOE also set targets for the performance and cost of CSP Gen3 plant components, summarized in Figure 20,to achieve the overall SunShot goal of CSP with a LCOE of $\leq 5 \varnothing / \mathrm{kWh}$.

The roadmap prioritized the R\&D steps needed to meet the CSP Gen3 goals. DOE funded three teams to design integrated CSP systems for each of the pathways in Figure 20 (DOE 2017). On March 25, 2021, DOE announced it selected the falling particle pathway as the most promising way to achieve Gen3 goals and would proceed with \$25 million USD in federal funding to build an integrated falling particle CSP test facility. The selection of the particle pathway will have significant influence on CSP technology development in the next decade and CSP power tower designs of the future. However, DOE is still funding efforts related to the molten salt and gas pathways, and researchers around the world are pursuing similar paths as well (Shultz 2021). 


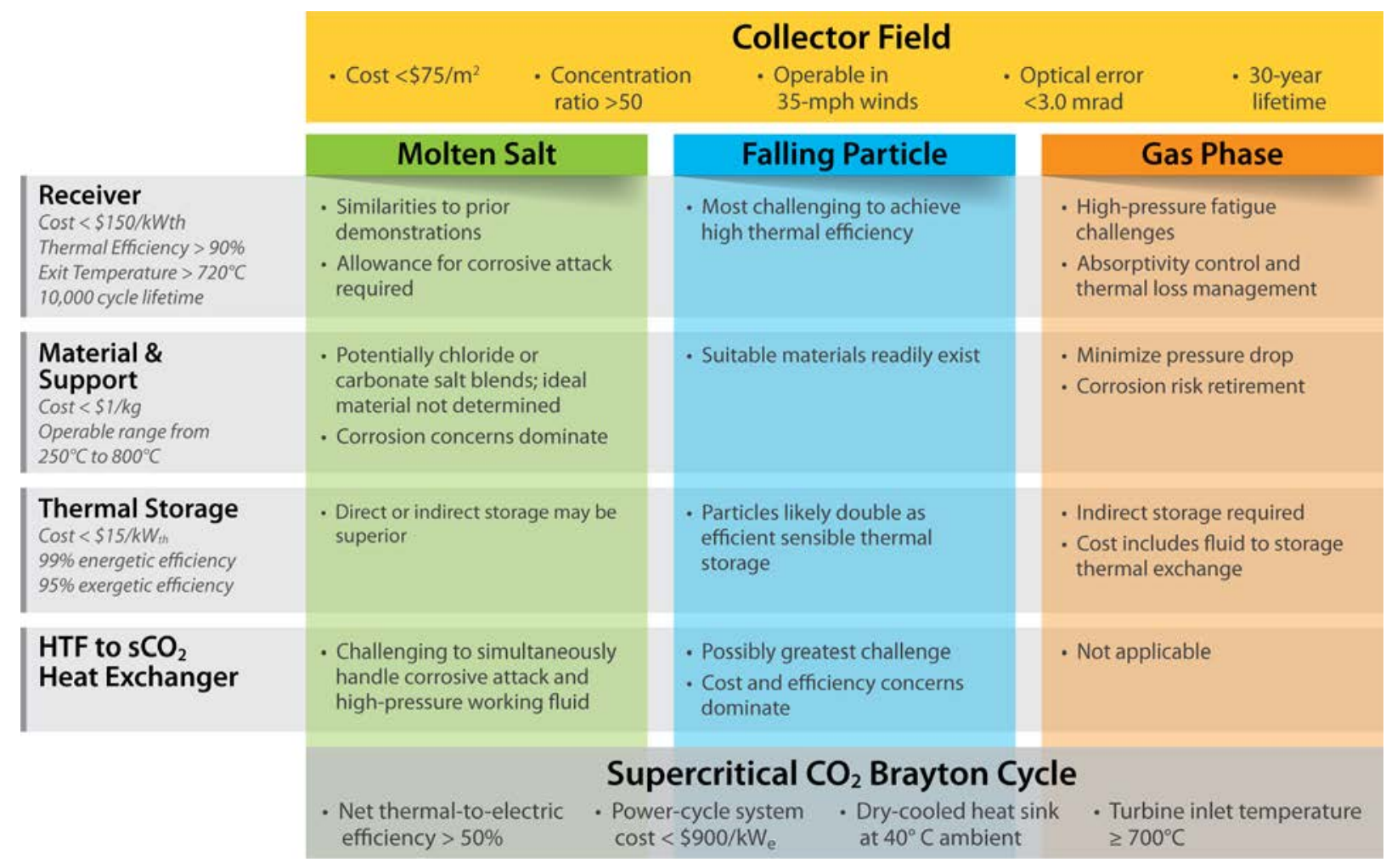

Figure 20. Pathways, component cost and performance targets, and risks for CSP Gen3 technology identified in the Gen 3 road mapping study

Source: Mehos et al. 2017

\subsubsection{Liquid Molten Salt Pathway}

The Gen3 liquid pathway seeks to leverage CSP and other industrial experience with liquid HTF and TES fluids. The liquid pathway proposes the use of low-cost molten chloride salts for energy storage, mated with a solar receiver that employs liquid-metal sodium for heat capture and transfer to the storage salt. This approach leverages molten-salt technology from the current state-of-the-art CSP power towers as well as the magnesium industry, where ternary-chloride molten salts are the feedstock for magnesium metal production. The liquid pathway team explored two HTFs for the receiver - ternary chloride storage salt and liquid-metal sodiumand concluded that the use of liquid-metal sodium provided the best case for achieving Gen3 performance and cost. A systematic risk/benefit analysis was undertaken in the selection process (C.S. Turchi et al. 2020). Liquid sodium has an extensive history in CSP research and nuclear plant applications, and it was recently championed by developer Vast Solar in its $50-\mathrm{MW}_{\mathrm{e}}$ Mount Isa CSP project in Australia.

The commercial representation of the proposed Gen3 design (Figure 21) incorporates a highefficiency sodium receiver operating at $\sim 740^{\circ} \mathrm{C}$, with a liquid-liquid heat exchanger feeding a two-tank, molten-chloride storage system. Chloride salt is dispatched to a $\mathrm{sCO}_{2}$ power cycle to provide electric power to the grid. The design integration is a conceptual match for the current sodium receiver $\rightarrow$ solar salt storage $\rightarrow$ steam-Rankine power cycle promoted by Vast Solar (Craig Turchi et al. 2021). 
Challenges for the liquid pathway technologies include:

- A very low but nonnegligible salt vapor pressure that can lead to salt deposition within the salt tank headspace, valve bodies, or sensor ports and may interfere with system or component operations

- Unproven reliability and durability components (e.g., valves, flowmeters, pressure sensors) in contact with high-temperature chloride salts

- Long-term integrity of the expansion joints and mortar joints in the protective and insulating salt tank liner

- Corrosion control in $\sim 700^{\circ} \mathrm{C}$ chloride salt and sodium systems

- Durability of the system components under thermal transients from cloud events or system operations

- Designing for creep-fatigue in the high-temperature, high-flux solar receiver

- Investor and market acceptance of a sodium-HTF system.

As in all the pathways, testing and derisking the technology challenges is the focus of the proposed 1-MW $\mathrm{M}_{\text {th }}$ pilot system under the Gen3 program.

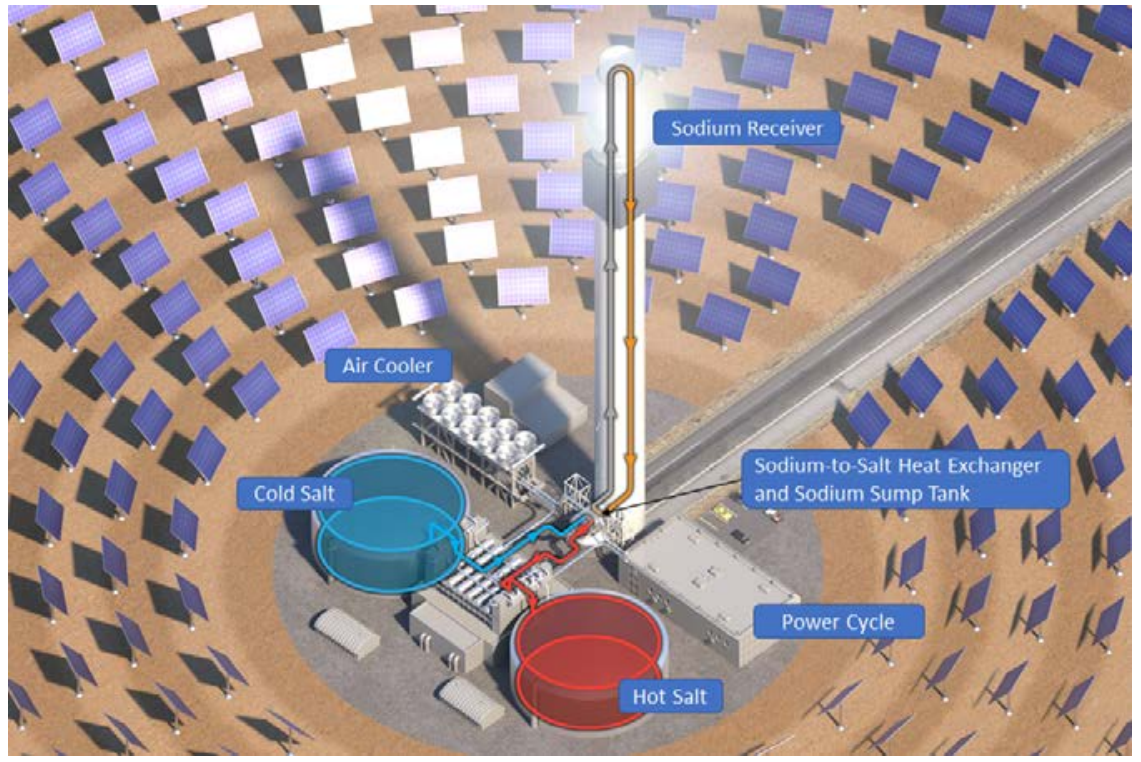

Figure 21. The Gen3 CSP design promoted by the liquid pathway team uses a liquid-sodium HTF for receiver flexibility and efficiency combined with molten-chloride salt storage.

\subsubsection{Particle Pathway}

The Gen3 Particle Pilot Plant (G3P3) seeks to utilize inexpensive, thermally stable solid particles as both the heat-transfer and energy-storage media (Ho et al. 2020). In the G3P3 design, a curtain of falling particles is directly exposed to concentrated sunlight, and the particles increase in temperature to more than $700^{\circ} \mathrm{C}$. Direct absorption by the particle media eliminates the flux limitations that are necessary for receiver systems that rely on irradiating tubes of flowing gas or liquid. The particles have sufficient thermal stability to withstand higher fluxes than is possible with receiver designs wherein the heat transfer media is contained within tubular panels, thus 
enabling higher concentration ratios and heating rates. Various particle types have been investigated, including natural sands and engineered ceramic media, with particle size on the order of $\sim 300-1,000$ microns.

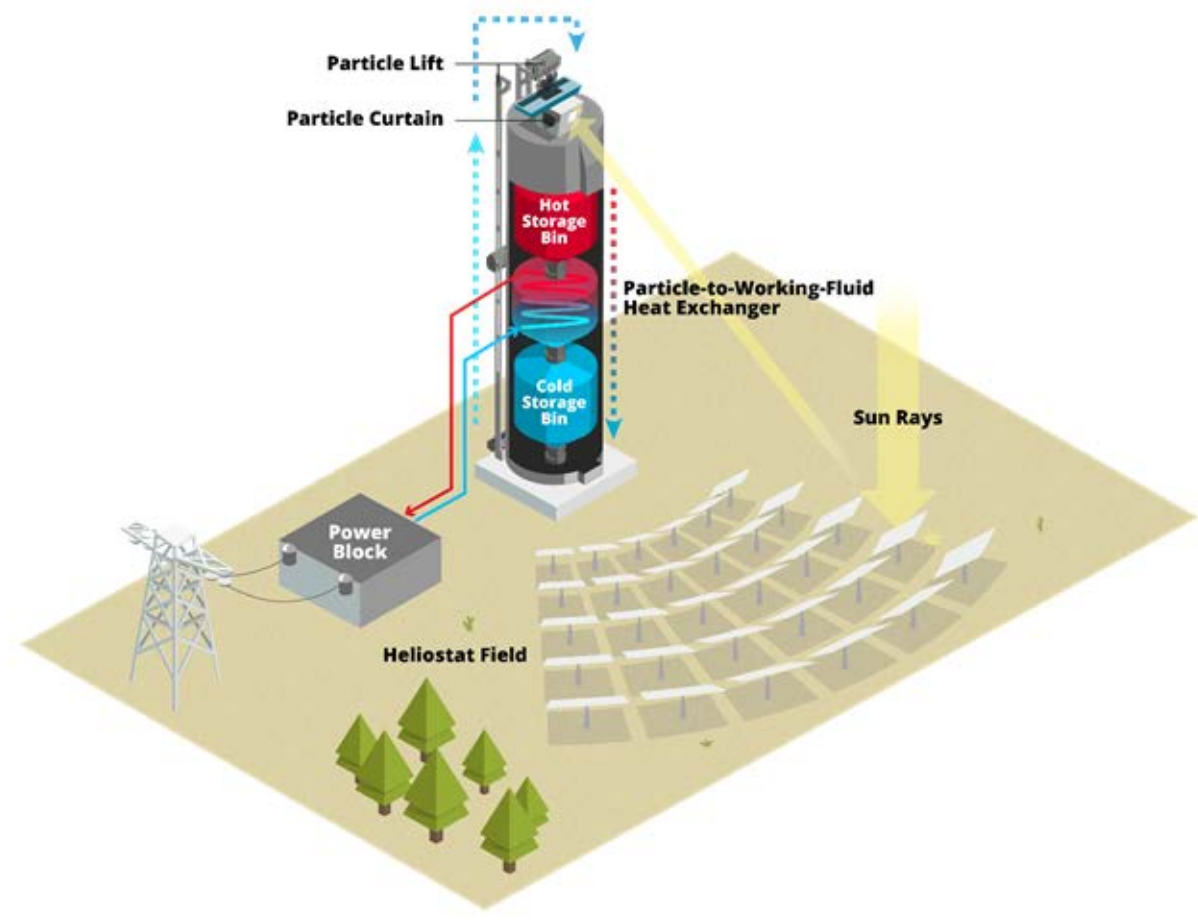

Figure 22. Artist's rendering of the Gen3 particle pathway concept that directly irradiates falling solid particles used for thermal energy storage.

Illustration from Sandia National Laboratories

The heated particles are stored within a refractory-insulated silo and flow by gravity into a particle-to-sCO $\mathrm{CO}_{2}$ heat exchanger to drive a $\mathrm{sCO}_{2}$ Brayton power cycle. The now-cooler particles are stored in a similar insulated silo. The cycle is repeated by hoisting the particles back to the receiver using efficient lifting technology borrowed from the mining industry.

Testing at Sandia National Laboratories has developed a 1-MW $\mathrm{MW}_{\text {th }}$ falling-particle receiver that is able to heat particles to over $700^{\circ} \mathrm{C}$. The design features a multistage catch-and-release flow path of the falling particles that has been shown to increase the particle-curtain opacity, increase flow stability, reduce backwall temperatures, and increase thermal efficiency. Accurate control of desired particle outlet temperature was demonstrated via a slide gate that automatically adjusted the particle flow rate into the receiver.

The use of solid particles for TES avoids the risks associated with corrosive, high-freezing-point molten salts but introduces its own unique challenges, such as:

- Reducing sensitivity to wind and reducing heat and particle losses through the open aperture of the receiver

- Enabling reliable and efficient operation of high-temperature particle conveyance systems 
- Achieving efficient heat transfer in the particle-to- $\mathrm{sCO}_{2}$ primary heat exchanger while meeting cost targets.

The G3P3 project team plans to build and demonstrate two systems: a 1-MW th, 6-MWh $\mathrm{M}_{\text {th }}$ pilotscale system, delivering heat to an $\mathrm{sCO}_{2}$ loop at the National Solar Thermal Test Facility at Sandia National Laboratories in Albuquerque, New Mexico, and a 1.3-MWe (3 MW $\mathrm{MW}_{\text {th }} \sim 10-20$ $\mathrm{MWh}_{\text {th }}$ ) precommercial electric generating system, using an air-Brayton cycle, in Saudi Arabia with partners at King Saud University and Saudi Electricity Company.

\subsubsection{Gas Pathway}

The Gen3 gas pathway team seeks to use $\mathrm{sCO}_{2}$ as the receiver HTF in addition to its function as the power cycle working fluid (Sullivan and Hinze 2020). The power cycle itself is used to circulate the HTF to the receiver, thereby avoiding the need for a dedicated high-temperature circulator or the thermal losses that would come from having to cool and recompress the HTF.

The TES design uses a particle system, similar to that proposed by the particle pathway. Cold particles are hoisted to the top of the hot-particle silo and flow by gravity into high-temperature and low-temperature heat exchanger sections in series. The particle-to-s $\mathrm{CO}_{2}$ heat exchangers are sequenced such that cold, high-pressure $\mathrm{sCO}_{2}$ coming from the power-cycle compressor passes through the low-temperature unit before being diverted to the solar receiver, as shown in Figure 23. The design integrates the compressor and recuperators into the receiver and TES systems, thereby reducing capital cost and parasitic power demand.

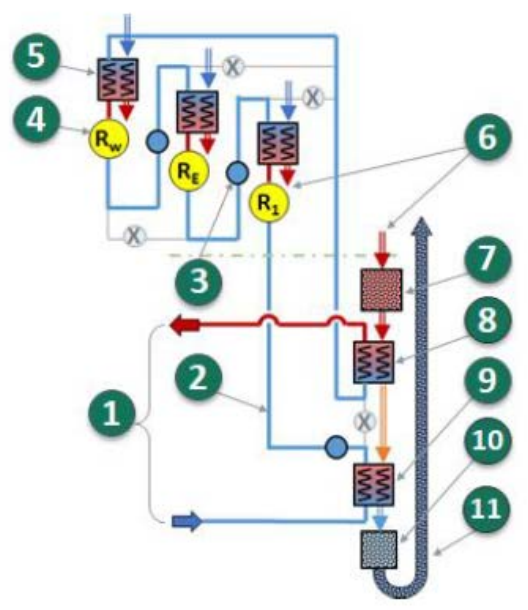

1. $\mathrm{RCBC} \mathrm{sCO} 2$ power block

2. Low temp. high press. $\mathrm{sCO}_{2}$ piping

3. Low temperature flow valves

4. TES charging receivers

5. TES charging heat exchangers

6. TES low pressure particle shaft

7. TES hot particle storage silo

8. High temp. TES discharge heat exchanger

9. Low temp. TES discharge heat exchanger

10. TES cold particle storage silo

11. TES particle lift

Figure 23. The gas pathway uses the supercritical fluid for the receiver HTF and in the power cycle. Integrating the power cycle compressor for HTF circulation and the TES heat exchangers as recuperators reduces operating and capital costs.

Source: Sullivan and Hinze 2020

While the gas pathway uses particle TES, it avoids the need for the particles to have properties that favor direct absorption of solar flux. Thus, a wider range of storage media can be explored than in the case of the particle pathway. As in the other pathways, the gas pathway must overcome several challenges for successful implementation. In this pathway, those include: 
- Avoiding excessive pressure drop across the system heat exchangers, including the solar receivers, as the efficiency of the power cycle is sensitive to overall pressure losses

- Designing for creep-fatigue in the high-temperature, high-pressure, high-flux solar receivers

- Balancing operation of the power cycle, receiver, and TES subsystems

- Enabling reliable and efficient operation of high-temperature particle conveyance systems

- Achieving efficient heat transfer in the particle-to- $\mathrm{SCO}_{2}$ primary heat exchanger while meeting cost targets.

Per the original funding announcement, ${ }^{8}$ all three of the Gen3 pathway teams are targeting an LCOE of less than $\$ 60 / \mathrm{MWh}_{\mathrm{e}}$ based on the financial assumptions set by the DOE program. The three pathways are each projecting that this goal is achievable, albeit with substantial risk and uncertainty in these nascent technologies.

\subsection{Solar Field Cost Reductions}

The cost of CSP systems is split between three major subsystems: solar collection, TES, and power cycle. Of these, the most significant is the solar collection system that consists of the solar heliostat field and the tower/receiver system. Historically the solar field has accounted for upwards of $50 \%$ of the total plant CAPEX. While heliostat costs have fallen over the past decade (Figure 24), it still is typically the largest contributor to plant CAPEX - a situation that is more pronounced as plant designs lean toward larger solar multiples to achieve greater capacity factor and lower overall LCOE.

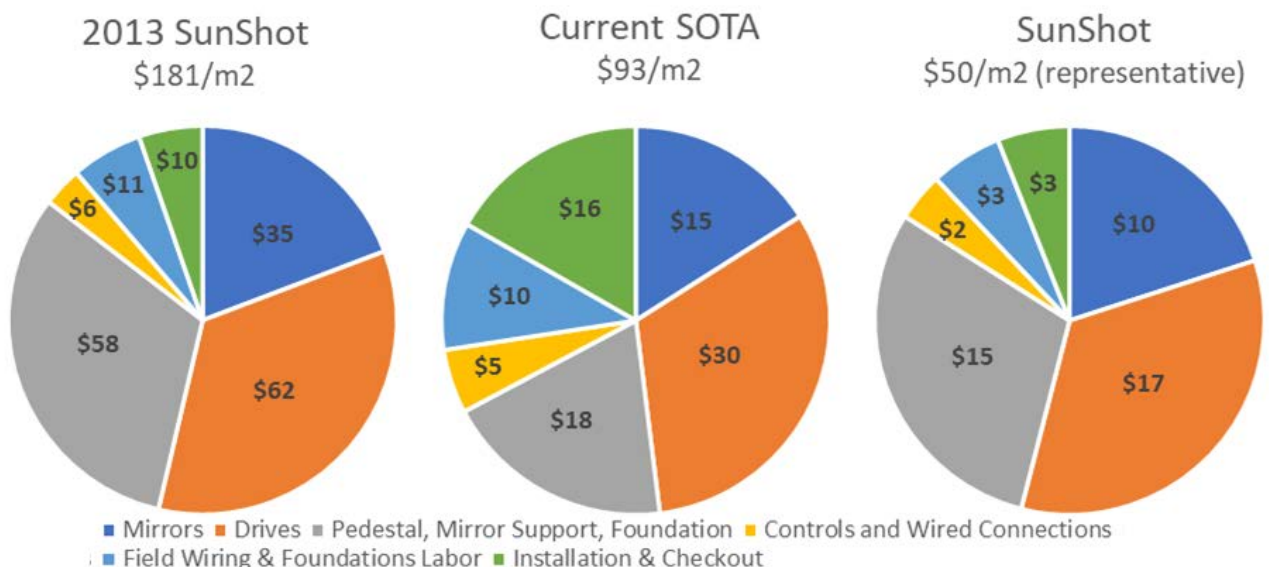

Figure 24. Heliostat costs have dropped by $50 \%$ since the inception of SunShot in 2013 , but further cost reductions are necessary to achieve DOE's $\$ 50 / \mathrm{m}^{2}$ cost target.

Sources: Values in 2013 at start of SunShot from Turchi and Heath 2013. Current state of the art (SOTA) from industry data shared with NREL. SunShot value from DOE SunShot cost target, with component costs representative of a potential cost reduction pathway.

\footnotetext{
${ }^{8}$ Generation 3 Concentrating Solar Power Systems, Funding Opportunity Announcement DE-FOA-0001697, 2017.
} 
The current state-of-the-art solar field in a utility-scale CSP plant is estimated ${ }^{9}$ at approximately $\$ 100 / \mathrm{m}^{2}$, whereas a solar field cost of $\$ 50 / \mathrm{m}^{2}$ is targeted to achieve the SunShot LCOE goal of $\$ 50 / \mathrm{MWh}_{\mathrm{e}}$. This twofold reduction in cost implies a demanding price reduction on each subcomponent of the heliostat, such as drive and supporting structures, as well as massproduction process efficiency for manufacturing, assembly, field installation, and commissioning.

No single heliostat design dominates the CSP landscape, and the industry has not standardized to take advantage of economies of scale. Opportunities for system LCOE reduction are indicated by studies that suggest heliostat performance may have a greater impact on LCOE than heliostat cost (Coventry et al. 2016) and that better O\&M practice may significantly improve field performance. Acknowledging the importance and status of solar field cost and performance, the DOE released a new funding opportunity in 2020 for a research consortium to bring together researchers, subject matter experts, and stakeholders to adopt a systems-oriented approach to advance research, development, and commercialization of high-performance, cost-effective solar field technology.

\subsection{Thermal Energy Storage Tanks}

The state of the art in CSP TES tanks is a $347 \mathrm{H}$ stainless steel, externally insulated hot salt tank with dimensions of approximately $40-\mathrm{m}$ diameter by $10-\mathrm{m}$ high, operating at $565^{\circ} \mathrm{C}$. The "cold salt" storage tank is a similar-size carbon steel vessel operating at about $300^{\circ} \mathrm{C}$. While the cold salt tanks have been reliable and cost-effective, the hot tanks are significantly more expensive and have suffered from reliability issues (Mehos et al. 2020).

Despite teething pains, the overall cost for the TES system is estimated at $\$ 22 / \mathrm{kWh}_{\mathrm{th}},{ }^{10}$ or about $\$ 55 / \mathrm{kWh}$, which is attractive for long-duration storage compared to technologies such as lithium-ion batteries. This indicates that understanding current failure modes and improving system durability are the primary needs in the TES subsystem, at least for the Gen 2 technology. Most salt tank research is focused on improving the reliability and reducing the cost of the hot salt tank by sharing best practices within the industry, investigating tank foundation design and welding practice, and exploring alternative materials for the hot tank.

As described briefly above, Gen3 technology pathways rely on higher temperature salts and solid particle TES systems. Tanks for high-temperature molten chlorides must be internally insulated to protect the steel or alloy shell from the high temperature and potential corrosive effects of the salt. These tanks will be more costly than the Gen 2 tanks. Particle storage systems can leverage knowledge from other industries to construct refractory lined, cone-, or flat-bottom silos. These holding tanks are significantly lower cost than salt tanks.

\subsection{Supercritical Carbon Dioxide Brayton Cycle}

All of the CSP Gen3 pathways discussed above plan to use a $\mathrm{sCO}_{2}$ Brayton cycle. The $\mathrm{sCO}_{2}$ Brayton cycle uses $\mathrm{CO}_{2}$ as the working fluid. The cycle operates at pressures and temperatures above the critical point of $\mathrm{CO}_{2}\left(31^{\circ} \mathrm{C}, 73.8 \mathrm{bar}\right)$, where it has properties similar to both a liquid

\footnotetext{
${ }^{9} 2021$ heliostat costs based on industry proprietary data shared with NREL.

${ }^{10}$ NREL System Advisor Model, released 2020-11-29.
} 
and a gas. The $\mathrm{sCO}_{2}$ Brayton cycle has several advantages over the steam Rankine cycle currently used at CSP power tower plants. First, the $\mathrm{sCO}_{2}$ Brayton cycle is theoretically more efficient than the steam Rankine cycle operating at or above about $500^{\circ}-600^{\circ} \mathrm{C}$, thanks in part to the use of a recuperator to recycle heat from the turbine exit (prior to the air cooler) to the main compressor outlet (Figure 25), increasing the difference between the average temperatures of heat input and heat rejection (Neises and Turchi 2019). Second, $\mathrm{CO}_{2}$ has a high density prior to entering the compressor after it nears its critical point exiting the air cooler, resulting in lower power requirements for compression (Neises and Turchi 2019) and compact turbomachinery compared to steam turbines (Vijaykumar et al. 2018). The compact turbomachinery could result in lower capital costs and a quicker response time because the turbomachinery does not have as much thermal mass to preheat before reaching its design operation point. The $\mathrm{sCO}_{2}$ Brayton cycle also works well with air cooling as its heat sink, mitigating the need for water for cooling. Finally, unlike steam Rankine cycles, which operate most efficiently at large scales, $\mathrm{sCO}_{2}$ Brayton cycles can be scaled down to 10-100 MW while still maintaining high efficiency (Vijaykumar et al. 2018), which could open the CSP market to small-scale systems.

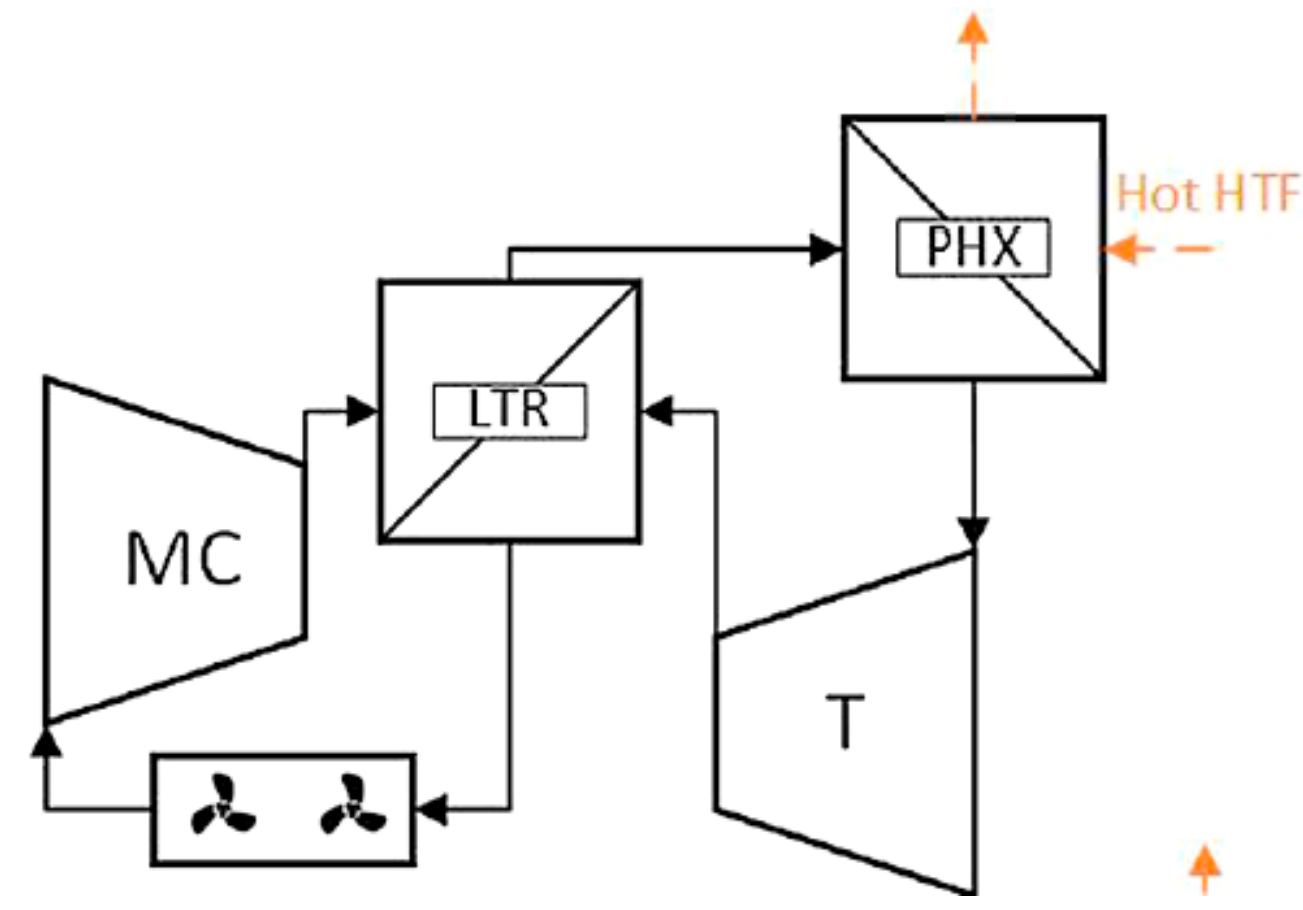

Figure 25. Schematic of simple supercritical carbon dioxide Brayton power cycle (different configurations are possible)

$\mathrm{PHX}=$ primary heat exchanger; $\mathrm{T}=$ turbine; $\mathrm{LTR}=$ low-temperature recuperator (heat exchanger); $M C=$ main compressor, $\mathrm{HTF}=$ heat transfer fluid; fan icons = air cooler

Source: Neises and Turchi 2019

DOE is funding several projects to build and test $\mathrm{sCO}_{2}$ Brayton cycles. A team led by the Gas Technology Institute (GTI), Southwest Research Institute (SwRI) and General Electric Global Research received $\$ 84$ million in DOE funding to build the Supercritical Transformational Electric Power (STEP) pilot plant utilizing a 10-MW sCO 2 turbine. STEP aims to demonstrate cycle operability at turbine inlet temperatures of $>700^{\circ} \mathrm{C}$ and a pathway to $>50 \%$ efficiency. SWRI has completed the detailed design and modeling of the $\mathrm{SCO}_{2}$ turbine and plans to 
commission its construction in 2021 (Marion et al. 2021). A variation of this turbine will be incorporated into the STEP pilot plant. DOE also awarded \$39 million to Heliogen Inc. to develop an Integrated Thermal Energy Storage and Brayton Cycle Equipment Demonstration (Integrated TESTBED). TESTBED will develop, build, and operate a 5-MWe $\mathrm{SCO}_{2}$ power cycle powered by a heliostat field and receiver and coupled with TES using solid media. The power cycle will operate at a turbine inlet temperature of $600^{\circ} \mathrm{C}$.

\subsection{Future O\&M Costs}

As mentioned previously, O\&M costs are typically 0.02-0.04 \$/kWh (IRENA 2020) and make up 20\%-25\% of CSP LCOE (Sargent \& Lundy 2003; Kutscher et al. 2010). As CSP capital costs decrease, O\&M costs will come to represent a larger share of plant LCOE in the future unless they are reduced as well. One commonly cited way to reduce O\&M costs is to increase the size and/or capacity factor of the CSP plant (Sargent \& Lundy 2003; Kutscher et al. 2010).

Staffing costs make up the majority of CSP plant O\&M costs. A typical 50-MWe parabolic trough plant has a staff of 30 employees for plant operation and another 10 employees for solar field maintenance (IEA 2010). A recent study on the potential for CSP in Chile reported that a $130-\mathrm{MW}_{\mathrm{e}} \mathrm{CSP}$ power tower plant requires 40 employees - 32 for operations and 8 for administrative work (Hernández et al. 2020). The 110-MW $\mathrm{M}_{\mathrm{e}}$ Crescent Dunes CSP power tower plant in Nevada reportedly requires 40 permanent workers for plant O\&M (Hashem 2018). However, the quantity and complexity of CSP plant equipment remains nearly constant as plant size increases.

The same is true of increasing the TES capacity, which increases the plant capacity factor. The only significant staff increases with plant size are those needed for additional cleaning and maintenance of the solar field, which increases proportional to the field size. The administration and plant staffing remains fairly constant (Sargent \& Lundy 2003).

Increasing the plant size and capacity factor results in more electricity generation, lowering O\&M costs on a per-kWh basis.

Another tactic to reduce O\&M costs is to increase automation. For example, natural gas combined cycle (NGCC) plants are just as complex as CSP plants, but combined cycle plant technology has advanced to the point where robust, field-tested designs are available from multiple competitors. NGCC plants can be safely and automatically controlled in all operation modes through a direct control system, whereas most CSP plants have not advanced to the point where the control system can routinely run the plant (Mehos et al. 2020). Automated plant control would help CSP increase plant operation reliability and lower O\&M costs. Automated mirror cleaning has been proposed as a way to reduce O\&M costs as well (Kutscher et al. 2010).

\subsection{CSP Demonstration Projects}

Commercial CSP development is ongoing, with activity in the Middle East, Chile, China, and Australia (see Figure 6). These projects are building molten-salt power towers that can be considered the "Gen2" CSP technology. Exceptions include projects using liquid-sodium HTF in Australia (Wood and Drewes 2019) and molten-salt linear-collector systems in China. 
A demonstration facility planned for the United States intends to mate the $\mathrm{sCO}_{2}$ Brayton cycle with a novel heliostat-field design and control system to investigate operational advantages and promote the commercial deployment of the new power cycle (Reuters Events 2020c). This "TESTBED" system (see Section 4.4) is funded by DOE with industry cost-share by Heliogen and partners. As mentioned at the beginning of Section 4.1, DOE also announced the selection of the Gen3 falling particle pathway technology in 2021 and will proceed with \$25 million USD in federal funding to build an integrated falling particle CSP test facility.

Elsewhere in the world, a consortium of European companies will build a particle-receiver system to supply process steam at a food processor in Italy. The plant will utilize a ceramic particle receiver developed by DLR in Germany that can reach temperatures of $965^{\circ} \mathrm{C}$ at the receiver outlet (Reuters Events 2020b). The particle technology offers higher temperatures for power generation and industrial process heat. 


\section{Potential Future Markets}

Beyond electric power generation, CST technologies can be used for direct thermal applications. Given that industrial heat demand exceeds electricity demand on a global basis (Epp and Oropeza 2017), decarbonizing this sector will be necessary to achieve aggressive targets for $\mathrm{CO}_{2}$ emissions reductions.

\subsection{Industrial Process Heat}

Industrial process heat (IPH) is thermal energy used in the industrial sector in the preparation, production, or treatment of manufactured goods. The industrial sector accounted for $23.7 \%$ of all primary energy use in the United States in 2020, and $90 \%$ of that primary energy comes from fossil fuels (EIA 2021b Tables 2.1 and 2.4). Roughly 75\% of the primary energy used in industry is for manufacturing. Over the past decade, process heat (from direct fuel use or boiler operation) has consistently accounted for about $40 \%$ of all manufacturing sector energy use (EIA 2013; EIA 2017; EIA 2021a).

Figure 26 shows manufacturing industry energy use by fuel type. Natural gas accounts for 91\% of fuel use for process heating and $85 \%$ of fuel use for boilers. The industrial sector in general and the manufacturing sector in particular are challenging markets to decarbonize, given the large number of processes involved, and represent a large market opportunity for concentrating solar energy. CST has an inherent advantage among renewable energy technologies in that it directly generates thermal energy, making it well-suited for supplying IPH.

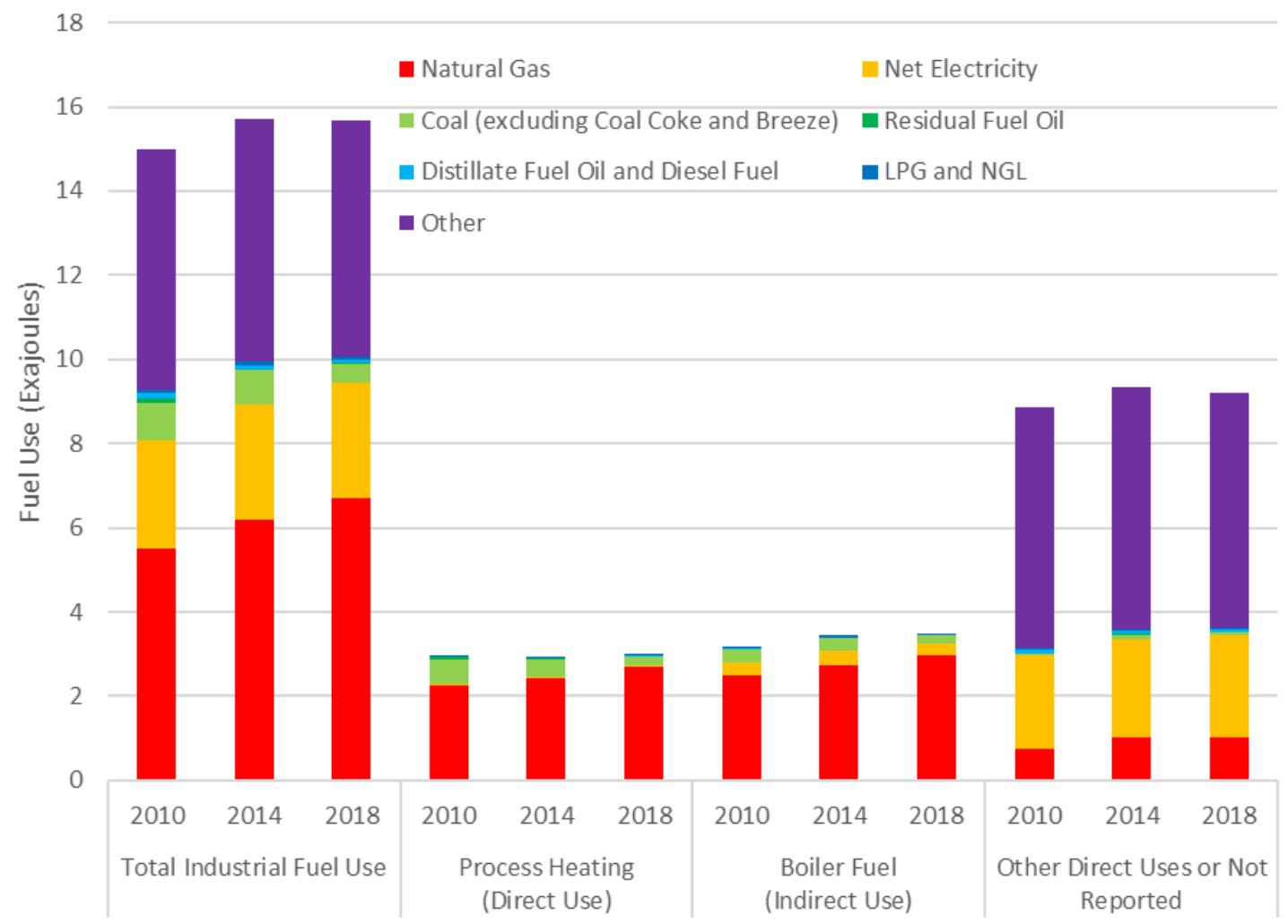

Figure 26. Total fuel use in the U.S. manufacturing sector by fuel type and end use Sources: EIA 2013, EIA 2017, EIA 2021a 


\subsubsection{Low- and Medium-Temperature Processes}

The choice of solar collector type depends on the temperature of the industrial process. Nonconcentrating solar collectors, such as flat plates and solar ponds, can be used for water and space heating. Evacuated tubes can provide process heat at temperatures $>150^{\circ} \mathrm{C}$. Parabolic trough and linear Fresnel solar collectors can be used typically to reach temperatures of $400^{\circ} \mathrm{C}$ and can extend their temperature range to $500^{\circ} \mathrm{C}$ using steam or molten salt as the HTF. Commercial CSP power tower plants are limited to $565^{\circ} \mathrm{C}$; however, higher temperatures are possible with Gen3 technologies, with receiver designs using nonconventional HTFs such as air, or by using a parabolic dish. Table 5 provides a summary of solar collector types, their temperature range and HTF, and their potential applications. The table does not consider hybrid systems, such as a power tower combined with an electric resistance heater to reach process temperatures.

Table 5. Typical Range of Operating Temperatures and Relevant Heat Transfer Fluid for SolarThermal Technologies

\begin{tabular}{|c|c|c|c|}
\hline Temp. Range & Solar Collector Type & HTF of Choice & Applications/Comments \\
\hline$<80^{\circ} \mathrm{C}$ & $\begin{array}{l}\text { Flat plate } \\
\text { Nontracking compound } \\
\text { parabolic (CPC) } \\
\text { Solar Pond }\end{array}$ & Water & $\begin{array}{l}\text { Hot water } \\
\text { Space heating }\end{array}$ \\
\hline $80^{\circ}-200^{\circ} \mathrm{C}$ & $\begin{array}{l}\text { Evacuated Tubes } \\
\text { Parabolic Trough } \\
\text { Linear Fresnel }\end{array}$ & Water/Steam & Hot water or steam for process heat \\
\hline $200^{\circ}-300^{\circ} \mathrm{C}$ & $\begin{array}{l}\text { Parabolic Trough } \\
\text { Linear Fresnel }\end{array}$ & Mineral oil & $\begin{array}{l}\text { Direct heat or steam for process } \\
\text { heat. Vacuum-jacketed receivers } \\
\text { minimize heat loss }\end{array}$ \\
\hline $300^{\circ}-400^{\circ} \mathrm{C}$ & & Synthetic oil & $\begin{array}{l}\text { Direct heat or steam for process } \\
\text { heat with vacuum receivers }\end{array}$ \\
\hline $400^{\circ}-550^{\circ} \mathrm{C}$ & & $\begin{array}{l}\text { Steam or } \\
\text { molten salt }\end{array}$ & Electric power \\
\hline$>550^{\circ} \mathrm{C}$ & $\begin{array}{l}\text { Heliostat/power tower } \\
\text { Parabolic dish }\end{array}$ & $\begin{array}{l}\text { Steam or } \\
\text { molten salt }\end{array}$ & Electric power \\
\hline
\end{tabular}

Adapted from Kurup and Turchi 2015b

There are many processes that use process heat employed over a range of temperatures. Figure 27 lists unit processes by industry and their typical temperature ranges and compares them to the temperature ranges of solar collector technologies. The United States lacks detailed data on the distribution of industrial processes by location, temperature, demand, and time of use (McMillan et al. 2021). McMillan and Ruth (2019) estimated IPH demand in the United States for 14 industries with significant greenhouse gas (GHG) emissions by using facility-level data on GHG emissions from the U.S. Environmental Protection Agency's (EPA's) Greenhouse Gas Reporting Program. This program requires facilities with $>25,000$ metric tons of $\mathrm{CO}_{2}$ equivalent emissions to report emissions details to the EPA. The 960 reporting facilities account for $25 \%$ of U.S. industrial-sector emissions. They reported IPH demand from the facilities by temperature range and county (Figure 28 ) and found $60 \%$ of their demand is below $300^{\circ} \mathrm{C}$ and $30 \%$ is at or above $600^{\circ} \mathrm{C}$ (McMillan and Ruth 2019). 


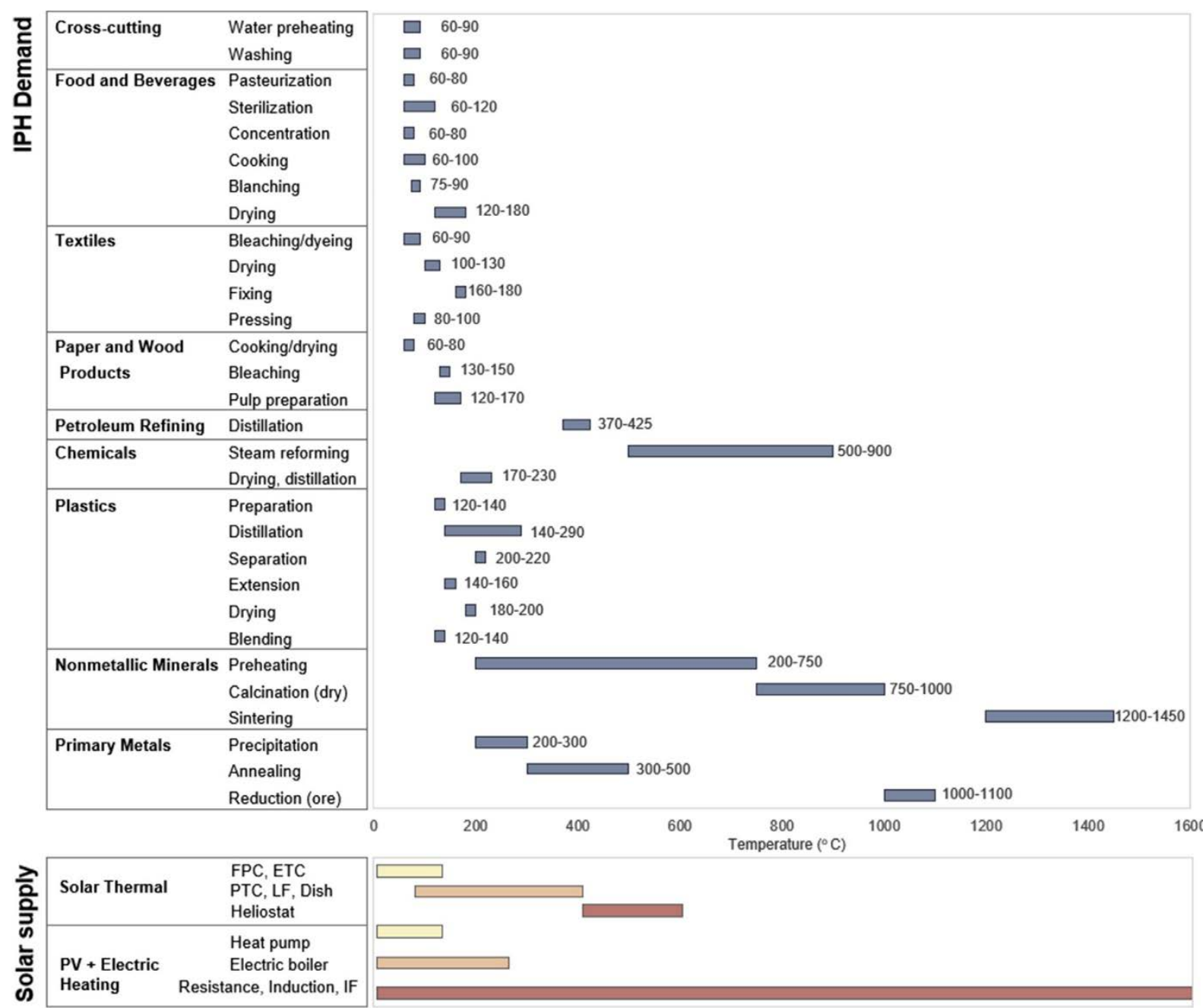

Figure 27. Industrial process heating unit processes and their temperature ranges compared to solar collector and electricity-powered heating technologies and their temperature ranges

Source: Schoeneberger et al. 2020 


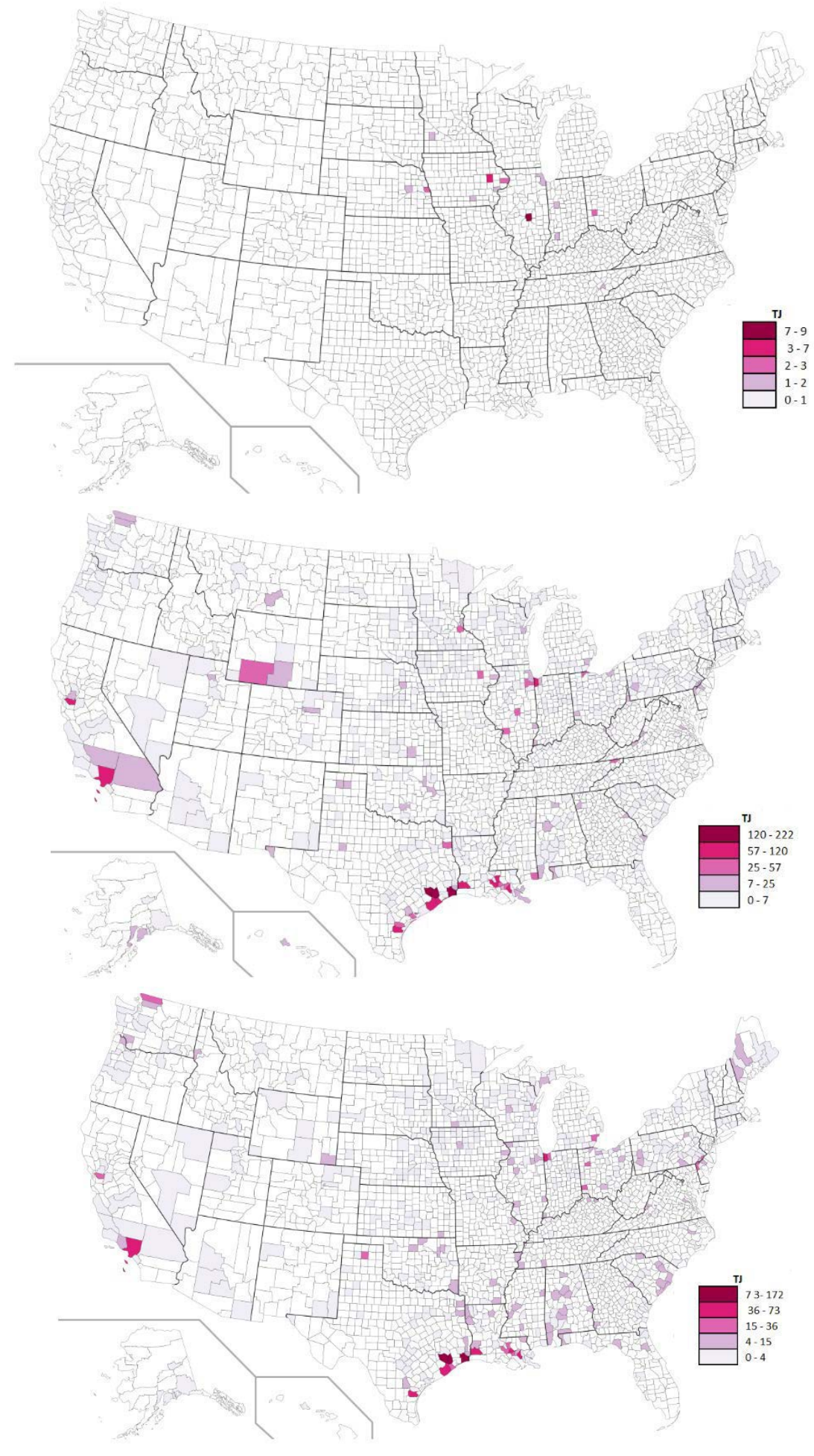

Figure 28. Industrial process heat estimated energy use (TJ) in $\mathbf{2 0 1 5}$ for facilities with largest emissions (>25,000 metric tons of $\mathrm{CO}_{2}$ equivalent emissions) in the United States by temperature range for (a) $<100 \mathrm{C}$, (b) $100^{\circ}-400^{\circ} \mathrm{C}$ and (c) $>400^{\circ} \mathrm{C}$

Source: McMillan and Ruth 2019 
McMillan et al. (2021) expanded on the 2019 study to estimate all IPH demand in the United States, including by process temperature at the county level (Figure 29), and provide the highestresolution estimates of combustion fuel use in U.S. industry for IPH. Figure 30 shows U.S. cumulative IPH demand in 2014 as a function of temperature. The study found $73 \%$ of IPH demand in the United States in 2014 was for temperatures below $300^{\circ} \mathrm{C}$, which can be met by parabolic trough or linear Fresnel concentrating technologies or by nonconcentrating technologies at temperatures below $100^{\circ} \mathrm{C}$. This temperature range represented one-third of total industrial and $11 \%$ of total U.S. primary energy use in 2014 (McMillan et al. 2021). Further, the research found parabolic trough collectors could cover $99 \%$ of the demand from combined heat and power/cogeneration and $100 \%$ of demand from conventional boiler processes (McMillan et al. 2021 Table 2).

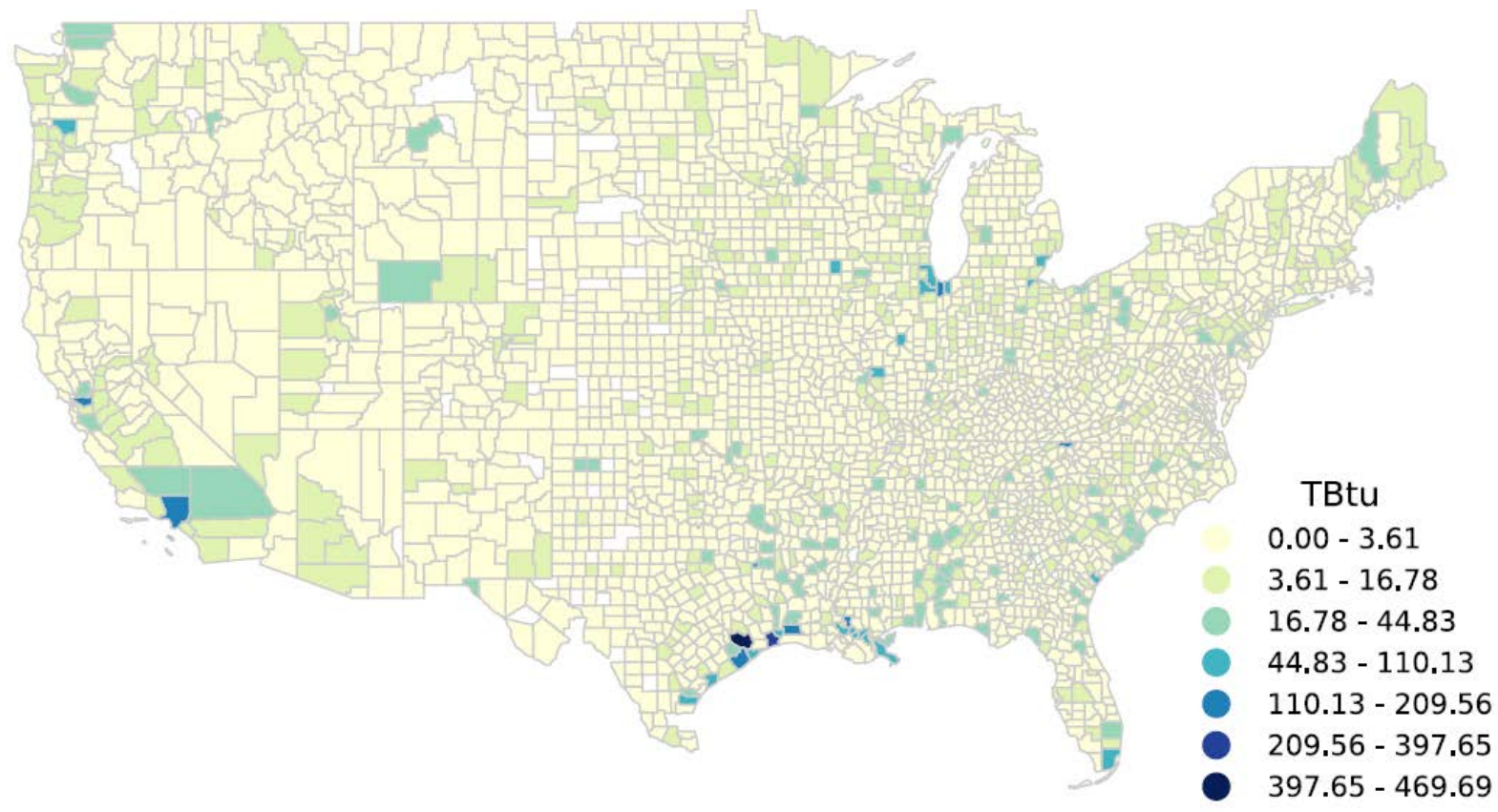

Figure 29. Industrial heat demand (TBtu) by county in 2014 in the continental United States

Source: McMillan et al. 2021 


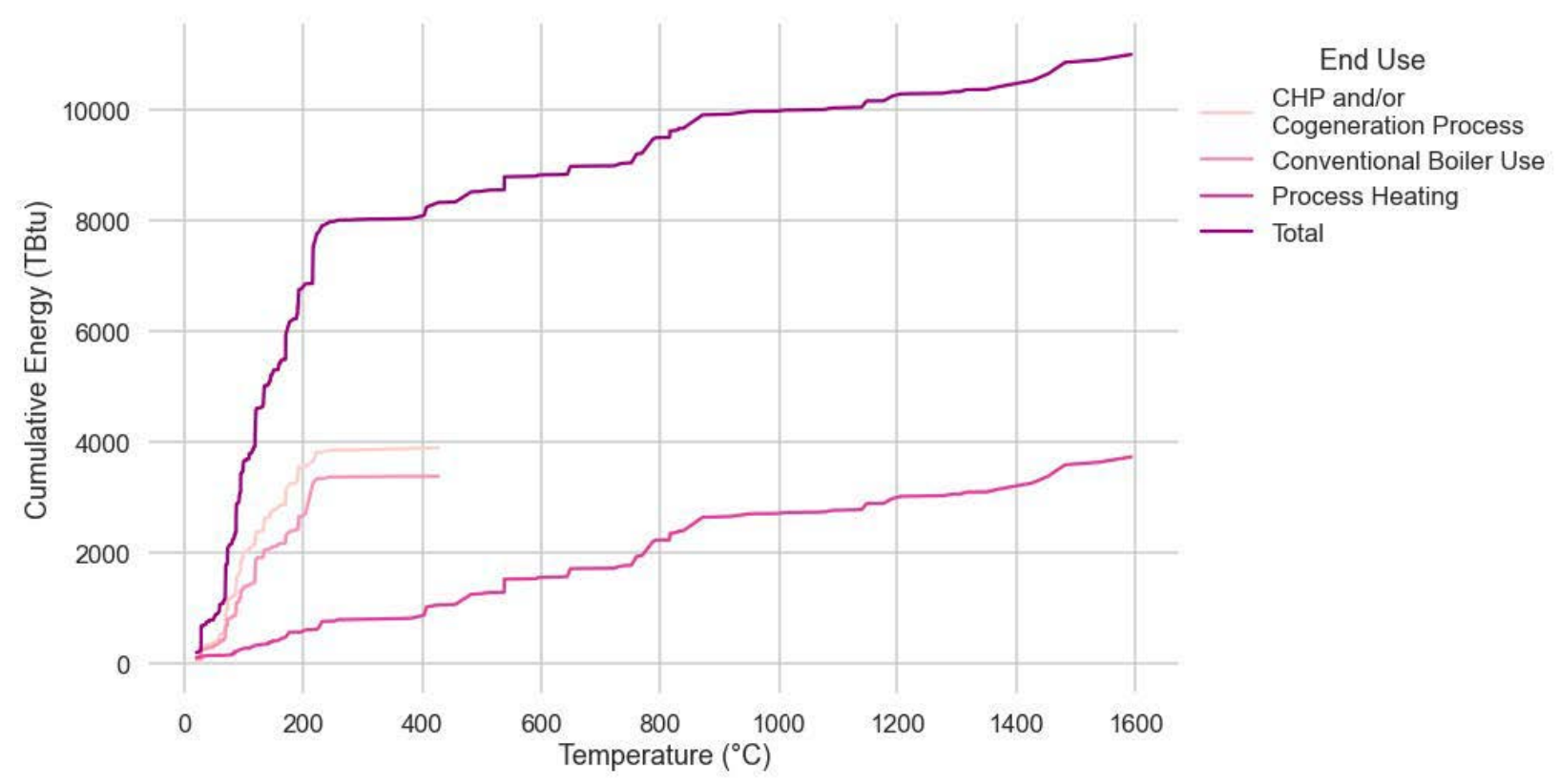

Figure 30. U.S. cumulative industrial process heat demand in 2014 by end-use category comparted to process temperature

Source: McMillan et al. 2021

\subsubsection{High-Temperature Processes}

As Figure 30 shows, process heating is dominated by higher-temperature unit processes. Two important industries, iron/steel manufacturing and cement production, require unit processes that operate at temperatures typically $>1,000^{\circ} \mathrm{C}$. These two processes account for half of global industrial GHG emissions (IEA 2020). Although these temperatures are out of the range of commercial CST technologies, research has been conducted on using CST energy for both processes.

CST technology can be used to thermally decompose limestone to lime for cement production. At temperatures of $900-1,300^{\circ} \mathrm{C}$, limestone $\left(\mathrm{CaCO}_{3}\right)$ decomposes to lime $(\mathrm{CaO})$ and $\mathrm{CO}_{2}$. Replacing fossil fuel combustion with CST to generate the heat for lime production can reduce $\mathrm{CO}_{2}$ emissions by $20 \%-40 \%$ (Koepf et al. 2017). Solar lime production was demonstrated in a $54 \mathrm{~kW}_{\text {th }}$ reactor comprised of a gas-particle separator modified to allow concentrated light in. During continuous operation, the reactor achieved $85 \%$ calcification of limestone at a conversion efficiency of $15 \%$ and process efficiency of $88 \%$ (Koepf et al. 2017). Solar limestone decomposition still produces $\mathrm{CO}_{2}$ as a byproduct of lime production.

Metals can be manufactured using CST technology as well, by thermolytic dissociation or by carbothermal reduction. Thermolytic dissociation uses extremely high temperatures to directly dissociate metal oxides into metal and oxygen $\left(\mathrm{O}_{2}\right)$. Carbothermal reduction reacts a metal oxide with carbon or methane $\left(\mathrm{CH}_{4}\right)$ to reduce it to bare metal while producing carbon monoxide $(\mathrm{CO})$ and hydrogen $\left(\mathrm{H}_{2}\right)$. Carbothermal reduction occurs at lower temperatures than thermolytic dissociation but is still a high-temperature process. Only zinc ( $\mathrm{Zn})$ and aluminum (Al) production from CST technologies has been studied in detail, although iron, silicon, and magnesium production have been looked at as well (Yadav and Banerjee 2016). Thermolytic dissociation 
and carbothermal reduction of metal oxides are also the first steps in some solar fuel manufacturing processes and are discussed in more detail in Section 5.2.3.

\subsubsection{Challenges in Industrial Process Heating}

Despite well-understood technology options, deployment of CST systems for IPH has been slow to develop. There were 741 solar IPH (SIPH) projects worldwide as of 2018 with a capacity of $567 \mathrm{MW}_{\text {th }}$ (Weiss and Mauthner 2019). Approximately 330 of these plants spread across 34 countries are recorded in the Solar Heat of Industrial Processes database. ${ }^{11}$ In the United States today, about $22 \mathrm{MW}_{\text {th }}$ of total installed power exists for SIPH applications (Schoeneberger et al. 2020).

One of the biggest challenges to decarbonizing the industrial sector is how heterogeneous the sector is (McMillan and Ruth 2019; Schoeneberger et al. 2020). Compared to the electricity, transportation, and building sectors, the industrial sector has a wide range of process technologies as well as additional difficulties in storing thermal energy and transporting it over long distances (McMillan et al. 2021). Likewise, integrating SIPH technologies into existing plants is challenging due to the need for process modification, the number and range of heating loads, the variety of HTFs used, and variations in process operation (McMillan et al. 2021). Industry itself is reluctant to adopt new technologies due to thin margins, tight production schedules, and concerns about the length of downtime during SIPH system installation (Schoeneberger et al. 2020).

Another barrier to SIPH deployment is a lack of current and disaggregated data from industry (McMillan et al. 2021). Without this information, researchers cannot accurately estimate the IPH demand in the United States. Modeling of SIPH systems will require a precise understanding of unit processes, their temperatures, heat load ( $\left.\mathrm{MW}_{\text {th }}\right)$, how the heat load changes daily and seasonally, the HTF used in the process, and how to integrate alternative technologies into processes (Schoeneberger et al. 2020). There must also be sufficient land or rooftop space available for SIPH systems and a sufficient solar resource to power them. Future demand projections should take into account changes in other sectors. For example, petroleum refining is currently a large source of process heat demand in the United States, but that could change in the future with the electrification of vehicles as modeled in some Solar Futures Study scenarios.

Along with process data from industry, SIPH needs models that show the performance and economics of SIPH systems and compares them to current and alternative systems. The models should incorporate process heat energy efficiency improvements. Energy efficiency options such as waste heat recovery, improved insulation and thermal management, improved heat transfer materials, and advanced process controls are the least-cost technology for decarbonizing industrial processes (Schoeneberger et al. 2020).

Globally, almost $60 \%$ of the long-term energy efficiency economic potential in the industrial sector will go unrealized under the status quo (IEA 2014). In the United States, DOE analytical studies of five major industries that use large amounts of process heat showed energy savings of $15 \%-30 \%$ are possible if U.S. plants adopt best-practice efficient process technologies. These

\footnotetext{
${ }^{11}$ http://ship-plants.info/solar-thermal-plants
} 
studies demonstrate significant potential for fuel use and emissions reductions at low costs that should be considered as a first step in IPH system models. Future SIPH models should also compare economic metrics such as payback period or levelized cost of heat and fuel savings to current and alternative process options. Shoenenberger et al. (2020) includes a list of parameters that should be included in any study of SIPH systems (Table 6).

Table 6. Key Parameters for Modeling SIPH Systems

\begin{tabular}{|l|l|}
\cline { 2 - 2 } \multicolumn{1}{c|}{} & Parameters \\
\hline Solar Supply & $\begin{array}{l}\text { Process heat characteristics } \\
\text { Process heat load profiles }\end{array}$ \\
\hline Economic Factors & $\begin{array}{l}\text { Energy efficiency potential } \\
\text { Solar irradiance } \\
\text { Land for solar/Rooftop area }\end{array}$ \\
\hline & $\begin{array}{l}\text { Integration into facility } \\
\text { Supply- and demand-side equipment costs } \\
\text { Payback period/Rate of return } \\
\text { Savings from reduced fuel use }\end{array}$ \\
\hline
\end{tabular}

Adapted from Schoeneberger et al. 2020

Finally, SIPH needs reliable, cheap TES. Thermal energy can be stored as sensible, latent, or thermochemical energy.

Sensible heat storage uses changes in the temperature of media to store thermal energy, and the amount of heat that can be stored is directly proportional to the heat capacity of the media and its temperature change over the storage cycle. Solid media, such as pebbles, rocks, and cement, have been proposed for sensible heat storage, and liquids, such as oils and molten salts, are used for TES at existing CSP plants. Sensible heat TES for IPH is commercially limited to storing hot water (Schoeneberger et al. 2020), which is an excellent storage medium due to its high heat capacity but is limited in temperature range by its low boiling point. Sensible heat storage has low energy densities and requires large storage volumes.

Latent heat storage uses phase changes in media (usually solid-to-liquid) to store thermal energy. The media is charged by melting it and discharged by heating an HTF while solidifying so that heat is stored and discharged at a constant temperature. The amount of TES depends on the latent heat of fusion/melting for the media, which is usually much higher than its heat capacity, resulting in smaller required storage volumes. Latent heat storage is well-suited to steam generation (Sharan, Turchi, and Kurup 2019) and is used commercially in the form of ice storage for building cooling. Crespo et al. (2019) review potential phase change materials for SIPH at temperatures of $120^{\circ}-400^{\circ} \mathrm{C}$.

Thermochemical heat storage uses energy stored in chemical bonds from temperature-dependent thermochemical reactions or sorption (adsorption and absorption) processes. The advantages of thermochemical heat storage are that they have the potential to be the most energy-dense storage material and require the smallest volume. The energy can also theoretically be stored indefinitely without degradation as stable chemicals. Lefebvre and Tezel (2017) provided a review of thermochemical storage research, along with other storage technologies. 
Given the variable nature of the solar resource versus the need for process reliability in industry, the need for TES in SIPH is obvious. This need is analytically illustrated in the results from the McMillan et al. (2021) study on U.S. IPH demand that matched the demand for IPH by county to the available solar resource for a range of solar thermal and PV-powered electric IPH options and estimated the ability of solar technologies to meet thermal demand. The study included options with and without energy storage. Figure 31 shows the percentage of counties in the United States where a given SIPH technology can meet $>50 \%$ of yearly demand and the percentage of time in each county where it can fully meet demand. The systems are sized to meet the summer peak IPH. Flat plate collectors (FPCs) were assumed to have hot water storage, and parabolic trough collector (PTC) systems were modeled with 6 hours of TES and without TES. PV-powered systems did not include electricity storage or external electricity sources. The noticeable difference between PTC systems with and without TES demonstrates the importance of TES in meeting IPH demand. FPCs also performed well due to TES. If the systems are sized for winter (larger), and/or if TES duration is increased, the percentages of IPH demand met could be greater.

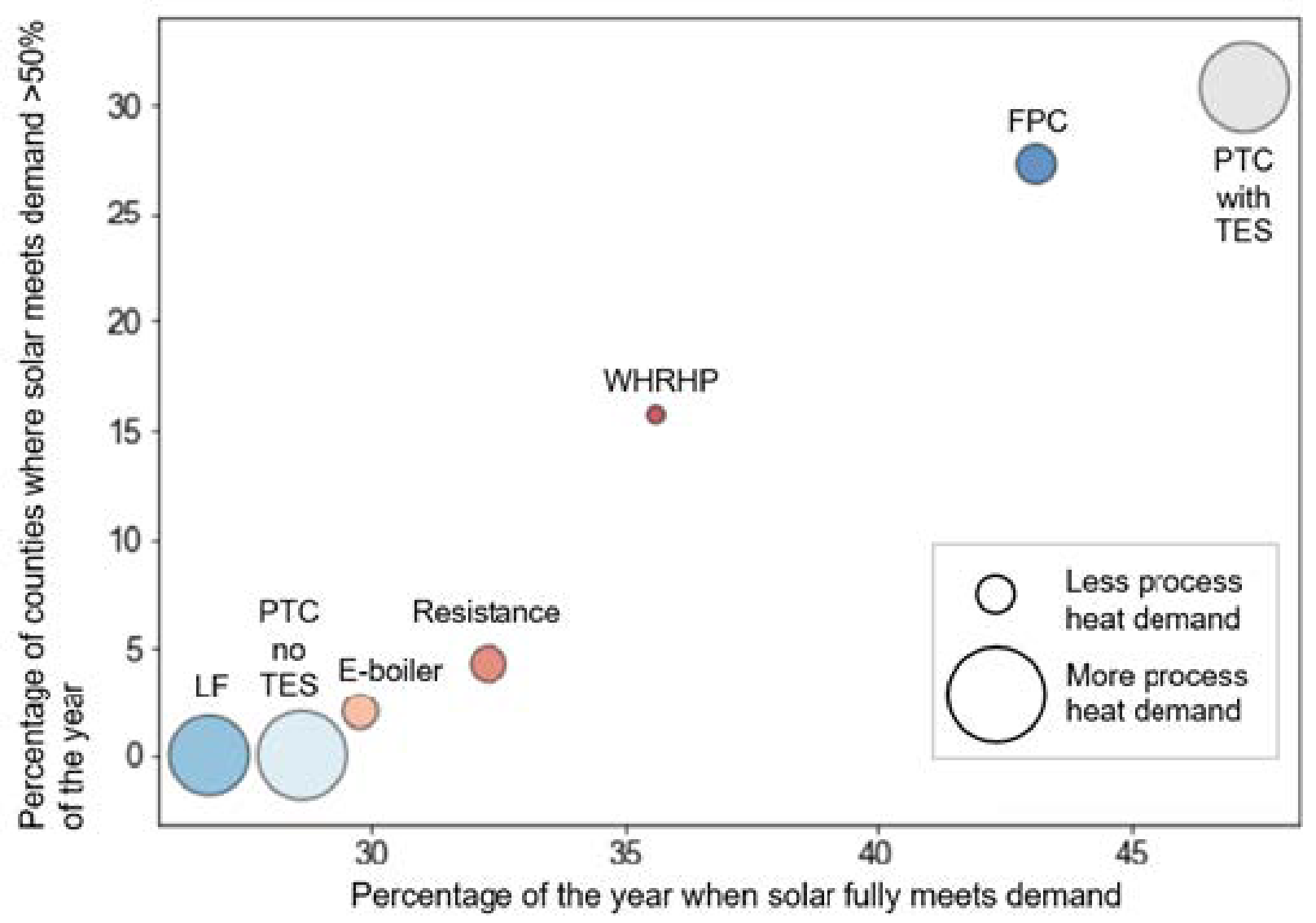

Figure 31. Comparison of solar industrial process technologies' ability to meet U.S. IPH demand Source: McMillan et al. 2021

e-boiler = electric boiler; LF = linear Fresnel; PTC = parabolic trough collector; TES $=$ thermal energy storage WHRHP = waste heat recovery heat pump 
The IPH market in the United States is a large potential future market for SIPH. Studies have shown the majority of IPH demand in the United States is at process temperatures that can be met by parabolic trough or linear Fresnel solar collector technologies. For high-temperature processes above the commercial temperature limit of CST, such as metal and cement production, solar technologies have been identified and studied at the laboratory and pilot scale. The role for commercial technologies using heliostats and central receivers is relatively small, with one study putting the IPH demand at temperatures between $300^{\circ} \mathrm{C}$ and $600^{\circ} \mathrm{C}$ at only $10 \%$ (McMillan and Ruth 2019).

Despite commercially available technologies, SIPH has not seen much deployment in the United States. Challenges to the SIPH industry include industry reluctance to change or adopt new technologies, a dearth of detailed, disaggregated data from industry, and a lack of models and decision support tools to compare SIPH technologies to current or alternative processes. Finally, SIPH deployment is hampered by the solar resource geographic distribution and the daily (un)availability of solar resources. Cheap and reliable TES is critical to increase the availability and reliability of SIPH technologies. As McMillan et al. (2021) concluded, "[T]he ability to match the temporal aspect of IPH demand is a more significant barrier than matching solar technologies to IPH temperatures."

\subsection{Solar Fuels}

As discussed by Ardani et al. (2021), the transportation sector and some industrial processes would benefit from cost-competitive sustainable fuels. Liquid fuels would be particularly attractive for long-term storage and ease of handling. The electrons to molecules (E2M) opportunity focuses on electrochemical reactions, but there are other opportunities that benefit from operation at high temperatures, wherein CST technologies could play a role.

Near-term options include upgrading fossil fuels by converting natural gas to liquids, and in the longer term, solar-produced syngas could be used as a feedstock for various liquid fuels. Solar fuels plants can also be sited in remote areas with high DNI and land availability, taking advantage of the ability to ship the produced fuel to users. The strong position afforded the RECT in the Solar Futures Study scenarios indicates a large potential market for solar fuels if the integrated CST and chemical reaction systems can achieve competitive fuel price targets. Solar fuels can play a role in the decarbonization of industrial processes as well, as when CST-derived hydrogen is used in the direct reduction of iron.

CST technology pathways can produce a range of solar fuels, including hydrogen, ammonia, methanol, and synthetic gasoline and diesel (Hinkley et al. 2017). Solar thermal technology pathways include reforming, redox reactions, gasification, and high-temperature electrolysis (Doron, Karni, and Slocum 2019; Hinkley et al. 2017). Many of these pathways include the production of $\mathrm{H}_{2}$ and syngas (a combination of $\mathrm{CO}$ and $\mathrm{H}_{2}$ ), which can be used as a feedstock for further fuel upgrading and processing. The reactions take place at temperatures of $800^{\circ} \mathrm{C}$ and higher so that heliostat fields with a central receiver or parabolic dishes are required to reach operating temperatures (Doron, Karni, and Slocum 2019). These pathways are summarized in Figure 32 and discussed in more detail below. 


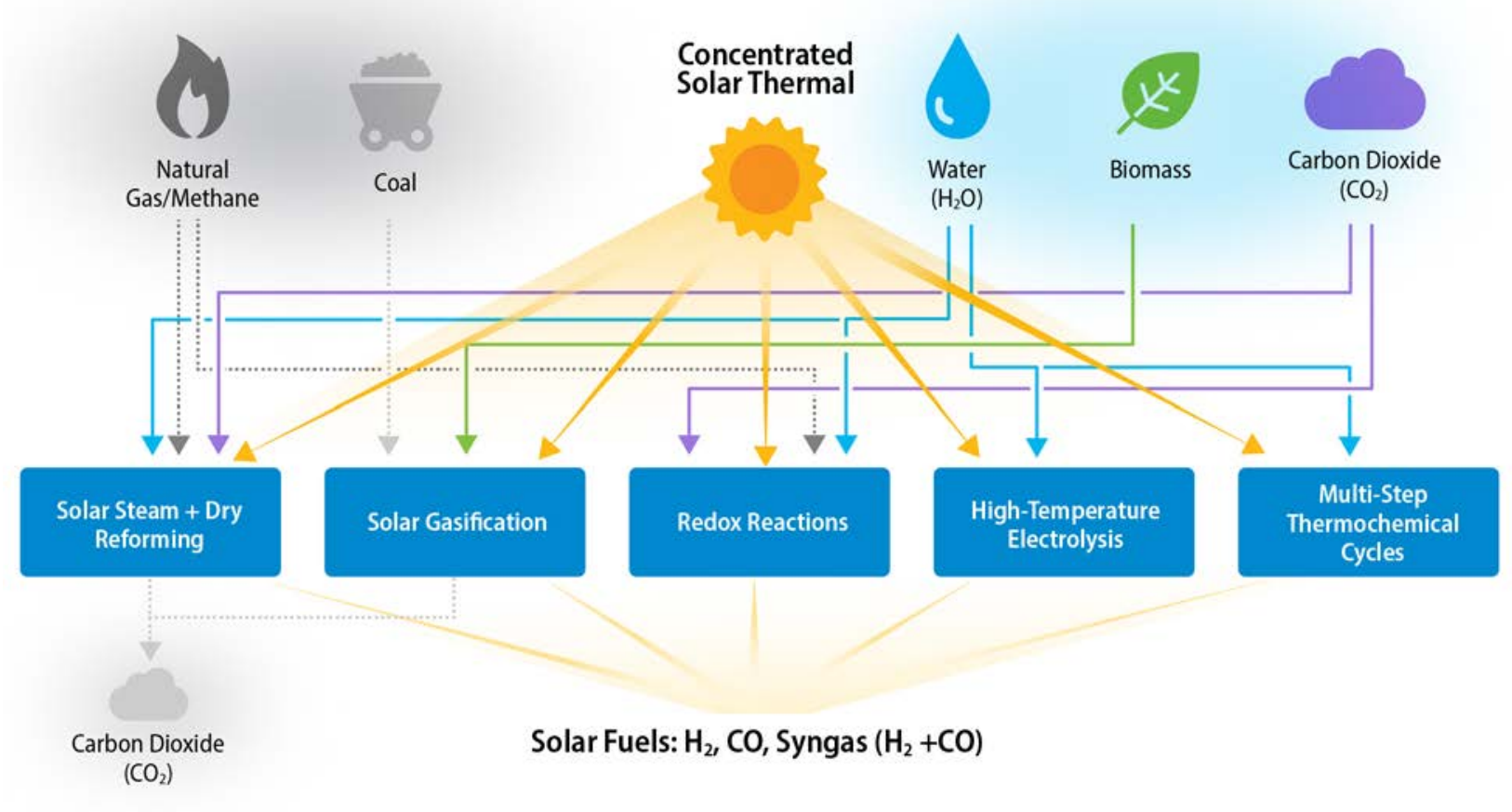

Figure 32. Summary of solar fuel chemical pathways

\subsubsection{Methane Reforming}

Methane $\left(\mathrm{CH}_{4}\right)$ reforming uses temperatures of about $800^{\circ}-1,000^{\circ} \mathrm{C}$ and a metal alloy catalyst to produce $\mathrm{H}_{2}$ from $\mathrm{CH}_{4}$, with $\mathrm{CO}_{2}$ as a byproduct. Alternatively, syngas $\left(\mathrm{H}_{2}+\mathrm{CO}\right)$ can be produced through reforming if desired. The traditional process uses fossil fuels, both as the source for the $\mathrm{CH}_{4}$ and to generate the high temperatures for the reaction. The most common reforming processes that incorporate concentrating solar power are steam methane reforming (steam and methane) and dry methane reforming $\left(\mathrm{CO}_{2}\right.$ and methane) (Sheu, Mokheimer, and Ghoniem 2015). CST energy can replace fossil fuels as the heat source to achieve a $30 \%$ reduction in $\mathrm{CO}_{2}$ intensity (Hinkley et al. 2017), but to comply with the Decarb scenario in the Solar Futures Study and achieve $\mathrm{H}_{2}$ production with zero GHG emissions, a bio-derived methane source or $\mathrm{CO}_{2}$ capture and sequestration of the reform reaction products would be needed. Numerous designs for solar thermal steam and dry methane reforming, including direct and indirect heating methods, have been tested (Sheu, Mokheimer, and Ghoniem 2015). The technology is ready for a large-scale demonstration to prove its bankability and is the most mature of the CST technology pathways (Hinkley et al. 2017).

\subsubsection{Steam Gasification}

Steam gasification is a potential solar fuel technology pathway that heats solid carbonaceous feedstocks such as coal, sugar cane bagasse, or dried sewage sludge, and steam to temperatures higher than $900^{\circ} \mathrm{C}$ to produce syngas. Solar steam gasification has several advantages over conventional gasification. Since part of the feedstock does not need to be combusted to generate the heat, as in conventional processes, the resulting syngas has a higher energy output per unit of feedstock. The syngas is also cleaner because it is free of combustion products and does not require downstream gas cleaning and separation. Finally, it can achieve gasification temperatures in excess of $1,100^{\circ} \mathrm{C}$, resulting in faster reaction kinetics and lower tar content (Koepf et al. 2017). 
A $150-\mathrm{kW}_{\text {th }}$ solar steam gasification pilot plant by the SOLSYN consortium successfully gasified carbonaceous waste feedstock that included industrial sludge, a mixture of paper and plastics, tire chips, dried sewage sludge, coal, and sugar cane bagasse in a batch process at solar-to-fuel energy conversion efficiencies from 22\%-35\% (Koepf et al. 2017).

One of the challenges with solar steam gasification is the difficulty of handling solids instead of gases and developing a continuous rather than batch process. Solar steam gasification has a relatively low technical maturity compared to solar steam methane reforming and requires additional work at the laboratory and pilot scale (Hinkley et al. 2017).

\subsubsection{Reduction-Oxidation (Redox) Reactions}

CST reduction-oxidation (redox) processes consist of a two-step chemical reaction in which a substance is reduced to produce oxygen gas during the addition of solar thermal energy in the first step and the same substance is oxidized to generate hydrogen, carbon monoxide, or syngas. The substance, called the redox material, is then recycled to the first step to be reduced again, and the process is repeated.

One of the main advantages of CST redox processes is that the reduction and oxidation reactions can be done as completely different steps, so the recovered redox material can be oxidized immediately, stored, and reacted later, or used in another process entirely. The other main advantage is that the separate steps also avoid the mixing of fuel $\left(\mathrm{H}_{2}\right.$ and/or $\left.\mathrm{CO}\right)$ and $\mathrm{O}_{2}$, which eliminates recombination of products after the reaction and the need for a separation step.

There are many candidate redox materials for CST processes and several potential feedstocks for generating solar fuels. The first step is generally thermolytic reduction or carbothermal reduction of the redox materials. Thermolytic reduction reduces the redox material through heating alone. In an example solar thermolytic redox reaction cycle, zinc oxide $(\mathrm{ZnO})$ is heated in a solar receiver reactor to over $1,700^{\circ} \mathrm{C}$ (Koepf et al. 2017) and reduced to zinc gas and oxygen gas (Eq. 2). The recovered zinc is then oxidized in a separate step by combining it with lower-temperature $\left(\sim 425^{\circ} \mathrm{C}\right)$ steam (Koepf et al. 2017$)$ to produce zinc oxide and hydrogen gas (Eq. 3). Carbon dioxide can be used in place of water in the second step to produce carbon monoxide (Eq. 4). The zinc oxide is reduced again to produce zinc and oxygen in a cyclic process.

$$
\begin{array}{lr}
\mathrm{ZnO} \rightarrow \mathrm{Zn}(\mathrm{g})+1 / 2 \mathrm{O}_{2} & \text { Eq. } 2 \\
\mathrm{Zn}+\mathrm{H}_{2} \mathrm{O} \rightarrow \mathrm{ZnO}+\mathrm{H}_{2} & \text { Eq. } 3 \\
\mathrm{Zn}+\mathrm{CO}_{2} \rightarrow \mathrm{ZnO}+\mathrm{CO} & \text { Eq. } 4
\end{array}
$$

In carbothermal reduction, redox materials are reduced via reaction with carbon to form carbon monoxide (Eq. 5) or with methane to produce syngas (Eq. 6). Carbothermal reduction has two advantages over thermolytic reduction: it lowers the required process temperature by $\sim 600^{\circ} \mathrm{C}$, and it avoids oxygen as a reaction product gas so zinc can be condensed and recovered without recombining with oxygen to reform $\mathrm{ZnO}$ (Koepf et al. 2017). The zinc reduction step (Eq. 2) is also still completely separated from the oxidation step so zinc can be stored and used later as needed. The GHG intensity of carbothermal reduction depends on the source of carbon and/or whether the produced carbon monoxide is later captured and sequestered or released to the air. 


$$
\begin{array}{cc}
\mathrm{ZnO}+\mathrm{C} \rightarrow \mathrm{Zn}(\mathrm{g})+\mathrm{CO} & \text { Eq. } 5 \\
\mathrm{ZnO}+\mathrm{CH}_{4} \rightarrow \mathrm{Zn}(\mathrm{g})+\mathrm{CO}+2 \mathrm{H}_{2} & \text { Eq. } 6
\end{array}
$$

Several materials have been proposed and studied for use in CST redox reactions. Metal oxides, such as zinc oxide, iron oxide $\left(\mathrm{Fe}_{2} \mathrm{O}_{3} / \mathrm{Fe}_{3} \mathrm{O}_{4}\right)$, aluminum oxide $\left(\mathrm{Al}_{2} \mathrm{O}_{3}\right)$, magnesium oxide $(\mathrm{MgO})$, and cerium oxide $\left(\mathrm{CeO}_{2}\right.$, aka ceria), require process temperatures of $>1,300^{\circ} \mathrm{C}$ for direct reduction (Doron, Karni, and Slocum 2019). Ceria can be doped with other metal cations to change its physicochemical properties and tune its performance (Koepf et al. 2017). Metal oxide perovskites also have been studied as a redox material due to their flexible arrangement and the ability to tune their properties by doping (Pregger et al. 2019).

As demonstrated in Eq. 2 and Eq. 5, most many metal oxides are volatile redox materials, meaning the reduced metal is produced as a gas from the reaction and must be quenched, condensed, and recovered. Both ceria and metal oxide perovskites are nonvolatile in the redox reactions, simplifying product separation and operating conditions. However, they typically use an inert purge gas during reduction and reoxidation to remove product gases. Also, the reduction and oxidation steps for nonvolatile redox materials usually occur in the same reactor so that multiple reactors are needed for continuous production, although designs allowing for continuous flow of materials between separate reactors have been demonstrated (Ermanoski, Siegel, and Stechel 2013). Redox reactions with volatile redox materials can be run continuously by simply adding more oxidized redox material to the ongoing reaction.

\subsubsection{Multistep Thermochemical Cycles}

Multistep thermochemical cycles produce hydrogen using at least three reaction steps and have been studied primarily for use with nuclear reactors operating around temperatures of $700^{\circ} \mathrm{C}$ (Yadav and Banerjee 2016). One multistep cycle, the sulfur-iodine (S-I) cycle, has been studied for use as a solar thermochemical process.

The S-I cycle begins with the decomposition of sulfuric acid $\left(\mathrm{H}_{2} \mathrm{SO}_{4}\right)$ at temperatures $\geq 800^{\circ} \mathrm{C}$ over a catalyst to produce sulfur dioxide $\left(\mathrm{SO}_{2}\right)$, water, and oxygen (Eq. 7). In the second step, aqueous $\mathrm{SO}_{2}$ is reacted with iodine $\left(\mathrm{I}_{2}\right)$ at around $100^{\circ} \mathrm{C}$ to regenerate sulfuric acid and produce hydriodic acid (HI) in the Bunsen reaction (Eq. 8). The sulfuric acid can be recycled for use in Step 1. In Step 3, hydriodic acid is heated to $200^{\circ}-250^{\circ} \mathrm{C}$ and decomposed into iodine and hydrogen (Eq. 9). The iodine can be reused in Step 2. The overall process results in the generation of hydrogen and oxygen gas from water. The final two steps (Eq. 8 and Eq. 9) can be replaced by a single electrolysis step that oxidizes sulfur dioxide $\left(\mathrm{SO}_{2}\right)$ with water to produce sulfuric acid $\left(\mathrm{H}_{2} \mathrm{SO}_{4}\right)$ and hydrogen.

$$
\begin{array}{cr}
\mathrm{H}_{2} \mathrm{SO}_{4} \rightarrow \mathrm{SO}_{2}+\mathrm{H}_{2} \mathrm{O}+1 / 2 \mathrm{O}_{2} & \text { Eq. } 7 \\
\mathrm{I}_{2}+\mathrm{SO}_{2}+2 \mathrm{H}_{2} \mathrm{O} \rightarrow \mathrm{H}_{2} \mathrm{SO}_{4}+2 \mathrm{HI} & \text { Eq. } 8 \\
2 \mathrm{HI} \rightarrow \mathrm{I}_{2}+\mathrm{H}_{2} & \text { Eq. } 9
\end{array}
$$




\subsubsection{High-Temperature Electrolysis}

Low-temperature electrolysis uses electricity to split water into hydrogen and oxygen and is considered the benchmark technology competitor for hydrogen production (Yadav and Banerjee 2016; Koepf et al. 2017). Solid oxide steam electrolysis, or high-temperature electrolysis, has the highest efficiency among water electrolysis technologies (Pregger et al. 2019). The higher temperatures result in faster reaction kinetics, and steam electrolysis requires less electricity than low-temperature water electrolysis.

The electric energy requirements can be reduced further by using high-temperature heat from solar thermal power (Pregger et al. 2019). Solar heat was successfully integrated into a commercial solid oxide electrolyzer operating at $770^{\circ} \mathrm{C}$ and $2 \mathrm{~kW}_{\mathrm{e}}$ of electrical power to achieve a steam conversion rate of $70 \%$ at an electrical stack efficiency of $93 \%$ (Schiller et al. 2019).

\subsubsection{Comparison to CSP for Power Generation}

Commercial CST solar fuel plants will share several common elements with CSP generation plants. As mentioned previously, solar fuel processes require high temperatures, usually over $800^{\circ} \mathrm{C}$. Achieving the solar concentration necessary for efficient operation at these temperatures will require the use of heliostat mirrors aimed at a tower-mounted receiver. (Doron, Karni, and Slocum 2019; Yadav and Banerjee 2016) (Table 7). The high temperatures and solar fuel reactor configuration may require a cavity receiver coupled with a polar heliostat field. This configuration is similar to a CSP power tower for electricity generation and would likely use the same heliostat mirror and tracking technology.

Table 7. Summary of Upper Operating Temperature, Annual-Average Solar Concentration Ratio, and Annual-Average Optical Efficiency for Solar-Thermal Collection Systems

\begin{tabular}{|l|c|c|c|}
\hline System & $\begin{array}{l}\text { Upper Operating } \\
\text { Temperature }\left({ }^{\circ} \mathbf{C}\right)\end{array}$ & $\begin{array}{l}\text { Annual-Average } \\
\text { Concentration Ratio }\end{array}$ & $\begin{array}{l}\text { Annual-Average } \\
\text { Optical Efficiency }\end{array}$ \\
\hline Linear Fresnel & $\sim 250$ & 10 & $\sim 50 \%$ \\
\hline Trough & $\sim 450$ & 60 & $\sim 55 \%$ \\
\hline Power Tower $\geq \sim 60 \mathrm{MW}_{\text {th }}$ & $\sim 500$ & 100 & $\sim 50 \%$ \\
\hline Power Tower $\leq \sim 60 \mathrm{MW}_{\text {th }}$ & $\sim 700$ & 500 & $\sim 60 \%$ \\
\hline Power Tower $\leq \sim 10 \mathrm{MW}_{\text {th }}$ & $\sim 900$ & 1,000 & $\sim 70 \%$ \\
\hline Parabolic Dish & $\sim 1,200$ & 1,500 & $\sim 85 \%$ \\
\hline
\end{tabular}

Adapted from Doron, Karni, and Slocum 2019. Numbers in table are approximations from several sources.

Concentrating solar fuel plants will likely be designed to operate continuously to maximize capacity factor and productivity, meaning they will require TES. Most CSP generation plants constructed in recent years incorporate TES, so that solar fuel and power generation CSP plants will both use TES. However, CSP power generation uses molten salts or thermal oils for TES and has only been proven commercially for temperatures under about $600^{\circ} \mathrm{C}$. Solar fuel processes use higher temperatures so that new TES technologies will need to be commercialized. Solid-particle TES (Section 4.1.2) uses thermally able solid particles to store thermal energy and may be able to store thermal energy at the temperatures required for some solar fuel processes. 
Beyond the heliostat field and a need for TES, concentrating solar fuel and power generation plants will not have much in common. Concentrating solar fuel plants will not require a power block to generate electricity like a CSP generation plant. They will still have a receiver mounted on a tower, but the receiver will be substantially different in design from those used in electricity generating plants. Each of the chemical processes discussed above have different temperatures, pressures, and design considerations, so specific chemical processes will lead to different reactor designs and development approaches (Koepf et al. 2017).

\subsubsection{Research and Development Challenges}

CST technology pathways have several unique R\&D challenges. One of the biggest challenges is developing receivers and reactors for solar fuels production. High temperatures required for solar fuels production - usually above $800^{\circ} \mathrm{C}$, often above $1,200^{\circ} \mathrm{C}$, and as high as $1,600^{\circ} \mathrm{C}$ - are among the main challenge.

Finding materials and designing receivers to operate at these temperatures is nontrivial. Most of the processes discussed for solar fuels require the reaction vessel to be isolated from the atmosphere. The reduction step in redox reactions is controlled by temperature and the partial pressure of oxygen in the reactor. If left open to the atmosphere, the extent of reaction is greatly reduced. Receiver reactors are typically sealed and fitted with a quartz window to allow concentrated sunlight in. However, the quartz windows must be kept clean and relatively cool. If reactants such as volatile metals condense on the window, they will lower optical transmission and could also cause localized heating that could break the window. Inert gases are often injected across the window face to cool it, prevent condensation, and reduce the partial pressure of oxygen in the reactor. Even reactor receivers that are indirectly heated often incorporate a quartz window and are sealed from the atmosphere to prevent oxidation of the reactor walls at high temperatures when exposed to the atmosphere (Koepf et al. 2017).

Processes like redox reactions and the S-I cycle require multiple steps and need multiple reactors or multiple steps within the same reactor. Gasification and some redox materials require handling particles. The CST technology processes discussed above have been demonstrated at the laboratory scale, and some at the pilot scale (Koepf et al. 2017; Yadav and Banerjee 2016), but have not yet been demonstrated at the commercial or precommercial scale. No dominant receiver or reactor design has emerged for any of the processes.

A second R\&D challenge for solar fuels is increasing the efficiency of the processes. The key drivers of cost-effectiveness for solar fuels are the cost of the feedstock and the solar-to-thermal efficiency that can be achieved (Hinkley et al. 2017). Theoretical solar-to-thermal efficiencies, defined as the ratio of the higher heating value of the produced gases compared to the solar input, for $\mathrm{ZnO}$ reduction via thermolysis followed by water splitting have been calculated to be up to $36.9 \%$ without heat recuperation and $61.0 \%$ with heat recuperation (Loutzenhiser and Steinfeld 2011). In practice, the volatile $\mathrm{Zn}$ and $\mathrm{O}_{2}$ produced in the reduction step must be separated by quenching with high volumes of inert gas. The inert gas must be separated from the $\mathrm{O}_{2}$ and recycled. Because of the quench step, actual efficiencies for zinc redox reactions achieved in the lab and pilot projects are up to two orders of magnitude lower than theoretical calculations (Koepf et al. 2017). In fact, Koepf et al. (2017) concluded that solar fuel production using zinc oxide as the redox material should not proceed unless significant advances in product separation 
and/or inert gas recycling are made. Heat recovery is the most important factor for increasing the overall efficiency of concentrating solar fuel processes (Pregger et al. 2019; Hinkley et al. 2017).

Figure 33 demonstrates the progress and difficulty of solar fuels research. The Solar Technology Laboratory at the Paul Scherrer Institute (PSI) has invested more than 25 years in solar R\&D (Koepf et al. 2017). Figure 33 shows the progress in reactor size and solar-to-chemical efficiency as a function of development time for four different CST technology pathways. The figure clearly shows the progress PSI has made, as reactors for each pathway have gotten larger and more efficient with each iteration. It also shows that progress can take decades.

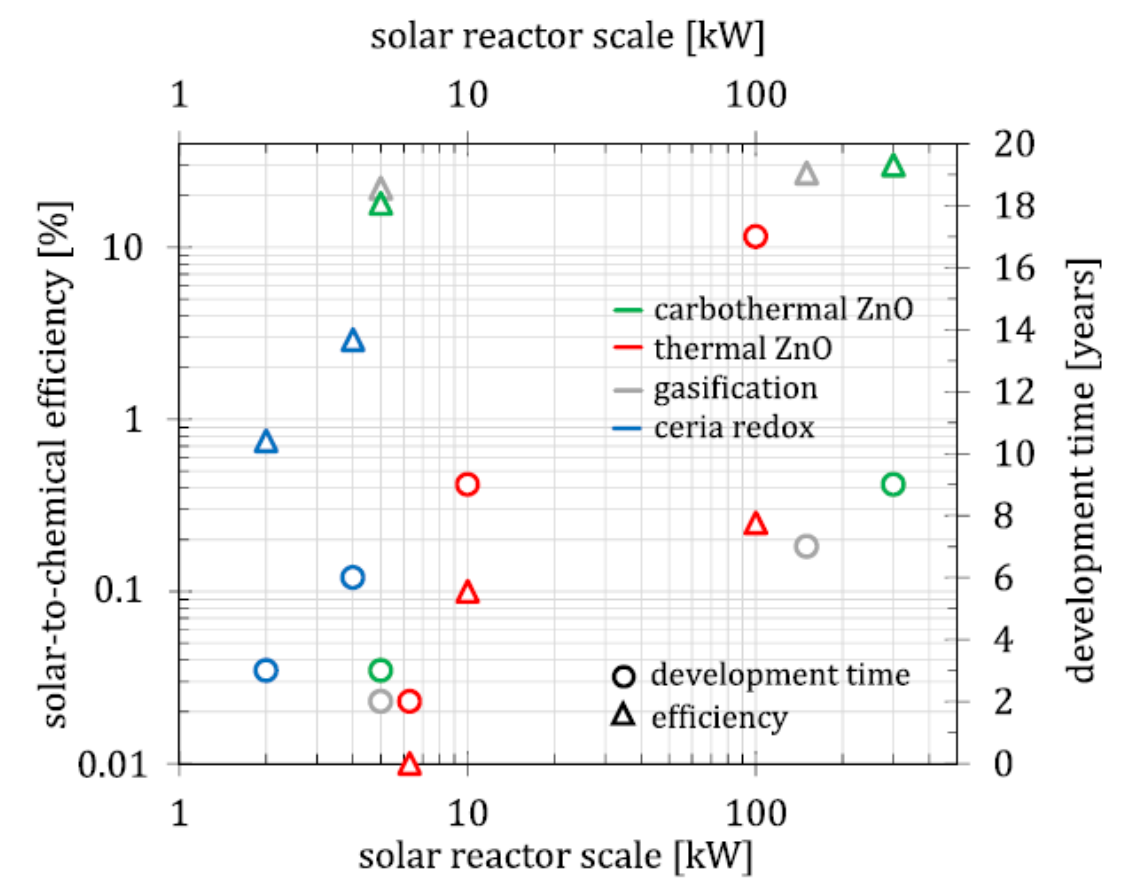

Figure 33. Solar-to-chemical efficiency and research and development time plotted against demonstration scale for solar reactor technology research projects at the Paul Scherrer Institute

Source: Koepf et al. 2017

A third challenge to solar fuels production is the need for high-temperature TES. TES is needed to allow the plant to operate 24 hours a day and increase the utilization of the capital equipment to lower fuel production costs. As mentioned previously, TES is commercially limited to $575^{\circ} \mathrm{C}$, whereas solar fuel processes usually require temperatures of $800^{\circ} \mathrm{C}$ and higher. New, highertemperature TES technologies, such as solid media storage, will be needed for continuous or high-capacity-factor solar fuels production. Significant thought will also have to be given to designing the plant to capture and store thermal energy while also operating the solar fuel reactor continuously. Enabling continuous operation will require high-temperature heat exchangers and material transport. 


\subsection{Electric Thermal Energy Storage}

Recent interest in electric thermal energy storage, or ETES, has been spurred by the projected need for longer-duration electricity storage in future grids containing a high penetration of variable renewable energy generation. ETES refers to any storage system that converts electricity to heat (thermal energy) in its charge phase and stores it in a hot storage system and a heat engine to convert the thermal energy back to electricity during discharge.

Given the range of TES materials and options, operating temperatures and pressures, expansion and compression technologies, working fluids, and integration schemes for heat recovery (e.g., recuperators), ETES systems can take many different forms. The efficiency of ETES can be increased by using an electrically driven heat pump during the charge phase, referred to as pumped thermal electricity storage (PTES) (Farres-Antunez, McTigue, and White 2019).

The general concept of PTES has been discussed under a variety of names in the literature, including "Carnot battery," which can also consider direct resistive heating to charge the hot storage (Walter et al. 2020). In common with many thermo-mechanical systems, the energy and power capacities of PTES can be decoupled, and the marginal cost of additional energy storage is potentially very low.

There are three main categories of PTES: Joule-Brayton PTES, transcritical PTES, and compressed-heat energy storage, or CHEST (Olympios et al. 2021). Joule-Brayton PTES systems are most likely to be designed at operating conditions where CSP TES technologies can be applied. A general Joule-Brayton PTES system is shown schematically in Figure 34(a). During charging, starting at point (1) in the figure and moving counterclockwise to point (2), the chosen working fluid is compressed (C) using electricity from the grid to a higher pressure, which also raises its temperature. Heat from the fluid is rejected to a hot store (HS), charging it in the process. The cooled fluid is then expanded (E) to lower pressure, further decreasing its temperature. Finally, the cold fluid draws heat from a cold store (CS), gaining energy, and the cycle is repeated.

The net energy required to run the compressor and expander is supplied by electricity from the grid and is stored as thermal energy. During discharge, the process is reversed. Starting at point (1) and moving clockwise to point (4), the fluid rejects heat to the cold store. The expander that was between points (4) and (3) during charging is replaced by a compressor, and the fluid temperature increases. The fluid gains heat from the hot store and is then expanded, generating electricity, and the cycle is repeated. The net energy from the expander and compressor is returned to the grid. The ratio of the energy returned to the grid during discharge to the energy taken from the grid during charging is the round-trip efficiency of the PTES system. It is estimated that PTES systems may be able to achieve round-trip efficiencies around $50 \%-70 \%$ (Farres-Antunez, McTigue, and White 2019). 


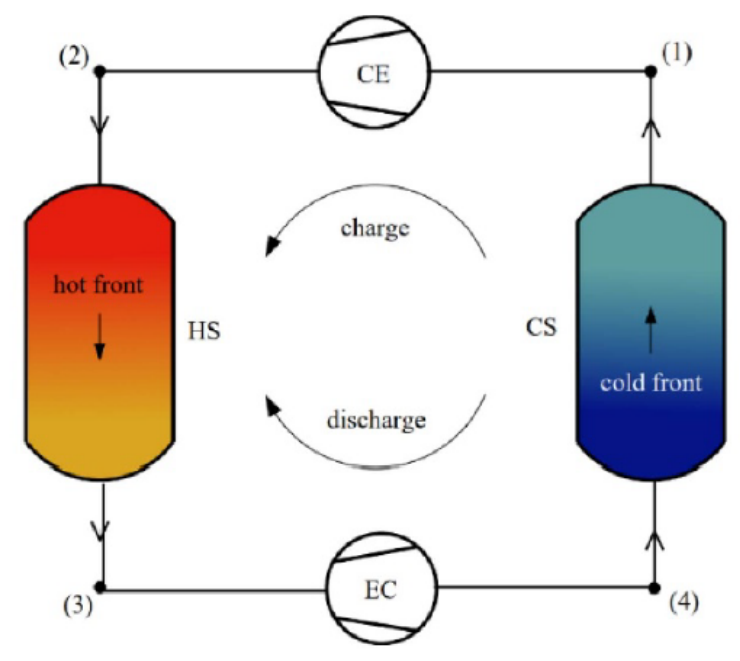

(a)

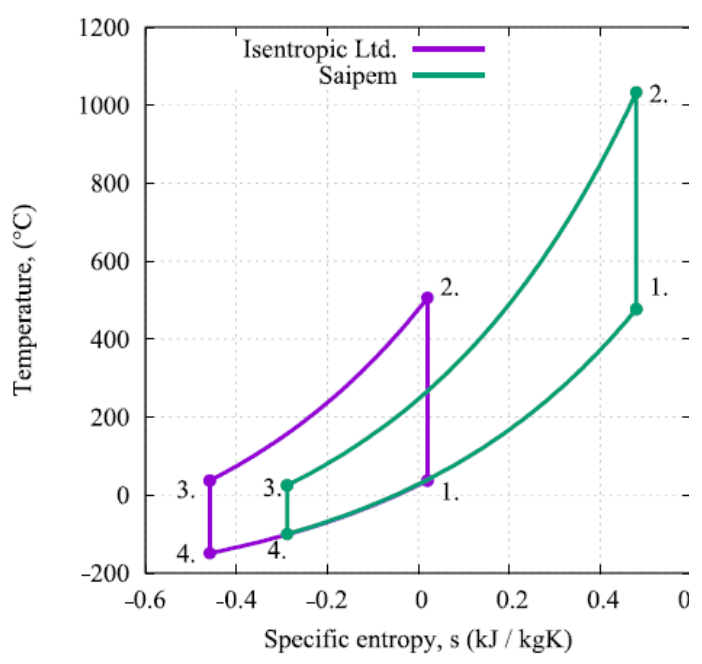

(b)

Figure 34. Schematic of a pumped thermal energy storage system using solid media

Source: Olympios et al. 2021

PTES is designed to store electric energy and does not require CST. As a stand-alone TES system, it is not dependent on the solar resource or other geographic constraints and can be deployed anywhere. However, it does require TES and represents a potential future market for CSP plant TES subcomponents. Hot and cold storage technology from CSP could be transferred to PTES systems. A large PTES industry could spur high-temperature TES technology advancements and deployments separate from the CST industry, which could drive down the costs of those components in CST systems. Although it does not use CST, PTES could represent a future market opportunity for some segments of the CST industry.

Figure 34(b) shows the temperature-entropy (T-s) diagram for two Joule-Brayton PTES cycles proposed for commercial development. Isentropic Ltd. developed a PTES design (Macnaghten and Howes 2009) that became the first demonstration of grid-scale (150-kW/600-kWh) PTES in 2019 (The Engineer 2019). Argon (Ar) is used as the working fluid. The PTES design has a maximum temperature of $500^{\circ} \mathrm{C}$, and heat is stored in a tank with a packed pebble bed by passing argon directly through the tank (direct storage). SAIPEM S.A. developed a similar PTES design that also uses direct TES in refractory materials with argon as the working fluid but with a high maximum storage temperature of $1,000^{\circ}-1,500^{\circ} \mathrm{C}$ (Ruer 2008), similar to those envisioned for some SIPH and solar fuel processes (see Sections 5.1.2 and 5.2). Malta Inc. is attempting to commercialize a PTES design using commercial or near-commercial technologies for the PTES components (McTigue et al. 2020). As part of this strategy, the Malta design plans to employ indirect TES using molten nitrate salt TES like that used in existing CSP facilities as part of a $10 \mathrm{MW}_{\mathrm{e}}$ pilot plant with at least 6 hours of TES (Kraemer 2019).

CSP technologies adaptable to PTES are not limited to TES. $\mathrm{sCO}_{2}$ power cycles that are being developed for CSP (Section 4.4) could also be used in PTES designs. McTigue et al. (2020) describes and compares PTES designs using a Joule-Brayton cycle with molten nitrate salt hot storage to one using a $\mathrm{sCO}_{2}$ power cycle with molten salt TES. The paper also explores combining PTES with a Gen2 CSP plant using a $\mathrm{sCO}_{2}$ power block. These designs, if adopted 
and deployed, would likely also accelerate the development of piping, valve, and heat exchanger technologies that can be used in CST plants.

PTES designs could benefit from TES technologies being developed for electricity generation, SIPH, and solar fuels. Several technologies developed and deployed by the CSP industry are viewed as possible PTES candidates - in particular, molten nitrate salt, which has attractive thermo-physical properties and low specific cost. The substantial experience that has been gained in the use of these salts via the CSP industry can be leveraged for use in PTES systems. Likewise, the CSP industry could benefit from technologies developed by a robust PTES industry. 


\section{Conclusions}

CSP technologies have been commercially deployed since the mid-1980s but have experienced episodes of boom and bust that have limited industry growth, development, and experience learning. In the decade starting in 2010, CSP experienced a 36\% decrease in capacity-weighted average installed capital costs and a 47\% decrease in LCOE. As of 2019, there were $6.3 \mathrm{GW}_{\mathrm{e}}$ of CSP electricity-generating capacity deployed worldwide. The majority of these systems use parabolic trough collectors, but power tower collectors are growing in popularity. Almost all new plants use TES to allow generation independent of solar irradiance. TES has also served to increase CSP plant capacity factors and lower LCOE.

The Solar Futures Study model results suggest CSP would play a limited role in the core scenarios the study explored. Under the Decarb scenario, requiring a $95 \%$ reduction in grid $\mathrm{CO}_{2}$ emissions by 2035 and a $100 \%$ reduction by 2050 , CSP deployments could reach nearly $40 \mathrm{GW}_{\mathrm{e}}$ by 2050. In all core scenarios, there are no new CSP deployments until after 2035. CSP provides firm capacity that the grid needs to displace the last $5 \%$ of fossil generators while still providing grid resilience and reliability. The main competitor for firm capacity in the core scenarios is RECT. Sensitivity scenarios showed that if RE-CT does not meet its cost targets, CSP could play a much larger role, with over $120 \mathrm{GW}_{\mathrm{e}}$ deployed by 2050 .

CSP R\&D in the next decade will focus on power tower technologies. The development of nextgeneration CSP plants, with target operating temperatures of $720^{\circ} \mathrm{C}$, is being led by the U.S. DOE Gen3 CSP effort. The Gen3 effort is looking at three pathways, using liquid, particles, or gas in the receiver, to lower costs and increase efficiency. Each pathway is also working to reduce heliostat field costs, which make up the largest part of CSP power tower installed capital costs. The pathways are also employing $\mathrm{sCO}_{2}$ power cycles that can operate at higher efficiencies than the steam Rankine cycles currently used in many plants. The CSP industry is also exploring the potential to adapt CST technologies to new markets, such as providing SIPH, producing net carbon-free fuels, and providing stand-alone TES. 


\section{References}

Ardani, Kristen. 2021. "Maximizing Solar and Transportation Synergies." NREL/TP-6A20-80779. Golden, CO: National Renewable Energy Laboratory. https://www.nrel.gov/docs/fy21osti/80779.pdf.

Boretti, Albert, Stefania Castelletto, and Sarim Al-Zubaidy. 2019. "Concentrating Solar Power Tower Technology: Present Status and Outlook." Nonlinear Engineering 8 (1): 10-31. https://doi.org/10.1515/nleng-2017-0171.

Coventry, J., J. Campbell, Y. Xue, C.J. Hall, Jin-Soo Kim, John Pye, Greg Burgess, et al. 2016. "Heliostat Cost Down Scoping Study - Final Report." STG-3261 Rev 01. Australian Solar Thermal Research Institute. https://astri.org.au/wp-content/uploads/2014/11/ASTRI-Heliostat-Cost-DownScoping-Study-\%E2\%80\%93-Final-Report.pdf.

Crespo, Alicia, Camila Barreneche, Mercedes Ibarra, and Werner Platzer. 2019. "Latent Thermal Energy Storage for Solar Process Heat Applications at Medium-High Temperatures - A Review." Solar Energy, Thermal Energy Storage for Solar Applications, 192 (November): 3-34. https://doi.org/10.1016/j.solener.2018.06.101.

DOE. 2012. "SunShot Vision Study." DOE/GO-102012-3037. Washington, D.C.: U.S. Department of Energy. https://doi.org/10.2172/1039075.

-- . 2017. "Generation 3 Concentrating Solar Power Systems, Funding Opportunity Announcement (FOA) Number: DE-FOA-0001697." U.S. Department of Energy. https://eereexchange.energy.gov/Default.aspx?Search=DE-FOA-0001697.

- - . 2021. "Solar Futures Study." Washington, D.C.: U.S. Department of Energy Office of Energy Efficiency and Renewable Energy. https://www.energy.gov/eere/solar/solar-futures-study.

DOE, Loan Programs Office. 2019. "Concentrating Solar Power Projects." Concentrating Solar Power Projects. 2019. https://www.energy.gov/lpo/concentrating-solar-power-projects.

Doron, Pinchas, Jacob Karni, and Alexander Slocum. 2019. "A Generalized Approach for Selecting Solar Energy System Configurations for a Wide Range of Applications." MRS Energy \& Sustainability 6 (1): 10. https://doi.org/10.1557/mre.2019.10.

Epp, B., and M. Oropeza. 2017. "Solar Heat for Industry." International Climate Initiative, German Federal Environment Ministry.

Ermanoski, Ivan, Nathan P. Siegel, and Ellen B. Stechel. 2013. "A New Reactor Concept for Efficient SolarThermochemical Fuel Production." Journal of Solar Energy Engineering 135 (3). https://doi.org/10.1115/1.4023356.

Farres-Antunez, Pau, Joshua D. McTigue, and Alexander J. White. 2019. "A Pumped Thermal Energy Storage Cycle with Capacity for Concentrated Solar Power Integration." In 2019 Offshore Energy and Storage Summit (OSES), 1-10. BREST, France: IEEE. https://doi.org/10.1109/OSES.2019.8867222.

Hashem, Heba. 2018. "CSP as an Engine of Job Creation." MENA CSP KIP (blog). December 5, 2018. https://cmimarseille.org/menacspkip/csp-engine-job-creation/.

Hernández, Catalina, Rodrigo Barraza, Alejandro Saez, Mercedes Ibarra, and Danilo Estay. 2020. "Potential Map for the Installation of Concentrated Solar Power Towers in Chile." Energies 13 (9): 2131. https://doi.org/10.3390/en13092131.

Hinkley, J.T., R.K. McNaughton, J.A. Hayward, and K. Lovegrove. 2017. "A Solar Fuels Roadmap for Australia - Study Outcomes." In SolarPACES 2016. Daegu, South Korea. https://doi.org/10.1063/1.4984467.

Ho, Clifford K. 2016. "A Review of High-Temperature Particle Receivers for Concentrating Solar Power." Applied Thermal Engineering 109 (October): 958-69. https://doi.org/10.1016/j.applthermaleng.2016.04.103. 
-- - 2017. "Advances in Central Receivers for Concentrating Solar Applications." Solar Energy 152 (August): 38-56. https://doi.org/10.1016/j.solener.2017.03.048.

Ho, Clifford K., N.R. Schroeder, H.F. Laubscher, L. Yue, B. Mills, R. Shaeffer, J.M. Christian, and K.J. Albrecht. 2020. "Receiver Design and On-Sun Testing for G3P3-USA." In SolarPACES 2020. Albuquerque, NM, USA.

IEA. 2010. "Technology Roadmap - Concentrating Solar Power." Paris. https://www.iea.org/reports/technology-roadmap-concentrating-solar-power.

- - . 2014. Capturing the Multiple Benefits of Energy Efficiency: A Guide to Quantifying the Value Added. OECD. https://doi.org/10.1787/9789264220720-en.

- - . 2020. "Tracking Industry 2020." Paris. www.iea.org/reports/tracking-industry-2020.

IRENA. 2012. "Concentrating Solar Power." Volume 1: Power Sector Issue 2/5. Renewable Energy Technologies: Cost Analysis Series. International Renewable Energy Agency. https://www.irena.org//media/Files/IRENA/Agency/Publication/2012/RE_Technologies_Cost_Analysis-CSP.pdf.

- - - 2016. "The Power to Change: Solar and Wind Cost Reduction Potential to 2025." Abu Dhabi, United Arab Emirates: International Renewable Energy Agency. https://www.irena.org//media/Files/IRENA/Agency/Publication/2016/IRENA_Power_to_Change_2016.pdf.

- - - 2020. "Renewable Power Generation Costs in 2019." Abu Dhabi, United Arab Emirates: International Renewable Energy Agency. https://www.irena.org//media/Files/IRENA/Agency/Publication/2020/Jun/IRENA_Power_Generation_Costs_2019.pdf.

Koepf, E., I. Alxneit, C. Wieckert, and A. Meier. 2017. "A Review of High Temperature Solar Driven Reactor Technology: 25 Years of Experience in Research and Development at the Paul Scherrer Institute." Applied Energy 188 (February): 620-51. https://doi.org/10.1016/j.apenergy.2016.11.088.

Kraemer, Susan. 2019. "VC-Funded Thermal 'Battery' Is Based on CSP Molten Salt Energy Storage." SolarPACES (blog). May 13, 2019. https://www.solarpaces.org/vc-funded-thermal-batterybased-molten-salt-energy-storage-csp/.

- - . 2020. "Morocco Pioneers PV with Thermal Storage at 800 MW Midelt CSP Project." SolarPACES (blog). April 25, 2020. https://www.solarpaces.org/morocco-pioneers-pv-to-thermal-storage-at800-mw-midelt-csp-project/.

Kurup, Parthiv, and Craig Turchi. 2015a. "Parabolic Trough Collector Cost Update for the System Advisor Model (SAM)." NREL/TP-6A20-65228. Golden, CO: National Renewable Energy Laboratory. https://www.nrel.gov/docs/fy16osti/65228.pdf.

- - . 2015b. "Initial Investigation into the Potential of CSP Industrial Process Heat for the Southwest United States." NREL/TP-6A20-64709. Golden, CO: National Renewable Energy Laboratory. https://www.nrel.gov/docs/fy16osti/64709.pdf.

Kutscher, C, M Mehos, C Turchi, G Glatzmaier, and T Moss. 2010. "Line-Focus Solar Power Plant Cost Reduction Plan (Milestone Report)." NREL/TP-5500-48175, 1001434. Golden, CO: National Renewable Energy Laboratory. https://doi.org/10.2172/1001434.

Lefebvre, Dominique, and F. Handan Tezel. 2017. "A Review of Energy Storage Technologies with a Focus on Adsorption Thermal Energy Storage Processes for Heating Applications." Renewable and Sustainable Energy Reviews 67 (January): 116-25. https://doi.org/10.1016/j.rser.2016.08.019.

Lilliestam, Johan, Mercè Labordena, Anthony Patt, and Stefan Pfenninger. 2017. "Empirically Observed Learning Rates for Concentrating Solar Power and Their Responses to Regime Change." Nature Energy 2 (7): 1-6. https://doi.org/10.1038/nenergy.2017.94.

Lilliestam, Johan, Lana Ollier, Mercè Labordena, Stefan Pfenninger, and Richard Thonig. 2020. "The Near- to Mid-Term Outlook for Concentrating Solar Power: Mostly Cloudy, Chance of Sun." 
Energy Sources, Part B: Economics, Planning, and Policy 0 (0): 1-19.

https://doi.org/10.1080/15567249.2020.1773580.

Lilliestam, Johan, and Robert Pitz-Paal. 2018. "Concentrating Solar Power for Less than USD 0.07 per KWh: Finally the Breakthrough?" Renewable Energy Focus 26 (September): 17-21. https://doi.org/10.1016/j.ref.2018.06.002.

Loutzenhiser, Peter G., and Aldo Steinfeld. 2011. "Solar Syngas Production from CO2 and H2O in a TwoStep Thermochemical Cycle via Zn/ZnO Redox Reactions: Thermodynamic Cycle Analysis." International Journal of Hydrogen Energy 36 (19): 12141-47. https://doi.org/10.1016/j.ijhydene.2011.06.128.

Macnaghten, James, and Jonathan Sebastian Howes. 2009. Energy Storage. World Intellectual Property Organization WO2009044139A2, filed October 3, 2008, and issued April 9, 2009. https://patents.google.com/patent/WO2009044139A2/en.

Marion, John, Brian Lariviere, Aaron McClung, Jason Mortzheim, and Robin Ames. 2021. "The STEP 10 MWe SCO2 Pilot Demonstration Status Update." In ASME Turbo Expo 2020: Turbomachinery Technical Conference and Exposition. American Society of Mechanical Engineers Digital Collection. https://doi.org/10.1115/GT2020-14334.

McMillan, Colin A., and Mark Ruth. 2019. "Using Facility-Level Emissions Data to Estimate the Technical Potential of Alternative Thermal Sources to Meet Industrial Heat Demand." Applied Energy 239 (April): 1077-90. https://doi.org/10.1016/j.apenergy.2019.01.077.

McMillan, Colin A., Carrie A. Schoeneberger, Jingyi Zhang, Parthiv Kuru, Eric Masanet, Robert Margolis, Steven Meyers, Mike Bannister, Evan Rosenlieb, and William Xi. 2021. "Opportunities for Solar Industrial Process Heat in the United States." NREL/TP-6A20-77760. Golden, CO: National Renewable Energy Laboratory. https://www.nrel.gov/docs/fy21osti/77760.pdf.

McTigue, Joshua, Pau Farres-Antunez, Kevin Ellingwood, Ty Neises, and Alexander White. 2020. "Pumped Thermal Electricity Storage with Supercritical CO2 Cycles and Solar Heat Input." In SolarPACES 2019 AIP Conference Proceedings, 2303:190024. Daegu, South Korea. https://doi.org/10.1063/5.0032337.

Mehos, Mark, Hank Price, Robert Cable, David Kearney, B. Kelly, Gregory Kolb, and Frederick Morse. 2020. "Concentrating Solar Power Best Practices Study." NREL/TP-5500-75763. Golden, CO: National Renewable Energy Laboratory. https://www.nrel.gov/docs/fy20osti/75763.pdf.

Mehos, Mark, Craig Turchi, Jennie Jorgenson, Paul Denholm, Clifford Ho, and Kenneth Armijo. 2016. “On the Path to SunShot: Advancing Concentrating Solar Power Technology, Performance, and Dispatchability." Technical Report NREL/TP-6A20-65688. Golden, CO: National Renewable Energy Laboratory. https://doi.org/10.2172/1344199.

Mehos, Mark, Craig Turchi, Judith Vidal, Michael Wagner, and Zhiwen Ma. 2017. "Concentrating Solar Power Gen3 Demonstration Roadmap." Technical Report NREL/TP-5500-67464. Golden, CO: National Renewable Energy Laboratory. https://doi.org/10.2172/1338899.

Morin, Gabriel, Jürgen Dersch, Werner Platzer, Markus Eck, and Andreas Häberle. 2012. "Comparison of Linear Fresnel and Parabolic Trough Collector Power Plants." Solar Energy 86 (1): 1-12. https://doi.org/10.1016/j.solener.2011.06.020.

Murphy, Caitlin, Yinong Sun, Wesley J. Cole, Galen J. Maclaurin, Mark S. Mehos, and Craig S. Turchi. 2019. "The Potential Role of Concentrating Solar Power within the Context of DOE's 2030 Solar Cost Targets." National Renewable Energy Lab.(NREL), Golden, CO (United States).

Neises, Ty, and Craig Turchi. 2019. "Supercritical Carbon Dioxide Power Cycle Design and Configuration Optimization to Minimize Levelized Cost of Energy of Molten Salt Power Towers Operating at $650{ }^{\circ} \mathrm{C} . "$ Solar Energy 181 (March): 27-36. https://doi.org/10.1016/j.solener.2019.01.078.

NREL. 2020. "2020 Annual Technology Baseline." Golden, CO: National Renewable Energy Laboratory. https://atb.nrel.gov/. 
-- - 2021. "Concentrating Solar Power Projects." National Renewable Energy Laboratory. https://solarpaces.nrel.gov/.

Olympios, Andreas, Josh McTigue, Pau Farres Antunez, Alessio Tafone, Alessandro Romagnoli, Yongliang Li, Yulong Ding, et al. 2021. "Progress and Prospects of Thermo-Mechanical Energy Storage - A Critical Review." Progress in Energy, January. https://doi.org/10.1088/2516-1083/abdbba.

Pfenninger, Stefan, Paul Gauché, Johan Lilliestam, Kerstin Damerau, Fabian Wagner, and Anthony Patt. 2014. "Potential for Concentrating Solar Power to Provide Baseload and Dispatchable Power." Nature Climate Change 4 (8): 689-92. https://doi.org/10.1038/nclimate2276.

Pregger, Thomas, Günter Schiller, Felix Cebulla, Ralph-Uwe Dietrich, Simon Maier, André Thess, Andreas Lischke, et al. 2019. "Future Fuels-Analyses of the Future Prospects of Renewable Synthetic Fuels." Energies 13 (1): 138. https://doi.org/10.3390/en13010138.

Reuters Events. 2012. "Ripasso Energy Sets New Solar-to-Electricity World Record!" Reuters Events Renewables (blog). November 19, 2012. https://www.reutersevents.com/renewables/csptoday/technology/ripasso-energy-sets-new-solar-electricity-world-record.

- - . 2018. "World's Largest CSP Plant Ties Tariffs to Big Storage to Hit Record Price | Reuters Events | Renewables." Reuters Events - Renewables (blog). December 12, 2018. https://www.reutersevents.com/renewables/csp-today/worlds-largest-csp-plant-ties-tariffs-bigstorage-hit-record-price.

-- - 2019. "Noor Midelt Winner Optimizes CSP Trough, Storage to Hit Record Price | Reuters Events | Renewables." Reuters Events - Renewables (blog). June 5, 2019. https://www.reutersevents.com/renewables/csp-today/noor-midelt-winner-optimizes-csptrough-storage-hit-record-price.

- - . 2020a. "Abengoa Completes First Parabolic Trough Array in Dubai." Reuters Events - Renewables (blog). September 30, 2020. https://www.reutersevents.com/renewables/solar/abengoacompletes-first-csp-array-giant-dubai-project-q-energy-fund-buys-117-mw-csp-capacity.

- - . 2020b. "Solar Tower at Pasta Plant Spurs New Generator Design." Reuters Events - Renewables (blog). November 18, 2020. https://www.reutersevents.com/renewables/solar-thermal/solartower-pasta-plant-spurs-new-generator-design.

-- . 2020c. "US to Build 5 MW SCO2 CSP Plant." Reuters Events - Renewables (blog). November 18, 2020. https://www.reutersevents.com/renewables/solar-thermal/us-build-5-mw-sco2-cspplant-spain-backs-global-tower-insulation-standards.

Río, Pablo del, Cristina Peñasco, and Pere Mir-Artigues. 2018. "An Overview of Drivers and Barriers to Concentrated Solar Power in the European Union." Renewable and Sustainable Energy Reviews 81 (January): 1019-29. https://doi.org/10.1016/j.rser.2017.06.038.

Ruer, Jacques. 2008. Installation et procedes de stockage et restitution d'energie electrique. World Intellectual Property Organization WO2008148962A2, filed April 21, 2008, and issued December 11, 2008. https://patents.google.com/patent/WO2008148962A2/en?oq=WO\%2f2008\%2f148962+A2.

Sargent \& Lundy. 2003. "Assessment of Parabolic Trough and Power Tower Solar Technology Cost and Performance Forecasts." NREL/SR-550-34440, 15005520. Golden, CO: National Renewable Energy Laboratory. https://doi.org/10.2172/15005520.

Schiller, Günter, Michael Lang, Patric Szabo, Nathalie Monnerie, Henrik von Storch, Jan Reinhold, and Pradeepkumar Sundarraj. 2019. "Solar Heat Integrated Solid Oxide Steam Electrolysis for Highly Efficient Hydrogen Production." Journal of Power Sources 416 (March): 72-78. https://doi.org/10.1016/j.jpowsour.2019.01.059.

Schoeneberger, Carrie A., Colin A. McMillan, Parthiv Kurup, Sertac Akar, Robert Margolis, and Eric Masanet. 2020. "Solar for Industrial Process Heat: A Review of Technologies, Analysis 
Approaches, and Potential Applications in the United States." Energy 206 (September): 118083. https://doi.org/10.1016/j.energy.2020.118083.

Sengupta, Manajit, Yu Xie, Anthony Lopez, Aron Habte, Galen Maclaurin, and James Shelby. 2018. "The National Solar Radiation Data Base (NSRDB)." Renewable and Sustainable Energy Reviews 89 (June): 51-60. https://doi.org/10.1016/j.rser.2018.03.003.

Sharan, Prashant, Craig Turchi, and Parthiv Kurup. 2019. "Optimal Design of Phase Change Material Storage for Steam Production Using Annual Simulation." Solar Energy 185 (June): 494-507. https://doi.org/10.1016/j.solener.2019.04.077.

Sheu, Elysia J., Esmail M.A. Mokheimer, and Ahmed F. Ghoniem. 2015. "A Review of Solar Methane Reforming Systems." International Journal of Hydrogen Energy 40 (38): 12929-55. https://doi.org/10.1016/j.ijhydene.2015.08.005.

Shultz, Avi. 2021. "SETO Introduction and Overview of the Gen3 CSP Program." Presented at the Gen3 CSP Summit 2021, Online Event, August 25. https://www.energy.gov/eere/solar/gen3-cspsummit-2021.

Sullivan, S.D., and J. Hinze. 2020. "Concentrating Solar Power Working Fluid Circulation via an Integrated Supercritical Carbon Dioxide Brayton Cycle Power Block." In SolarPACES 2020. Albuquerque, NM, USA.

The Engineer. 2019. "Newcastle University Connects First Grid-Scale Pumped Heat Energy Storage System." The Engineer (blog). January 9, 2019. https://www.theengineer.co.uk/grid-scalepumped-heat-energy-storage/.

Trieb, Franz, Christoph Schillings, Marlene O'Sullivan, Thomas Pregger, and Carsten Hoyer-Click. 2009. "Global Potential of Concentrating Solar Power." In SolarPACES 2009. Berlin, Germany. https://dlr.de/tt/Portaldata/41/Resources/dokumente/institut/system/publications/Solar_Pace s_Paper_Trieb_Final_Colour_corrected.pdf.

Turchi, C. 2010. "Parabolic Trough Reference Plant for Cost Modeling with the Solar Advisor Model (SAM)." NREL/TP-550-47605. Golden, CO: National Renewable Energy Laboratory. https://doi.org/10.2172/983729.

Turchi, C. S., and G. A. Heath. 2013. "Molten Salt Power Tower Cost Model for the System Advisor Model (SAM)." NREL/TP-5500-57625. Golden, CO: National Renewable Energy Laboratory. https://doi.org/10.2172/1067902.

Turchi, Craig, Samuel Gage, Janna Martinek, Sameer Jape, Ken Armijo, Joe Coventry, John Pye, et al. 2021. "CSP Gen3: Liquid-Phase Pathway to SunShot." NREL/TP-5700-79323. Golden, CO: National Renewable Energy Laboratory. https://doi.org/10.2172/1807668.

Turchi, Craig S, and Matthew Boyd. 2019. "CSP Systems Analysis - Final Project Report." NREL/TP-550072856. Golden, CO: National Renewable Energy Laboratory. https://www.nrel.gov/docs/fy19osti/72856.pdf.

Turchi, C.S., C. Libby, J. Pye, and J. Coventry. 2020. "Molten Salt vs. Liquid Sodium Receiver Selection Using the Analytic Hierarchy Process." In SolarPACES 2020. Albuquerque, New Mexico.

U.S. Energy Information Administration (EIA). 2013. "2010 MECS Survey Data." Manufacturing Energy Consumption Survey. Washington, DC: U.S. Energy Information Administration. https://www.eia.gov/consumption/manufacturing/data/2010/.

- - . 2017. "2014 MECS Survey Data." Manufacturing Energy Consumption Survey. Washington, DC: U.S. Energy Information Administration. https://www.eia.gov/consumption/manufacturing/data/2014/.

- - . 2021a. "2018 MECS Survey Data." Manufacturing Energy Consumption Survey. Washington, DC: U.S. Energy Information Administration. https://www.eia.gov/consumption/manufacturing/data/2018/. 
---. 2021b. "Monthly Energy Review: April 2021." DOE/EIA-0035(2021/4). Total Energy. Washington, DC: U.S. Energy Information Administration. https://www.eia.gov/totalenergy/data/monthly/archive/00352104.pdf.

Vijaykumar, Rajgopal, Matthew L. Bauer, Mark Lausten, and Abraham M. Shultz. 2018. "Optimizing the Supercritical CO2 Brayton Cycle for Concentrating Solar Power Application." In Proceedings of the 6th Int Symp-Supercrit CO2 Power Cycles, Pittsburgh, PA, USA, 27-29.

Walter, Oliver, Alexander Tremel, Marco Prenzel, Stefan Becker, and Jochen Schaefer. 2020. "TechnoEconomic Analysis of Hybrid Energy Storage Concepts via Flowsheet Simulations, Cost Modeling and Energy System Design." Energy Conversion and Management 218 (August): 112955. https://doi.org/10.1016/j.enconman.2020.112955.

Weiss, Werner, and Franz Mauthner. 2019. "Solar Heat Worldwide." Austria: IEA Solar Heating \& Cooling Programme. https://www.iea-shc.org/Data/Sites/1/publications/Solar-Heat-Worldwide2019.pdf.

Wood, Craig, and Kurt Drewes. 2019. "Vast Solar: Improving Performance and Reducing Cost and Risk Using High Temperature Modular Arrays and Sodium Heat Transfer Fluid." In SolarPACES 2019. Daegu, South Korea. https://www.solarpaces.org/wp-content/uploads/Vast-Solar-improvingperformance-and-reducing-cost-and-risk-using-high-temperature-modular-arrays-and-sodiumheat-transfer-fluid.pdf.

Yadav, Deepak, and Rangan Banerjee. 2016. "A Review of Solar Thermochemical Processes." Renewable and Sustainable Energy Reviews 54 (February): 497-532.

https://doi.org/10.1016/j.rser.2015.10.026. 